\title{
Exercise-based cardiac rehabilitation for adult patients with an implantable cardioverter defibrillator (Review)
}

Nielsen KM, Zwisler AD, Taylor RS, Svendsen JH, Lindschou J, Anderson L, Jakobsen JC, Berg SK

Nielsen KM, Zwisler AD, Taylor RS, Svendsen JH, Lindschou J, Anderson L, Jakobsen JC, Berg SK.

Exercise-based cardiac rehabilitation for adult patients with an implantable cardioverter defibrillator.

Cochrane Database of Systematic Reviews 2019, Issue 2. Art. No.: CD011828.

DOI: 10.1002/14651858.CD011828.pub2.

www.cochranelibrary.com 
TABLE OF CONTENTS

HEADER

ABSTRACT

PLAIN LANGUAGE SUMMARY

SUMMARY OF FINDINGS

BACKGROUND

OBJECTIVES

METHODS

Figure 1.

RESULTS

Figure 2.

Figure 3.

Figure 4.

Figure 5.

Figure 6.

DISCUSSION

AUTHORS' CONCLUSIONS

ACKNOWLEDGEMENTS

REFERENCES

CHARACTERISTICS OF STUDIES

DATA AND ANALYSES

Analysis 1.1. Comparison 1 Exercise-based cardiac rehabilitation versus control at the end of the intervention, Outcome 1 Allcause mortality.

Analysis 1.2. Comparison 1 Exercise-based cardiac rehabilitation versus control at the end of the intervention, Outcome 2 Serious adverse events.

Analysis 1.3. Comparison 1 Exercise-based cardiac rehabilitation versus control at the end of the intervention, Outcome 3 Exercise capacity (VO2 peak) (random-effects model).

Analysis 1.4. Comparison 1 Exercise-based cardiac rehabilitation versus control at the end of the intervention, Outcome 4 Exercise capacity (VO2 peak) (fixed-effect model).

Analysis 1.5. Comparison 1 Exercise-based cardiac rehabilitation versus control at the end of the intervention, Outcome 5 ICD, antitachycardia pacing.

Analysis 1.6. Comparison 1 Exercise-based cardiac rehabilitation versus control at the end of the intervention, Outcome 6 ICD, appropriate shock.

Analysis 1.7. Comparison 1 Exercise-based cardiac rehabilitation versus control at the end of the intervention, Outcome 7 ICD, inappropriate shock.

Analysis 1.8. Comparison 1 Exercise-based cardiac rehabilitation versus control at the end of the intervention, Outcome 8 Nonserious adverse events.

Analysis 2.1. Comparison 2 Exercise-based cardiac rehabilitation versus control at the end of the intervention (best-worst case meta-analysis), Outcome 1 All-cause mortality.

Analysis 2.2. Comparison 2 Exercise-based cardiac rehabilitation versus control at the end of the intervention (best-worst case meta-analysis), Outcome 2 Serious adverse events.

Analysis 3.1. Comparison 3 Exercise-based cardiac rehabilitation versus control at the end of the intervention (worst-best case meta-analysis), Outcome 1 All-cause mortality (random-effects model).

Analysis 3.2. Comparison 3 Exercise-based cardiac rehabilitation versus control at the end of the intervention (worst-best case meta-analysis), Outcome 2 All-cause mortality (fixed-effect model).

Analysis 3.3. Comparison 3 Exercise-based cardiac rehabilitation versus control at the end of the intervention (worst-best case meta-analysis), Outcome 3 All-cause mortality.

Analysis 3.4. Comparison 3 Exercise-based cardiac rehabilitation versus control at the end of the intervention (worst-best case meta-analysis), Outcome 4 Serious adverse events.

Analysis 4.1. Comparison 4 Exercise-based cardiac rehabilitation versus control at longest follow-up, Outcome 1 All-cause mortality.

Analysis 4.2. Comparison 4 Exercise-based cardiac rehabilitation versus control at longest follow-up, Outcome 2 Serious adverse events (random-effects model).

Analysis 4.3. Comparison 4 Exercise-based cardiac rehabilitation versus control at longest follow-up, Outcome 3 Serious adverse events (fixed-effect model). 
Analysis 4.4. Comparison 4 Exercise-based cardiac rehabilitation versus control at longest follow-up, Outcome 4 Exercise capacity (VO2 peak).

Analysis 4.5. Comparison 4 Exercise-based cardiac rehabilitation versus control at longest follow-up, Outcome 5 ICD, appropriate shock (random-effects model).

Analysis 4.6. Comparison 4 Exercise-based cardiac rehabilitation versus control at longest follow-up, Outcome 6 ICD, appropriate shock (fixed-effect model).

Analysis 4.7. Comparison 4 Exercise-based cardiac rehabilitation versus control at longest follow-up, Outcome 7 ICD, all shocks.

Analysis 5.1. Comparison 5 Exercise-based cardiac rehabilitation versus control at longest follow-up (best-worst case metaanalysis), Outcome 1 All-cause mortality.

Analysis 5.2. Comparison 5 Exercise-based cardiac rehabilitation versus control at longest follow-up (best-worst case metaanalysis), Outcome 2 Serious adverse events.

Analysis 6.1. Comparison 6 Exercise-based cardiac rehabilitation versus control at longest follow-up (worst-best case metaanalysis), Outcome 1 All-cause mortality.

Analysis 6.2. Comparison 6 Exercise-based cardiac rehabilitation versus control at longest follow-up (worst-best case metaanalysis), Outcome 2 Serious adverse events (random-effects model).

Analysis 6.3. Comparison 6 Exercise-based cardiac rehabilitation versus control at longest follow-up (worst-best case metaanalysis), Outcome 3 Serious adverse events (fixed-effect model).

Analysis 7.1. Comparison 7 Subgroup analysis, Outcome 1 All-cause mortality: exercise intervention only compared to exercise intervention plus any other co-intervention at longest follow-up.

Analysis 7.2. Comparison 7 Subgroup analysis, Outcome 2 Serious adverse events: follow-up.

Analysis 7.3. Comparison 7 Subgroup analysis, Outcome 3 Serious adverse events: exercise intervention only compared to exercise intervention plus any other co-intervention at end of intervention.

APPENDICES

CONTRIBUTIONS OF AUTHORS 
[Intervention Review]

\section{Exercise-based cardiac rehabilitation for adult patients with an implantable cardioverter defibrillator}

Kim M Nielsen ${ }^{1}$, Ann-Dorthe Zwisler ${ }^{1}$, Rod S Taylor ${ }^{2}$, Jesper H Svendsen ${ }^{1}$, Jane Lindschou ${ }^{3}$, Lindsey Anderson², Janus C Jakobsen 4,5 , Selina K Berg1

1Department of Cardiology, The Heart Centre, Copenhagen University Hospital, Rigshospitalet, Copenhagen, Denmark. ${ }^{2}$ Institute of Health Research, University of Exeter Medical School, Exeter, UK. ${ }^{3}$ Copenhagen Trial Unit, Centre for Clinical Intervention Research, Department 7812, Rigshospitalet, Copenhagen University Hospital, Copenhagen, Denmark. ${ }^{4}$ Cochrane Hepato-Biliary Group, Copenhagen Trial Unit, Centre for Clinical Intervention Research, Department 7812, Rigshospitalet, Copenhagen University Hospital, Copenhagen, Denmark. ${ }^{5}$ Department of Cardiology, Holbaek Hospital, Holbaek, Denmark

Contact address: Kim M Nielsen, Department of Cardiology, The Heart Centre, Copenhagen University Hospital, Rigshospitalet, Blegdamsvej 9, Copenhagen, 2100, Denmark.kim.mechta.nielsen@regionh.dk.

Editorial group: Cochrane Heart Group.

Publication status and date: New, published in Issue 2, 2019.

Citation: Nielsen KM, Zwisler AD, Taylor RS, Svendsen JH, Lindschou J, Anderson L, Jakobsen JC, Berg SK. Exercise-based cardiac rehabilitation for adult patients with an implantable cardioverter defibrillator. Cochrane Database of Systematic Reviews 2019 , Issue 2. Art. No.: CD011828. DOI: 10.1002/14651858.CD011828.pub2.

Copyright @ 2019 The Cochrane Collaboration. Published by John Wiley \& Sons, Ltd.

\section{A B S T R A C T}

\section{Background}

An effective way of preventing sudden cardiac death is the use of an implantable cardioverter defibrillator (ICD). In spite of the potential mortality benefits of receiving an ICD device, psychological problems experienced by patients after receiving an ICD may negatively impact their health-related quality of life, and lead to increased readmission to hospital and healthcare needs, loss of productivity and employment earnings, and increased morbidity and mortality. Evidence from other heart conditions suggests that cardiac rehabilitation should consist of both exercise training and psychoeducational interventions; such rehabilitation may benefit patients with an ICD. Prior systematic reviews of cardiac rehabilitation have excluded participants with an ICD. A systematic review was therefore conducted to assess the evidence for the use of exercise-based intervention programmes following implantation of an ICD.

\section{Objectives}

To assess the benefits and harms of exercise-based cardiac rehabilitation programmes (exercise-based interventions alone or in combination with psychoeducational components) compared with control (group of no intervention, treatment as usual or another rehabilitation programme with no physical exercise element) in adults with an ICD.

\section{Search methods}

We searched CENTRAL, MEDLINE, Embase and four other databases on 30 August 2018 and three trials registers on 14 November 2017 . We also undertook reference checking, citation searching and contacted study authors for missing data.

\section{Selection criteria}

We included randomised controlled trials (RCTs) if they investigated exercise-based cardiac rehabilitation interventions compared with no intervention, treatment as usual or another rehabilitation programme. The trial participants were adults (aged 18 years or older), who had been treated with an ICD regardless of type or indication. 


\section{Data collection and analysis}

Two review authors independently extracted data and assessed risk of bias. The primary outcomes were all-cause mortality, serious adverse events and health-related quality of life. The secondary outcomes were exercise capacity, antitachycardia pacing, shock, nonserious adverse events, employment or loss of employment and costs and cost-effectiveness. Risk of systematic errors (bias) was assessed by evaluation of predefined bias risk domains. Clinical and statistical heterogeneity were assessed. Meta-analyses were undertaken using both fixed-effect and random-effects models. We used the GRADE approach to assess the quality of evidence.

\section{Main results}

We identified eight trials published from 2004 to 2017 randomising a total of 1730 participants, with mean intervention duration of 12 weeks. All eight trials were judged to be at overall high risk of bias and effect estimates are reported at the end of the intervention with a follow-up range of eight to 24 weeks.

Seven trials reported all-cause mortality, but deaths only occurred in one trial with no evidence of a difference between exercise-based cardiac rehabilitation and control (risk ratio (RR) 1.96, 95\% confidence interval (CI) 0.18 to 21.26; participants = 196; trials = 1 ; quality of evidence: low). There was also no evidence of a difference in serious adverse events between exercise-based cardiac rehabilitation and control (RR 1.05, 95\% Cl 0.77 to 1.44; participants = 356; trials = 2; quality of evidence: low). Due to the variation in reporting of healthrelated quality of life outcomes, it was not possible to pool data. However, the five trials reporting health-related quality of life at the end of the intervention, each showed little or no evidence of a difference between exercise-based cardiac rehabilitation and control.

For secondary outcomes, there was evidence of a higher pooled exercise capacity $\left(\right.$ peak $\mathrm{VO}_{2}$ ) at the end of the intervention (mean difference (MD) $0.91 \mathrm{~mL} / \mathrm{kg} / \mathrm{min}, 95 \% \mathrm{Cl} 0.60$ to 1.21 ; participants = 1485; trials = 7; quality of evidence: very low) favouring exercise-based cardiac rehabilitation, albeit there was evidence of substantial statistical heterogeneity $(12=78 \%)$. There was no evidence of a difference in the risk of requiring antitachycardia pacing ( $\mathrm{RR} 1.26,95 \% \mathrm{Cl} 0.84$ to 1.90 ; participants $=356$; trials $=2$; quality of evidence: moderate), appropriate shock (RR $0.56,95 \% \mathrm{Cl} 0.20$ to 1.58 ; participants $=428$; studies $=3$; quality of evidence: low) or inappropriate shock $(\mathrm{RR} 0.60,95 \% \mathrm{Cl} 0.10$ to 3.51 ; participants $=160$; studies $=1$; quality of evidence: moderate).

\section{Authors' conclusions}

Due to a lack of evidence, we were unable to definitively assess the impact of exercise-based cardiac rehabilitation on all-cause mortality, serious adverse events and health-related quality of life in adults with an ICD. However, our findings do provide very low-quality evidence that patients following exercise-based cardiac rehabilitation experience a higher exercise capacity compared with the no exercise control. Further high-quality randomised trials are needed in order to assess the impact of exercise-based cardiac rehabilitation in this population on all-cause mortality, serious adverse events, health-related quality of life, antitachycardia pacing and shock.

\section{PLAIN LANGUAGE SUMMARY}

\section{Exercise-based cardiac rehabilitation for adult patients with an implantable cardioverter defibrillator}

\section{Review question}

We reviewed the benefits and harms of exercise-based cardiac rehabilitation programmes in adults who have been treated with an implantable cardioverter defibrillator from any cause.

\section{Background}

An implantable cardioverter defibrillator is a very effective device that prevents sudden cardiac death. This is done by the use of either antitachycardia pacing, high-voltage shock therapy, or both. In spite of the potential mortality benefits, patients may also experience a negative impact on their health-related quality of life, increased readmission to hospital and healthcare facilities, loss of productivity and employment earnings, and increased morbidity and mortality. Exercise-based cardiac rehabilitation may benefit patients with an implantable cardioverter defibrillator.

\section{Study characteristics}

We searched for randomised controlled trials (experiments in which participants are randomly allocated to an experimental intervention compared with a control intervention) that investigated exercise-based interventions compared with no exercise intervention control. We found eight trials published from 2004 to 2017 with a total of 1730 participants. Two trials did not report on funding and one trial reported funding from industry. The evidence is current to 30 August 2018.

\section{Key results}

The review showed no evidence of an impact on the risk of death, harmful side effects or having antitachycardia pacing or shock therapy when comparing the exercise intervention to the control. There was also little or no evidence of a difference on health-related quality of life. However, there was an improvement in exercise capacity in favour of the exercise group. 


\section{Quality of the evidence}

The quality of the evidence ranged from moderate to very low for all outcomes. The number of events was low, it was possible for people in the trials to know to which intervention group they were randomised, the reporting of the results was not complete in some trials, and for some outcomes, the results varied across trials. These considerations limited our confidence in the overall results of the review.

\section{Conclusion}

Further adequately powered and well-conducted randomised trials are needed to assess the impact of exercise-based cardiac rehabilitation in adults with an implantable cardioverter defibrillator. 


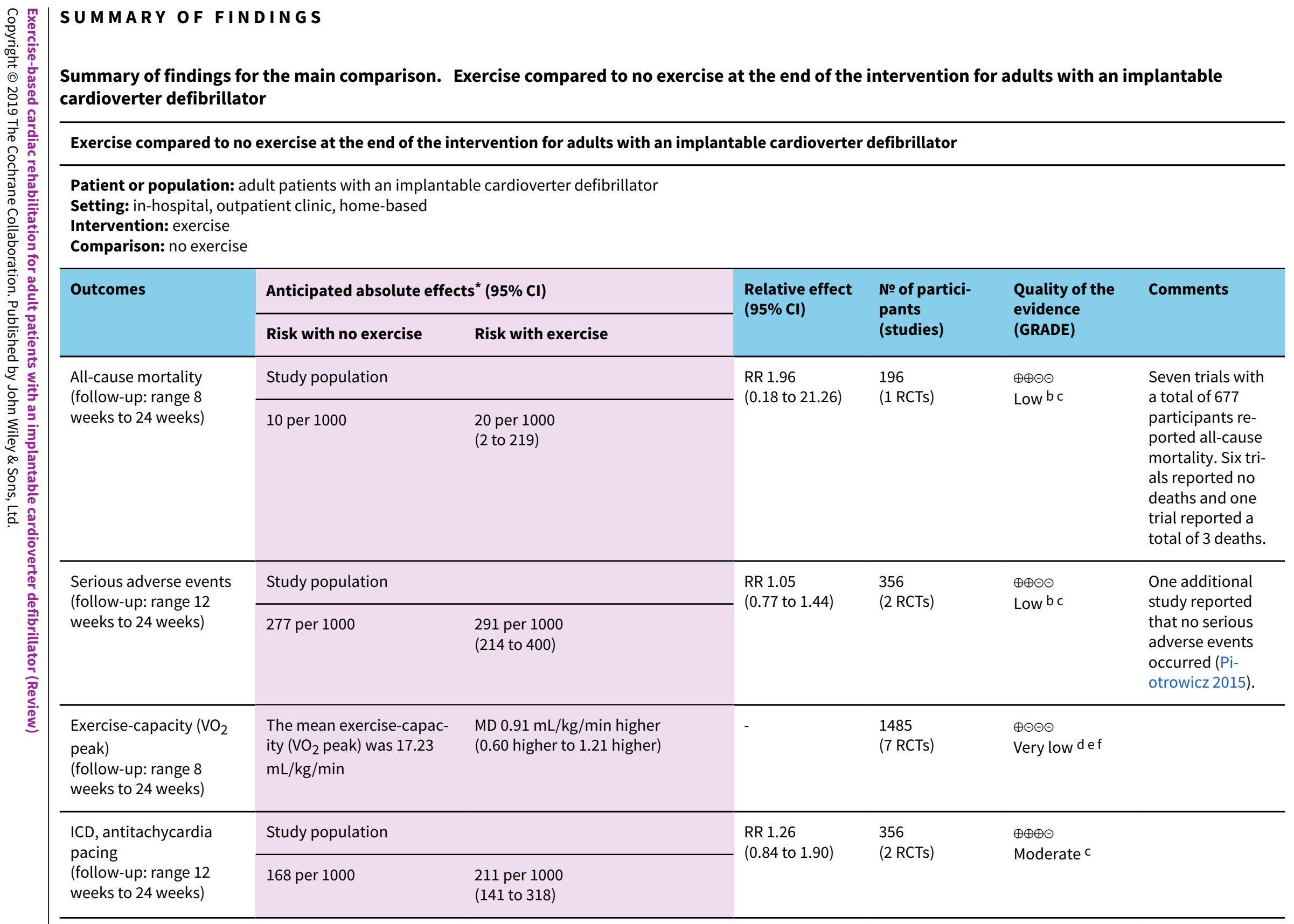

Patient or population: adult patients with an implantable cardioverter defibrillator

位, home-based 


\begin{tabular}{|c|c|c|c|c|c|c|c|}
\hline \multirow{2}{*}{\multicolumn{2}{|c|}{ 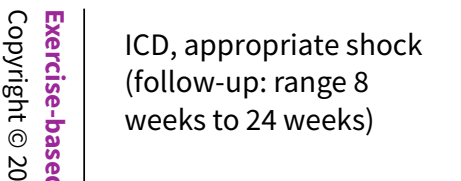 }} & \multicolumn{2}{|c|}{ Study population } & \multirow{2}{*}{$\begin{array}{l}\text { RR } 0.56 \\
(0.20 \text { to } 1.58)\end{array}$} & \multirow{2}{*}{$\begin{array}{l}428 \\
\text { (3 RCTs) }\end{array}$} & \multirow{2}{*}{$\begin{array}{l}\oplus \oplus \ominus \ominus \\
\text { Low cd }\end{array}$} & \multirow{4}{*}{$\begin{array}{l}\text { One additional } \\
\text { study reported } \\
\text { that no inappro- } \\
\text { priate shocks oc- } \\
\text { curred (Piotrow- } \\
\text { icz 2015). }\end{array}$} \\
\hline & & 132 per 1000 & $\begin{array}{l}74 \text { per } 1000 \\
(26 \text { to } 209)\end{array}$ & & & & \\
\hline 袍 & \multirow{2}{*}{$\begin{array}{l}\text { ICD, inappropriate shock } \\
\text { (follow-up: } 24 \text { weeks) }\end{array}$} & Study popul & & \multirow{2}{*}{$\begin{array}{l}\text { RR } 0.60 \\
\text { (0.10 to } 3.51)\end{array}$} & \multirow{2}{*}{$\begin{array}{l}160 \\
\text { (1 RCTs) }\end{array}$} & \multirow{2}{*}{$\begin{array}{l}\oplus \oplus \oplus \ominus \\
\text { Moderatec }\end{array}$} & \\
\hline 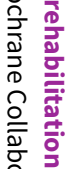 & & 39 per 1000 & $\begin{array}{l}24 \text { per } 1000 \\
(4 \text { to } 139)\end{array}$ & & & & \\
\hline 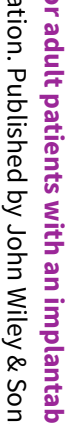 & $\begin{array}{l}\text { Health-related quality of } \\
\text { life (HRQoL) } \\
\text { (assessed with different } \\
\text { scales - } \\
\text { follow-up: range } 8 \\
\text { weeks to } 24 \text { weeks) }\end{array}$ & \multicolumn{2}{|c|}{$\begin{array}{l}\text { One trial reported the official version of SF- } 36 \text { showing evidence } \\
\text { of a greater improvement in the exercise-based cardiac rehabil- } \\
\text { itation group on SF- } 36 \text { Mental Component Score but no differ- } \\
\text { ence in Physical Component Score. One trial reported another } \\
\text { version of SF- } 36 \text { showing no evidence of a difference between } \\
\text { the groups. One trial reported the Nottingham Health Profile } \\
\text { showing no evidence of a difference between the groups. One tri- } \\
\text { al reported the Minnesota Living with Heart Failure showing no } \\
\text { evidence of a difference between the groups. One trial reported } \\
\text { the EuroQual showing no evidence of a difference between the } \\
\text { groups. }\end{array}$} & - & $\begin{array}{l}433 \\
\text { (5 RCTs) }\end{array}$ & \multicolumn{2}{|l|}{$\begin{array}{l}\oplus \odot \ominus \ominus \\
\text { Very low a g }\end{array}$} \\
\hline 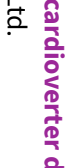 & \multicolumn{7}{|c|}{$\begin{array}{l}{ }^{*} \text { The risk in the intervention group (and its } 95 \% \text { confidence interval) is based on the assumed risk in the comparison group and the relative effect of the intervention (and } \\
\text { its } 95 \% \mathrm{CI} \text { ). } \\
\text { Cl: confidence interval; ICD: implantable cardioverter defibrillator; HRQoL: health-related quality of life; MD: mean difference; } \mathbf{R C T} \text { : randomised controlled trial; RR: risk ra- } \\
\text { tio. }\end{array}$} \\
\hline 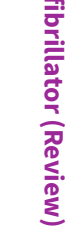 & \multicolumn{7}{|c|}{$\begin{array}{l}\text { GRADE Working Group grades of evidence } \\
\text { High quality: we are very confident that the true effect lies close to that of the estimate of the effect } \\
\text { Moderate quality: we are moderately confident in the effect estimate; the true effect is likely to be close to the estimate of the effect, but there is a possibility that it is sub- } \\
\text { stantially different } \\
\text { Low quality: our confidence in the effect estimate is limited; the true effect may be substantially different from the estimate of the effect } \\
\text { Very low quality: we have very little confidence in the effect estimate; the true effect is likely to be substantially different from the estimate of effect }\end{array}$} \\
\hline
\end{tabular}

a Random sequence generation, allocation concealment, blinding of participants and personnel, blinding of outcome assessment, incomplete outcome data, performance bias where poorly described in over $50 \%$ of included studies; risk of bias (downgraded by 2 levels).

b Not enough number of events to calculate a precise effect estimate, risk of imprecision (downgraded by 1 level).

c The $95 \%$ Cls includes both no effect and appreciable harm (i.e. $\mathrm{Cl}>1.25$ ) and appreciable benefit (i.e. $\mathrm{Cl}<0.75$ ), risk of imprecision (downgraded by 1 level),

$\mathrm{d}$ Random sequence generation, allocation concealment, blinding of participants and personnel, blinding of outcome assessment, incomplete outcome data, performance bias where poorly described in less then $50 \%$ of included studies; risk of bias (downgraded by 1 level).

e There was a degree of variability between studies of $50 \%$ to $90 \%$, which might represent substantial heterogeneity, risk of inconsistency (downgraded by 1 level).

$\mathrm{f}$ The upper or lower confidence limit crosses the effect size of 0.5 in either direction, risk of imprecision (downgraded by 1 level). 


\begin{tabular}{|c|c|c|c|c|c|c|c|}
\hline \multicolumn{8}{|c|}{ Exercise compared to no exercise at longest available follow-up for adults with an implantab } \\
\hline 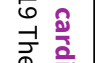 & \multicolumn{7}{|c|}{ Exercise compared to no exercise at longest available follow-up for adults with an implantable cardioverter defibrillator } \\
\hline 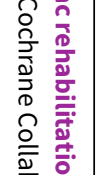 & \multicolumn{7}{|c|}{$\begin{array}{l}\text { Patient or population: adult patients with an implantable cardioverter defibrillator } \\
\text { Setting: in-hospital, outpatient clinic, home-based } \\
\text { Intervention: exercise } \\
\text { Comparison: no exercise }\end{array}$} \\
\hline 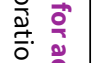 & \multirow[t]{2}{*}{ Outcomes } & \multicolumn{2}{|c|}{ Anticipated absolute effects ${ }^{*}(95 \% \mathrm{Cl})$} & \multirow{2}{*}{$\begin{array}{l}\text { Relative effect } \\
(95 \% \mathrm{CI})\end{array}$} & \multirow{2}{*}{$\begin{array}{l}\text { № of partici- } \\
\text { pants } \\
\text { (studies) }\end{array}$} & \multirow{2}{*}{$\begin{array}{l}\text { Quality of the } \\
\text { evidence } \\
\text { (GRADE) }\end{array}$} & \multirow[t]{2}{*}{ Comments } \\
\hline 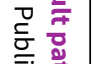 & & Risk with no exercise & Risk with exercise & & & & \\
\hline$\frac{0}{0}$ & \multirow{2}{*}{$\begin{array}{l}\text { All-cause mortality } \\
\text { (follow-up: range } 12 \\
\text { months to } 45 \text { months) }\end{array}$} & Study population & & \multirow{2}{*}{$\begin{array}{l}\text { RR } 1.18 \\
\text { (0.65 to } 2.14)\end{array}$} & \multirow{2}{*}{$\begin{array}{l}332 \\
\text { (3 RCTs) }\end{array}$} & \multirow{2}{*}{$\begin{array}{l}\oplus \odot \odot \ominus \\
\text { Very lowb c e }\end{array}$} & \multirow[b]{2}{*}{$\begin{array}{l}\text { Four trials with } \\
\text { a total of } 384 \\
\text { participants re- } \\
\text { ported all-cause } \\
\text { mortality. One } \\
\text { trial reported } \\
\text { no deaths and } \\
\text { three trials re- } \\
\text { ported a total of } \\
46 \text { deaths. }\end{array}$} \\
\hline 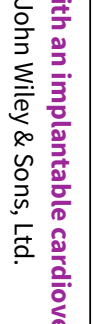 & & 127 per 1000 & $\begin{array}{l}149 \text { per } 1000 \\
\text { (82 to } 271)\end{array}$ & & & & \\
\hline$\frac{7}{10}$ & \multirow{2}{*}{$\begin{array}{l}\text { Serious adverse events } \\
\text { (follow-up: range } 12 \\
\text { months to } 18 \text { months) }\end{array}$} & \multicolumn{2}{|l|}{ Study population } & \multirow{2}{*}{$\begin{array}{l}\text { RR } 0.81 \\
\text { (0.61 to } 1.08 \text { ) }\end{array}$} & \multirow{2}{*}{$\begin{array}{l}188 \\
\text { (3 RCTs) }\end{array}$} & \multirow{2}{*}{$\begin{array}{l}\oplus \ominus \Theta \odot \\
\text { Very low a c d }\end{array}$} & \\
\hline 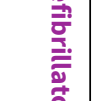 & & 527 per 1000 & $\begin{array}{l}427 \text { per } 1000 \\
(322 \text { to } 570)\end{array}$ & & & & \\
\hline 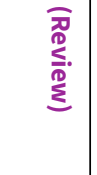 & $\begin{array}{l}\text { Exercise-capacity }\left(\mathrm{VO}_{2}\right. \\
\text { peak) } \\
\text { (follow-up: mean } 12 \\
\text { months) }\end{array}$ & $\begin{array}{l}\text { The mean exercise-capaci- } \\
\text { ty }\left(\mathrm{VO}_{2} \text { peak) was } 14.5 \mathrm{~mL} /\right. \\
\mathrm{kg} / \mathrm{min}\end{array}$ & $\begin{array}{l}\text { MD } 0.83 \mathrm{~mL} / \mathrm{kg} / \mathrm{min} \text { higher } \\
\text { ( } 0.66 \text { lower to } 2.32 \text { higher) }\end{array}$ & - & $\begin{array}{l}136 \\
(2 \mathrm{RCTs})\end{array}$ & $\begin{array}{l}\oplus \ominus \ominus \ominus \\
\text { Very low ac }\end{array}$ & \\
\hline & $\begin{array}{l}\text { ICD, antitachycardia pacing } \\
\text { (follow-up: } 45 \text { months) }\end{array}$ & \multicolumn{2}{|c|}{$\begin{array}{l}\text { One trial with a total of } 196 \text { participants reported results on } \\
\text { antitachycardia pacing at } 45 \text { months of follow-up with no ev- } \\
\text { idence of a difference between exercise-based cardiac reha- } \\
\text { bilitation and control group (Berg 2014). }\end{array}$} & - & $\begin{array}{l}196 \\
(1 \mathrm{RCT})\end{array}$ & $\begin{array}{l}\oplus \ominus \odot \odot \\
\text { Very low a b }\end{array}$ & \\
\hline & \multirow{2}{*}{$\begin{array}{l}\text { ICD, appropriate shock } \\
\text { (follow-up: range } 12 \\
\text { months to } 45 \text { months) }\end{array}$} & Study population & & \multirow[t]{2}{*}{$\begin{array}{l}\text { RR } 0.28 \\
\text { (0.05 to } 1.65)\end{array}$} & \multirow[t]{2}{*}{$\begin{array}{l}384 \\
(4 \mathrm{RCTs})\end{array}$} & \multirow[t]{2}{*}{$\begin{array}{l}\oplus \odot \Theta \odot \\
\text { Very low a c d }\end{array}$} & \\
\hline a & & 356 per 1000 & 100 per 1000 & & & & \\
\hline
\end{tabular}




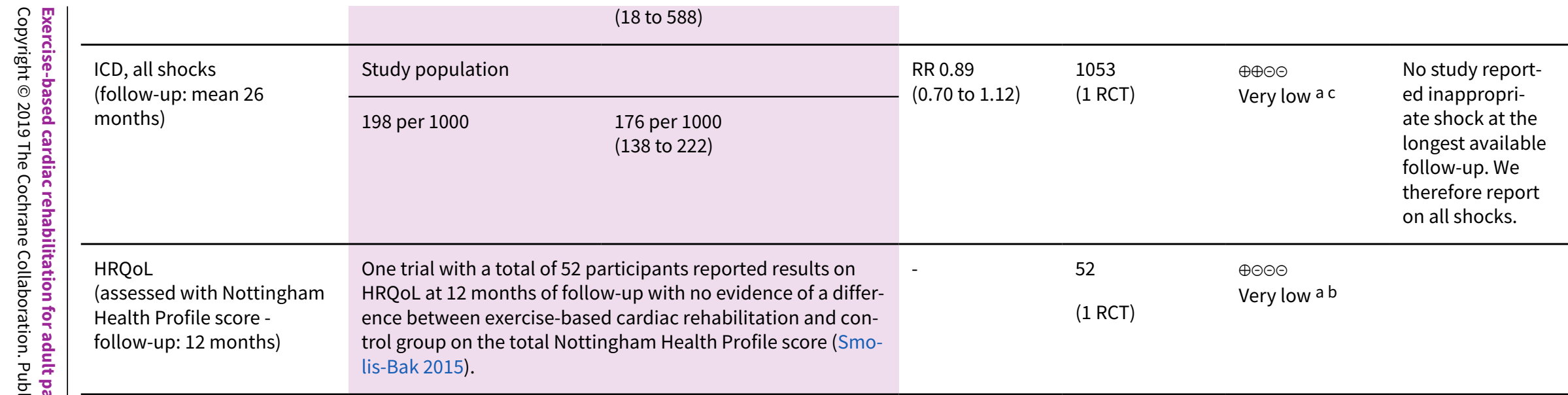

*The risk in the intervention group (and its $95 \%$ confidence interval) is based on the assumed risk in the comparison group and the relative effect of the intervention (and its $95 \% \mathrm{Cl}$ ).

Cl: confidence interval; HRQoL: health-related quality of life; ICD: implantable cardioverter defibrillator; RCT: randomised controlled trial; RR: risk ratio.

\section{GRADE Working Group grades of evidence}

High quality: we are very confident that the true effect lies close to that of the estimate of the effect

Moderate quality: we are moderately confident in the effect estimate; the true effect is likely to be close to the estimate of the effect, but there is a possibility that it is substantially different

Low quality: our confidence in the effect estimate is limited; the true effect may be substantially different from the estimate of the effect

Very low quality: we have very little confidence in the effect estimate; the true effect is likely to be substantially different from the estimate of effect

a Random sequence generation, allocation concealment, blinding of participants and personnel, blinding of outcome assessment, incomplete outcome data, performance bias where poorly described in over $50 \%$ of included studies; bias likely, therefore quality of evidence was downgraded by two levels.

b Not enough number of events to calculate a precise effect estimate, risk of imprecision (downgraded by 1 level).

c The $95 \%$ Cls includes both no effect and appreciable harm (i.e. $\mathrm{Cl}>1.25$ ) and appreciable benefit (i.e. $\mathrm{Cl}<0.75$ ), therefore quality of evidence was downgraded by one level.

d There was a degree of variability between studies of $50 \%$ to $90 \%$, which might represent substantial heterogeneity (downgraded by 1 level)

e Random sequence generation, allocation concealment, blinding of participants and personnel, blinding of outcome assessment, incomplete outcome data, performance bias where poorly described in less then $50 \%$ of included studies; risk of bias (downgraded by 1 level). 


\section{B A C K G R O U N D}

\section{Description of the condition}

Cardiovascular disease is a leading cause of global mortality with approximately 17.3 million deaths each year (2009-2012) and this figure is expected to rise to 23.6 million by 2030 (Mozaffarian 2015). A major cause of cardiovascular deaths are sudden cardiac death; even though absolute rates of sudden cardiac death are declining it remains a significant public health burden (Niemeijer 2015).

An effective way of preventing sudden cardiac death, and one of the reasons for the decline is the use of implantable cardioverter defibrillators (ICDs) (Niemeijer 2015). An ICD can perform both monitoring and diagnosis of arrhythmia, but its main function is to give therapy to potentially life-threatening ventricular tachyarrhythmia, including ventricular tachycardia and ventricular fibrillation by use of antitachycardia pacing and highvoltage shock therapy, respectively. In addition to this, an ICD can give conventional bradycardia pacing if the patient has episodes of bradyarrhythmia. It is well documented that ICD shock and antitachycardia pacing can reduce mortality in patients with previous cardiac arrest due to ventricular tachyarrhythmia, and in primary prevention studies ICD implantation has been shown beneficial in patients with symptomatic heart failure despite optimal medical therapy and reduced contractile function. The implantation of an ICD is very similar to a conventional pacemaker with a lead in the right ventricle connected to the ICD which is typically positioned subcutaneously on the anterior chest wall below the clavicle (Tracy 2012). In recent years, primary prevention ICD treatment, either with or without cardiac re synchronisation therapy, has been extended to patients with symptomatic heart failure as part of the Heart Failure Guidelines from the American College of Cardiology/American Heart Association and European Society of Cardiology (Ponikowski 2016; Yancy 2013). This has led to a marked increase in the implantation rates in the USA and Europe (Gersh 2011; Jessup 2009). In 2013, the ICD implantation rate for first-time implants was approximately 214 per million inhabitants in the Nordic Countries (Denmark, Sweden and Norway) and approximately 125 per million inhabitants in the UK (Kuck 2014). These numbers are low compared with the USA, where the implantation rate in 2006 was almost twice as high, with 370 per million inhabitants (Scott 2009).

In addition to preventing sudden cardiac death, a number of randomised controlled trials (RCTs) has shown that the implantation of an ICD (either alone or in combination with cardiac resynchronisation therapy) in both the primary and secondary prevention setting has significant mortality and health-related quality of life effects (Mark 2008; Schron 2002). Adverse events for ICD recipients are mostly implantation-related complications (coronary vein dissection, coronary vein perforation, lead dislodgement, infection and death) and inappropriate defibrillator shocks (Kirkfeldt 2014). Patients who experience defibrillator shocks may experience psychological difficulties (Berg 2014; Dunbar 2009; Lemon 2004). A systematic review of anxiety and depression in ICD participants that included 45 studies and more than 5000 patients concluded that approximately $20 \%$ of ICD patients have clinically significant psychological distress (MagyarRussell 2011). This is twice as high as in individuals with general cardiac and chronic medical conditions (Lichtman 2008).
In spite of the potential mortality benefits of receiving an ICD device, psychological problems experienced by patients after receiving an ICD may negatively impact their health-related quality of life, and lead to increased readmission to hospital and healthcare needs, loss of productivity and employment earnings, and increased morbidity and mortality (Berg 2014; Dunbar 2012; Lemon 2004; Thomas 2001).

\section{Description of the intervention}

Cardiac rehabilitation is a comprehensive, complex intervention that includes components of exercise training, education, psychosocial management and a behaviour-modification programme designed to improve the physical and emotional conditions of people with heart disease (Piepoli 2010). Cardiac rehabilitation includes, for example, patient assessment, nutritional counselling, and risk factor management for lipids, blood pressure, weight, diabetes mellitus and smoking cessation (Piepoli 2010).

The beneficial effects of cardiac rehabilitation in post-myocardial, revascularisation and heart failure patients is well established in terms of potential reductions in mortality, hospitalisation and healthcare costs, as well as improvements in exercise capacity and health-related quality of life (Adamopoulos 1993; Anderson 2016; Belardinelli 1995; Coats 1992; Piepoli 2010; Sullivan 1988; Taylor 2014; Wilson 1996).

The European Society of Cardiology recommends that exercise training for people with cardiovascular disease should consist of two and a half hours per week, but recommendations stretch to four hours per week (Piepoli 2010).

Although their psychological needs may be high, no specific evidence-based cardiac rehabilitation guidelines exist for patients with ICDs, as evidence concerning rehabilitation for this patient group is very limited (Berg 2014; Dunbar 2012; Isaksen 2012). Neither the European Society of Cardiology nor the American Heart Association/American College of Cardiology have published separate or specific guidelines on exercise training for the ICD patient. We have been unable to identify any international consensus reports or guidelines that provide detailed recommendations for exercise training after receiving an ICD. Consequently, recommendations for ICD patients regarding exercise training vary widely (Isaksen 2012). RCTs and observational studies evaluating the effect of physical exercise for ICD patients have employed many different training protocols (Isaksen 2012).

Current cardiac rehabilitation recommendations for postmyocardial infarction/revascularisation, heart failure and heart valve replacement patients recommend that, in addition to exercise training, psychosocial or educational support, or both, should be offered (Piepoli 2010); so-called 'comprehensive cardiac rehabilitation'. However, as with exercise training, there are no separate or specific guidelines on psychoeducational interventions for the ICD patient. Many psychoeducational intervention studies in ICD recipients, some of which are RCTs, have reported improvements in anxiety, depression and healthrelated quality of life outcomes, as well as fewer unplanned hospital admissions and phone calls to healthcare providers compared with the control group (Berg 2014; Dunbar 2009; Lewin 2009; Pedersen 2007). Some of these studies have 
employed different psychoeducational intervention protocols, which again reflect the uncertainty surrounding the specific nature of cardiac rehabilitation for patients with ICDs and what kind of psychoeducational intervention they should receive.

In summary, there is evidence from other heart conditions (post-myocardial infarction, revascularisation and heart failure) that suggests that cardiac rehabilitation for patients with ICD should consist of both exercise training and psychoeducational intervention, but evidence-based rehabilitation guidelines for ICD recipients are currently lacking.

\section{How the intervention might work}

Studies of exercise training or psychoeducational interventions, or both, in ICD patients have reported improvements in psychological outcomes or physical outcomes, or both (Belardinelli 2006; Berg 2014; Davids 2005; Dougherty 2005; Dougherty 2008; Dunbar 2009; Fan 2009; Fitchet 2003; Irvine 2011; Vanhees 2004). RCTs have reported that comprehensive cardiac rehabilitation significantly increased average peak oxygen uptake $\left(\mathrm{VO}_{2}\right)$ after exercise training, with improvements of $16 \%$ to $27 \%$ in metabolic equivalents (METS) or peak $\mathrm{VO}_{2}$ (Belardinelli 2006; Berg 2014; Davids 2005; Fan 2009; Fitchet 2003; Vanhees 2004). A retrospective study of 82 ICD recipients indicated that patients who did not participate in outpatient rehabilitation had a higher rate of ICD shock therapy than ICD recipients who participated in outpatient rehabilitation, after adjusting for physical limitations (Davids 2005). Randomised trials have also reported reduced anxiety and depressive symptoms, increased health-related quality of life and decreased disability days/calls to healthcare providers (Belardinelli 2006; Berg 2014; Dougherty 2005; Dougherty 2008; Dunbar 2009; Fitchet 2003; Irvine 2011). As exercise-based rehabilitation emphases aspects of behavioural change (e.g. exercise/physical activity levels, improvements in diet and adherence to medication), beneficial effects may extend beyond the initial intervention period where patients are in direct contact with rehabilitation providers.

The safety of exercise training after ICD implantation may be compromised due to the risk of inappropriate ICD shocks. Therefore, patients are uncertain as to the level of exercise that is safe to perform without receiving an ICD shock. However, several studies have shown only a few exercise-related cardiac events during or soon after the training session (Berg 2014; Dougherty 2008; Fan 2009; Vanhees 2004).

In summary, randomised and observational studies suggest that exercise training has a positive effect on the exercise capacity, general health and quality of life of ICD patients. Furthermore, inclusion of psychosocial or educational support may have positive effects in terms of reduced anxiety and depression.

\section{Why it is important to do this review}

Firstly, whilst summaries of the evidence for cardiac rehabilitation in patients with ICD have been published (Dunbar 2012; Isaksen 2012), we are unaware of any systematic reviews of trials in this area. Secondly, we seek to extend the trial evidence base considered by the Cochrane Review, Exercise-based rehabilitation for heart failure (Taylor 2014). Many trials included in this Cochrane Review excluded ICD implants. However, we are aware that some of the more recent RCTs of exercise-based cardiac rehabilitation for heart failure include a proportion of patients with ICD, e.g. approximately $55 \%$ of patients in the HF-ACTION randomised trial (O'Connor 2009). While these randomised trials were included in the heart failure Cochrane Review, outcomes for the ICD subgroup were not reported separately. This Cochrane Review will therefore seek to report the outcomes for ICD subgroups included in those heart failure trials.

As outlined above, a proportion of ICD patients have arrhythmia (secondary prevention) and not heart failure (primary prevention). Traditionally, the ICD population has been considered as a single group due to their similar high risk of sudden cardiac death, ICD shock and device-dependence. As cardiac rehabilitation studies have been carried out in mixed ICD populations (both arrhythmia and heart failure), we will seek to include patients of all indications who have received an ICD, but aim to stratify our results by primary versus secondary indication.

By conducting this review we will also add to the body of knowledge about cardiac rehabilitation in complex cardiac conditions (Risom 2017; Sibilitz 2016; Taylor 2014).

\section{O B J E C T IVES}

To assess the benefits and harms of exercise-based cardiac rehabilitation programmes (exercise-based interventions alone or in combination with psychoeducational components) compared with control ( group of no intervention, treatment as usual or another rehabilitation programme) in adults with an ICD.

\section{METHODS}

\section{Criteria for considering studies for this review}

\section{Types of studies}

We included RCTs irrespective of language, publication year, publication type and publication status in the review.

\section{Types of participants}

We considered for inclusion adult participants (18 years or older), of both sexes and all ethnicities, who have been treated with an ICD. We included participants regardless of their indication or whether the device was implanted for primary or secondary prevention of sudden cardiac death. We included participants with ICD devices combined with cardiac resynchronisation therapy and permanent ICDs with any additional leads for pacing, including single chamber, dual chamber and biventricular pacemakers. In trials that included both participants with and without ICDs, we contacted trial authors for separate data on the ICD participants. If this was not possible, we only included the trial if at least $50 \%$ of participants were ICD recipients or if the trial had less than $50 \%$ but presented the results in a subgroup of ICD patients separately. We only found one trial that included both participants with and without ICDs (Chrysohoou 2015). As the number of ICD participants was below $50 \%$, we contacted the lead author for separated data on the ICD population; we are still waiting for this data and therefore the trial awaits classification.

\section{Types of interventions}

\section{Experimental}

The experimental intervention included an exercise-based cardiac rehabilitation programme for adults treated with an ICD. We 
defined interventions as 'exercise-based' when being either a supervised or unsupervised programme conducted in an inpatient, outpatient, community or home setting that included any kind of exercise training. The intervention included a physical exercise component that focused on increasing exercise capacity, and some trials also included a psychoeducational intervention that focused on improving mental health and the patient's self-management skills. The exercise intervention must have been initiated after ICD implantation. There was no restriction in the length, intensity or content of the training programme and there was no minimum length of follow-up for the studies that were eligible for inclusion in the review.

\section{Control}

We included control interventions that excluded exercise training, as listed below.

- Treatment as usual (e.g. standard medical care, such as ICD follow-up).

- No intervention.

- Any other type of cardiac rehabilitation programme, as long as it did not include a physical exercise element.

The included trials had different approaches to the control group. However, none of the trials reported any data on the control groups, why it is not possible to differentiate between them. Therefore, we grouped these three types of control into a single control and therefore only refer to control throughout the review.

\section{Co-interventions}

We included trials when they had co-interventions other than cardiac rehabilitation of any kind, as long as these were identical and delivered equally in the experimental and control groups. Co-interventions included anything other than the experimental exercise intervention (e.g. drug delivery, surgery techniques or dietary interventions).

\section{Types of outcome measures}

We assessed all outcomes at two time points as follows.

- End of the intervention (as defined by the trial authors).

- Longest available follow-up after the intervention period.

We considered 'end of intervention' to be the primary time point of interest.

\section{Primary outcomes}

- All-cause mortality.

- Serious adverse events, defined as any adverse event that results in death, is life threatening, requires hospitalisation, or results in persistent or significant disability or incapacity $(\mathrm{ICH}-$ GCP 2015).

- Health-related quality of life using generic or disease-specific validated instruments, e.g. Short Form-36 (SF-36) (Ware 1992), EuroQual (Brooks 1996) and Minnesota Living with Heart Failure Questionnaire (Rector 1992).

\section{Secondary outcomes}

- Exercise capacity: any measure of exercise capacity, including direct measurement of $\mathrm{VO}_{2}$ peak or $\mathrm{VO}_{2}$ max or indirect measures, such as exercise time, walking distance, etc.

- ICD antitachycardia pacing.

- ICD shock, defined as either inappropriate shock, appropriate shock or all shock (if it is not clear wether shock is appropriate or inappropriate).

- Non-serious adverse events, such as musculoskeletal injury, palpitations, dyspnoea, dizziness.

- Employment or loss of employment.

- Costs and cost-effectiveness of cardiac rehabilitation.

\section{Search methods for identification of studies}

\section{Electronic searches}

We identified trials through systematic searches of the following bibliographic databases on 30 August 2018.

- Cochrane Central Register of Controlled Trials (CENTRAL Issue 8 of 12, 2018) in the Cochrane Library.

- Epub Ahead of Print, In-Process \& Other Non-Indexed Citations, MEDLINE Daily and MEDLINE (Ovid, 1946 to 30 August 2018).

- Embase (Ovid, 1980 to 2018 Week 34).

- CINAHL Plus (EBSCO, 1937 to 30 August 2018).

- PsycINFO (Ovid, 1806 to August week 4 2018).

- LILACS (Bireme, 1982 to 30 August 2018).

- Conference Proceedings Citation Index-Science (CPCI-S) on Web of Science (Clarivate Analytics, 1990 to 30 August 2018).

We adapted the preliminary search strategy for MEDLINE (Ovid) for use in the other databases (Appendix 1). We applied the Cochrane sensitivity-maximising RCT filter to MEDLINE (Ovid) (Lefebvre 2011), and adapted it to the other databases, except CENTRAL.

We searched all databases from their inception and did not impose any date or language of publication restrictions.

\section{Searching other resources}

We searched the following clinical trials registers on 14 November 2017 to identify ongoing trials. See the search strategy in Appendix 1.

- ClinicalTrial.gov (www.clinicaltrials.gov).

- Controlled-trials.com (www.controlled-trials.com).

- World Health Organization (WHO) International Clinical Trials Registry Platform (ICTRP) (apps.who.int/trialsearch/).

We checked the reference lists of all primary studies and relevant publications for additional references to relevant trials and any unidentified RCTs. Finally, we also searched articles that had cited the included trials.

\section{Data collection and analysis}

\section{Selection of studies}

Two review authors, KMN and SKB, independently screened the titles and abstracts of all the potential studies that were identified as a result of the search, and coded them as 'retrieve' (eligible or 
potentially eligible/unclear) or 'do not retrieve'. If there were any queries, the full-text was retrieved. Two review authors, KMN and SKB, independently screened the full-text and identified studies for inclusion, and identified and recorded reasons for exclusion of the ineligible studies. Any disagreements were resolved through discussion or, if required, a third review author (RST) was consulted. The selection process was recorded in sufficient detail to complete a PRISMA flow diagram (Figure 1), and the 'Characteristics of excluded studies' table. 
Figure 1. Study flow diagram.

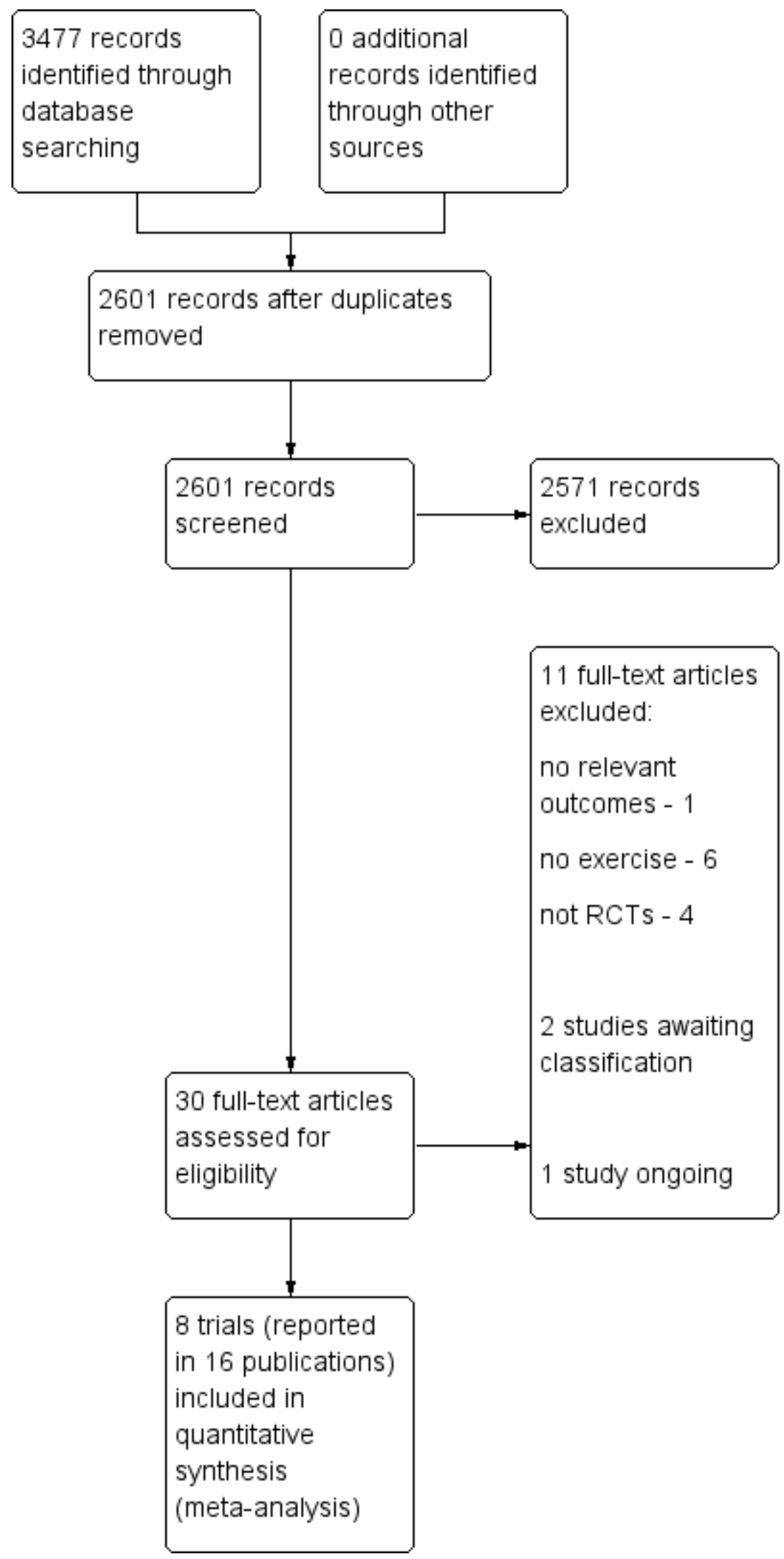




\section{Data extraction and management}

Two review authors (KMN and SKB) independently extracted trial data from the included RCTs using standardised data extraction forms. For the trial conducted by SKB, data were extracted by RST, who was not involved in the trial (Berg 2014). Data were presented both in tables and text and we resolved any discrepancies by consensus. KMN entered all data into Cochrane's statistical software Review Manager 5 (Review Manager 2014). It was doublechecked that data were entered correctly by comparing the data presented in the systematic review with the study reports. A second review author, SKB, spot-checked study characteristics entered in Review Manager 5 for accuracy against the trial report. In cases where there were not sufficient data or data were unclear in the included RCTs, we contacted trial authors to clarify the missing or unclear data. We extracted the following data.

- General information: publication status, title, authors' names, source, country, contact address, language of publication, year of publication, and duplicate publication.

- Methods: study design, total duration of study, details of any 'run in' period, number of study centres and location, study setting, withdrawals, and date of study.

- Participants: number randomised, mean age, age range, sex, severity of condition, diagnostic criteria, baseline lung function, smoking history, inclusion criteria, exclusion criteria, and number of participants lost to follow-up.

- Interventions: type of physical exercise, type of rehabilitation programme (does it consist of only physical exercise or are there any other components included, e.g. psychoeducational intervention, diet intervention, behavioural intervention), setting (e.g. inpatient, outpatient, community, home setting or a combination), time after hospitalisation, and type of control intervention.

- Outcomes: primary and secondary outcomes specified and collected, and time points reported. Please see Types of outcome measures.

- Bias: please see Assessment of risk of bias in included studies.

- Notes: trial funding and notable conflicts of interest of trial authors.

\section{Assessment of risk of bias in included studies}

Two review authors (KMN and SKB) independently assessed risk of bias for each study using the core criteria outlined in the Cochrane Handbook for Systematic Reviews of Interventions: generation of random sequence and allocation concealment, blinding of participants and personnel, blinding of outcome assessment, incomplete outcome data, and selective outcome reporting (Higgins 2011a). In addition to these core items and in accordance with previous Cochrane cardiac rehabilitation Reviews (Risom 2017; Sibilitz 2016), we assessed three other possible sources of bias: performance bias (relating to co-interventions), intention-to-treat analysis, and groups balanced at baseline. We resolved any disagreements by discussion or by involving another review author (RST). We judged the 'Risk of bias' criteria as either 'low', 'high' or 'unclear' risk and evaluated individual bias items as described in Higgins 2011a. The criteria for all items were detailed in Appendix 2.

\section{Overall risk of bias}

We categorised a trial as being at low risk of bias if we rated the trial at low risk in all the domains listed above. We categorised a trial as being at high risk of bias if we rated the risk of bias as either uncertain or high in any of the domains listed above. We expected though, that we would categorise all trials as an overall high risk of bias, as it was not possible to blind participants and personnel (Savović 2012; Wood 2008). Therefore, we categorised trials at overall low risk of bias if we rated a trial at low risk of bias in all the risk of bias domains listed above, except blinding of participants and personnel. We also took into account the risk of bias of the trials that contributed to that outcome, when considering intervention effects.

\section{Measures of treatment effect}

We expressed results of dichotomous outcomes as risk ratios (RRs) with $95 \%$ confidence intervals (Cls). We estimated continuous outcomes as the mean difference (MD) with 95\% Cls between intervention groups. Whilst standardised mean difference (SMD) can be calculated if different instruments across trials assessing the same outcome are used, given the range of reported instruments and domains, we did not calculate SMDs for health-related quality of life outcomes in this review. Instead we provide a tabular summary of exercise-based cardiac rehabilitation versus control health-related quality of life outcome results, as reported by studies.

\section{Unit of analysis issues}

We only included RCTs with an individual allocation and parallel design. The trial of Belardinelli 2006 was designed as a cross-over $\mathrm{RCT}$, therefore we only used data from the first part of the trial before cross-over.

\section{Dealing with missing data}

We contacted investigators or study sponsors in order to verify key trial characteristics and missing outcome data.

\section{Assessment of heterogeneity}

We explored clinical heterogeneity by comparing the population, experimental intervention and control intervention. We assessed statistical heterogeneity in the included trials both by visual inspection of a forest plot, and by using a standard $\mathrm{Chi}^{2}$ test value with a significance level of $P=0.10$. We assessed heterogeneity by using the $\mathrm{I}^{2}$ statistic. We interpreted an $\mathrm{I}^{2}$ statistic value of $\geq 50 \%$ with a statistically significant value for the $\mathrm{Chi}^{2}$ test as evidence of substantial statistical heterogeneity (Higgins 2011b).

\section{Assessment of reporting biases}

There was an insufficient number of trials to assess reporting bias using either funnels plot or the Egger test for any of the stated outcomes (Egger 1997; Higgins 2011b).

\section{Data synthesis}

We performed data synthesis according to recommendations in the Cochrane Handbook for Systematic Reviews of Interventions (Higgins 2011b), using Review Manager 2014 for statistical analysis and trial sequential analysis (TSA) for explorative reasons (Thorlund 2011). We undertook random-effects meta-analysis except where there was evidence of substantial statistical heterogeneity and both 
random-effects and fixed-effect models were reported (Deeks 2011; Demets 1987; DerSimonian 1986). Given the range of instruments and outcome domains, we did not undertake a meta-analysis of health-related quality of life outcomes; we presented a narrative summary instead.

\section{TSA}

For explorative reasons we undertook TSA to assess the risk of random errors, because cumulative meta-analyses are at risk of producing random errors due to sparse data and repetitive testing on the accumulating data (Thorlund 2009; Thorlund 2011; TSA 2011; Wetterslev 2008). The underlying assumption of TSA is that testing for significance may be performed each time a new trial is added to the meta-analysis. We added the trials according to their year of publication and, if more than one trial had been published in a year, we added trials alphabetically according to the last name of the first author (Wetterslev 2008). To minimise random errors, we calculated the required information size (that is, the number of participants needed in a meta-analysis to detect or reject a certain intervention effect) (Wetterslev 2008). The information size calculation also accounted for the heterogeneity or diversity present in the meta analysis (Wetterslev 2009).

We based the required information size for dichotomous outcomes on the assumption of a plausible RR reduction of $20 \%$ from the proportion with the outcome in the control group, or on the $R R$ reduction observed in the included trials at low risk of bias (Wetterslev 2008). For continuous outcomes, we tested for a difference of $0.5 \mathrm{SD}$ using the SD from the control groups. As a default, we used a type I error of $5 \%$, a type II error of $20 \%$, and diversity of $30 \%$ and $60 \%$, or as suggested by the trials in the metaanalysis (Wetterslev 2008; Wetterslev 2009).

Trial sequential monitoring boundaries can be constructed on the basis of the required information size and the risks for type I (5\%) and type II (20\%) errors (Thorlund 2011; Wetterslev 2008). These boundaries will determine the statistical inference that can be drawn regarding the cumulative meta-analysis that has not reached the required information size: if the trial sequential monitoring boundary is crossed before the required information size is reached, it is possible that firm evidence may be established and further trials may turn out to be superfluous. On the other hand, if the boundary is not surpassed, it is probably necessary to continue conducting trials in order to detect or reject a certain intervention effect.

\section{Subgroup analysis and investigation of heterogeneity}

There were insufficient data to undertake the following subgroup analyses for the primary outcomes using stratified meta-analysis or meta-regression.

- Trials at overall low risk of bias compared with trials at overall high risk of bias; if we did not categorise any trials as being at overall low risk of bias, we planned to perform sensitivity analysis on trials at overall lower risk of bias compared to trials at overall higher risk of bias.

- Trials in the primary prevention ICD population versus secondary prevention ICD populations.

- Trials including women only versus trials including men only.

- Trials including younger participants (defined according to the trial authors as, for example, under 60 years) only versus trials including older participants (defined according to the trial authors as, for example, over 60 years) only.

- Trials including only ICD participants compared to trials with mixed participant populations (both ICD and non-ICD participants).

- Trials with high compliance in the intervention groups (defined according to the trial authors) compared to trials with low compliance in the intervention groups (defined according to the trial authors).

But there were sufficient data to perform the following subgroup analyses.

- Trials with a short follow-up period (end of intervention) versus trials with a longer follow-up period (longest available followup).

- Trials with an exercise intervention only compared to trials with an exercise intervention plus any other co-intervention, such as a psychoeducational intervention.

\section{Sensitivity analysis}

Without individual patient data, it was not possible to consider the impact of loss to follow-up on the continuous outcome of healthrelated quality of life. Therefore we limited our sensitivity analyses to the primary outcomes of all-cause mortality and serious adverse events, based on the information provided on losses for follow-up.

\section{Best-worse case scenario}

For the best-worst case analysis, we assumed that all participants lost to follow-up in the exercise-based cardiac rehabilitation group had not experienced the outcome, and all those with missing outcomes in the control group had experienced the outcome.

\section{Worst-best case scenario}

For the worst-best case analysis, we assumed that all participants lost to follow-up in the exercise-based cardiac rehabilitation group had experienced the outcome, and all those with missing outcomes in the control group had not experienced the outcome

\section{Summary of findings}

Two review authors (KMN and SKB) created 'Summary of findings' tables using the following outcomes: all-cause mortality, serious adverse events, health-related quality of life, exercisecapacity, antitachycardia pacing, and ICD shock. We developed two 'Summary of findings' tables, one for each time point that outcomes were assessed. We used the five GRADE considerations (study limitations, consistency of effect, imprecision, indirectness, and publication bias) to assess the quality of the body of evidence supporting each of the listed outcomes. We used methods and recommendations described in Section 8.5 and Chapter 12 of the Cochrane Handbook for Systematic Reviews of Interventions (Higgins 2011a), using GRADEpro software (gradepro.org). We justified all decisions to downgrade the quality of studies using footnotes. Please see Summary of findings for the main comparison for results at end of intervention and Summary of findings 2 for results at longest available follow-up. 


\section{RESULTS}

\section{Description of studies}

The selection process is summarised in the PRISMA flowchart shown in Figure 1, Characteristics of included studies, Characteristics of excluded studies, and Characteristics of studies awaiting classification.

\section{Results of the search}

The electronic searches yielded a total of 2601 titles after deduplication. After reviewing titles and abstracts, we obtained 30 full text papers for possible inclusion. After reviewing the texts, we included eight RCTs published in 16 publications.

\section{Included studies}

The included trials randomised a total of 1730 ICD participants with or without cardiac resynchronisation therapy (CRT) function to exercise-based cardiac rehabilitation or control. The majority of the trials were small ( 7 trials $<200$ patients) and single centre ( 6 trials) with one large trial contributing about $61 \%$ (1053 participants) of all the included participants (Piccini 2013). Participants were predominantly male with heart failure and the mean age of participants across the included trials ranged from 54 to 65 years. Only two trials reported on ethnicity and $69 \%$ to $84 \%$ of the study population was white (Dougherty 2015; Piccini 2013). The percentage of included patients with heart failure ranged from $76.8 \%$ to $100 \%$ (exercise group) and $75.3 \%$ to $100 \%$ (control group). All trials assessed the effects of physical exercise training as the experimental intervention and two trials used psychoeducation in addition to the physical exercise training, but only in the experimental intervention group (Berg 2014; Frizelle 2004). Exercise-based-cardiac rehabilitation programmes were mostly delivered by a combination of centre-based setting and home exercise sessions. The dose of exercise training ranged widely across the eight trials with two to seven sessions per week with session duration of 10 to 60 minutes for a period of eight to 26 weeks. In one trial the control group were asked not to start a new exercise programme (Dougherty 2015). The rest of the trials either did not report on this or the control group had no restriction in activity. None of the trials reported any data on the control groups. All trials reported that exercise-based cardiac rehabilitation was safe with no ICD shocks during exercise. Three trials reported ICD settings and all three trials reported that the defibrillator discharge threshold was set 20 beat per minute higher than maximal training heart rate (Belardinelli 2006; Dougherty 2015; Piotrowicz 2015). The reported follow-up on the primary outcome ranged from the end of the intervention to the longest follow-up of 45 months, with a median follow-up of 18 months. Only the trials of Belardinelli 2006 and Frizelle 2004 did not report on funding nor their potential conflicts of interest.

Details for each of the specific trials included in the review are shown in the 'Characteristics of included studies' table.

\section{Studies awaiting classification}

Two studies are awaiting classification. The reasons for this are presented in the section 'Characteristics of studies awaiting classification'.

\section{Excluded studies}

We excluded 11 studies.The reasons for this are presented in the section 'Characteristics of excluded studies'.

\section{Ongoing studies}

One study was an ongoing study and is presented in the section 'Characteristics of ongoing studies'.

\section{Risk of bias in included studies}

Risk of bias assessments are summarised in Figure 2 and Figure 3. Many trials failed to give sufficient detail to enable a clear assessment of their potential risk of bias. Based on the information available, we classified all trials as having an overall high risk of bias. 
Figure 2. Risk of bias graph: review authors' judgements about each risk of bias item presented as percentages across all included studies.

Random sequence generation (selection bias)

Allocation concealment (selection bias)

Blinding of participants and personnel (performance bias)

Blinding of outcome assessment (detection bias)

Incomplete outcome data (attrition bias)

Selective reporting (reporting bias)

Performance bias

Groups balanced at baseline bias

Intention-to-treat analysis

For-profit bias

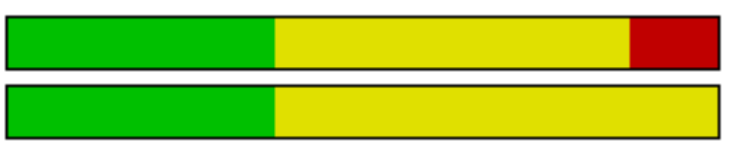


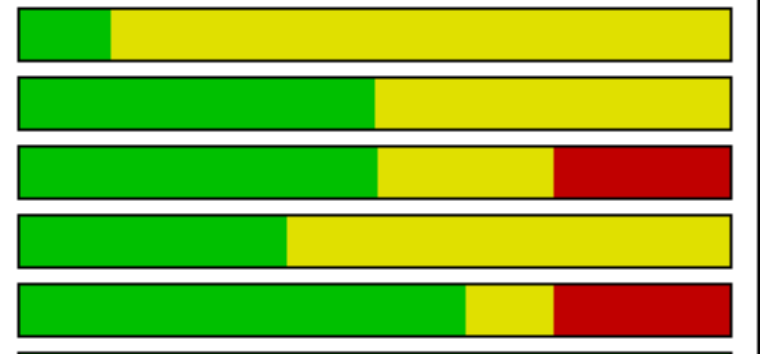

-

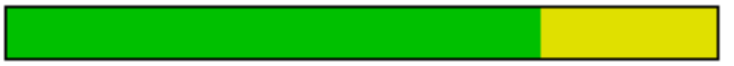

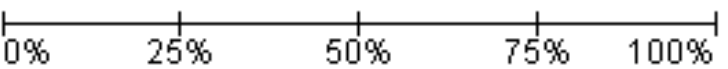


Figure 3. Risk of bias summary: review authors' judgements about each risk of bias item for each included study.

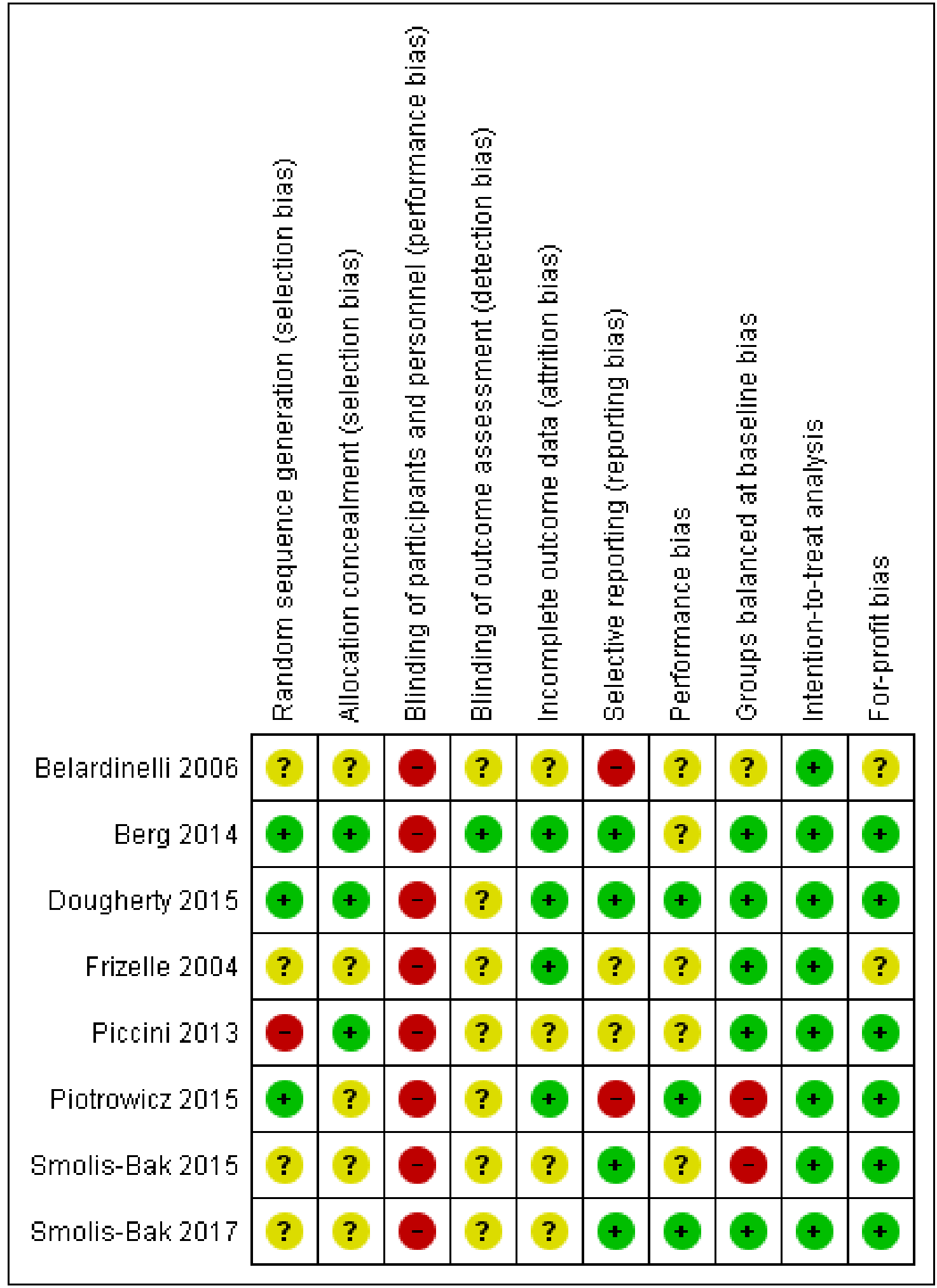

\section{Allocation}

\section{Random sequence generation}

In the randomisation process, three trials had a low risk of bias as they used either a computer random-number generator or a table of random numbers (Berg 2014; Dougherty 2015; Piotrowicz 2015). One trial also used a table of random numbers, but there were 30 patients in the intervention group and only 22 patients in the control group, and we therefore marked the trial as unclear risk of bias (Belardinelli 2006). Three trials had an unclear risk of

Exercise-based cardiac rehabilitation for adult patients with an implantable cardioverter defibrillator (Review) 
bias because of insufficient details (Frizelle 2004; Smolis-Bak 2015; Smolis-Bak 2017), and one trial had a high risk of bias because it was a subgroup analysis of a larger trial including heart failure patients (Piccini 2013).

\section{Allocation concealment}

In the concealment process, three trials had a low risk of bias as they used either an independent randomisation unit or an interactive voice response (Berg 2014; Dougherty 2015; Piccini 2013). Five trials had an unclear risk of bias because of insufficient reporting (Belardinelli 2006; Frizelle 2004; Piotrowicz 2015; Smolis-Bak 2015; Smolis-Bak 2017).

\section{Blinding}

Given the nature of cardiac rehabilitation, we judged all trials to be of high risk given the lack of blinding of participants and personnel. Blinding of outcome assessment was only reported in two trials (Berg 2014; Dougherty 2015). Berg 2014 had a low risk bias as the outcome assessment was blinded and Dougherty 2015 had an unclear risk of bias as the statistician was not blinded to the group assignment.

\section{Incomplete outcome data}

The number of and reasons for dropouts and withdrawals was fully described in four trials (Berg 2014; Dougherty 2015; Frizelle 2004; Piotrowicz 2015). Four trials did not provide any information about dropouts and withdrawals and were therefore marked as unclear risk (Belardinelli 2006; Piccini 2013; Smolis-Bak 2015; Smolis-Bak 2017).

\section{Selective reporting}

Two trials reported all outcomes reported in their protocol publication and therefore we marked them as low risk (Berg 2014; Dougherty 2015). All intended outcomes for Frizelle 2004 and Smolis-Bak 2015 were reported as stated in the objectives of the trial, but we did not identify any published protocols for the trials to confirm this, and we therefore marked them as unclear risk. The trial of Belardinelli 2006 did not have a published design paper, there was no hierarchy of outcomes and there was no sample size calculation. The trial of Piotrowicz 2015 did not report on left ventricular ejection fraction (LVEF) after intervention as described in the methods section. We therefore marked both trials as high risk.

\section{Other potential sources of bias}

\section{Performance bias}

Two trials reported that they had no co-interventions (Dougherty 2015; Piotrowicz 2015) and one trial reported that both groups received guidelines on a healthy lifestyle (physical activity,diet) (Smolis-Bak 2017), therefore we marked them as low risk. The remaining trials either did not report any co-intervention (Belardinelli 2006; Frizelle 2004; Piccini 2013; Smolis-Bak 2015) or the control group were not denied to receive rehabilitation at a local hospital (Berg 2014), therefore we marked them as unclear risk.

\section{Groups balanced at baseline}

We assessed five trials to be comparable in regards to the characteristics of the participants before the start of the intervention in the intervention/control groups and therefore we marked them as low risk of bias (Berg 2014; Dougherty 2015; Frizelle 2004; Piccini 2013; Smolis-Bak 2017). We assessed two trials to be not comparable because of a large age difference in the cardiac rehabilitation and control groups and therefore we marked them as high risk of bias (Piotrowicz 2015; Smolis-Bak 2015). We assessed one trial to be comparable in regards to the characteristics of the participants, but because of an unequal randomisation with 30 participants in the exercise-based cardiac rehabilitation group and only 22 participants in the control group we marked it as unclear risk of bias (Belardinelli 2006).

\section{Intention-to-treat analysis}

All trials conducted the analyses according to an intention-totreat analysis and therefore we marked them as low risk of bias (Belardinelli 2006; Berg 2014; Dougherty 2015; Frizelle 2004; Piccini 2013; Piotrowicz 2015; Smolis-Bak 2015; Smolis-Bak 2017).

\section{For-profit bias}

Six trials reported their sources of funding (Berg 2014; Dougherty 2015; Piccini 2013; Piotrowicz 2015; Smolis-Bak 2015; Smolis-Bak 2017). Berg 2014 was funded by several foundations, none of which had any conflicts of interest in the trial. Dougherty 2015 was funded by the National Institutes of Health, National Heart, Lung, and Blood Institute. Piccini 2013 was founded by several grants, e.g. from companies that produce ICDs. Piotrowicz 2015 was funded by the National Science Centre, Poland. Smolis-Bak 2015 and Smolis-Bak 2017 were funded by the State Committee for Scientific Research. The rest of the included trials did not report on their source of funding (Belardinelli 2006; Frizelle 2004).

\section{Overall risk of bias}

We judged all of the included trials and outcome results at an overall high risk of bias as we judged all of the trials to be 'unclear' or 'high risk' in one or more risk of bias domains.

\section{Effects of interventions}

See: Summary of findings for the main comparison Exercise compared to no exercise at the end of the intervention for adults with an implantable cardioverter defibrillator; Summary of findings 2 Exercise compared to no exercise at longest available follow-up for adults with an implantable cardioverter defibrillator

See: Summary of findings for the main comparison for results at the end of the intervention and Summary of findings 2 for results at the longest available follow-up.

\section{Primary outcomes}

\section{All-cause mortality}

Meta-analysis

\section{End of the intervention}

Seven trials with a total of 677 participants and a follow-up ranging from eight weeks to 24 weeks reported all-cause mortality (Belardinelli 2006; Berg 2014; Dougherty 2015; Frizelle 2004; SmolisBak 2015; Piotrowicz 2015; Smolis-Bak 2017). Six trials reported no deaths and one trial reported a total of three deaths (exercise-based cardiac rehabilitation: 2 deaths; control: 1 death). One trial reported a combined endpoint of shock and death with 176 events in the exercise-based cardiac rehabilitation group and 177 events in the control group (Piccini 2013). As only one trial reported results at 
the end of the intervention, it was not possible to perform a metaanalysis. Instead we have reported on a single study result, with no evidence of a difference between the exercise-based cardiac rehabilitation group and the control group at the end of the intervention (risk ratio (RR) 1.96, 95\% confidence interval (CI) 0.18 to 21.26; quality of evidence: low; Analysis 1.1).

\section{Longest available follow-up after the intervention period}

Four trials with a total of 384 participants and a follow-up ranging from 12 months to 45 months reported all-cause mortality (Belardinelli 2006; Berg 2014; Smolis-Bak 2015; Smolis-Bak 2017). One trial reported no deaths and three trials reported a total of 46 deaths (exercise-based cardiac rehabilitation: 25 deaths; control 21 deaths). Meta-analysis showed that there was no evidence of a difference between the exercise-based cardiac rehabilitation group and control group at longest available follow-up (RR 1.18, 95\% Cl 0.65 to 2.14; quality of evidence: very low; Analysis 4.1).

\section{Heterogeneity}

\section{End of intervention}

We were unable to test for statistical heterogeneity as only one trial reported deaths.

\section{Longest available follow-up after the intervention period}

Neither visual inspection of the forest plots nor tests for statistical heterogeneity $(12=7 \% ; P=0.34)$ indicated evidence of heterogeneity.

\section{Sensitivity analyses}

\section{End of the intervention}

The best-worst case meta-analysis (RR $0.07,95 \% \mathrm{Cl} 0.02$ to 0.22; Analysis 2.1) showed that incomplete outcome data bias might potentially influence the results. The worst-best case metaanalyses in a random-effects model (RR $13.50,95 \% \mathrm{Cl} 3.24$ to 56.25 Analysis 3.1) showed that incomplete outcome data bias would not influence the results, but in a fixed-effect model the metaanalyses (RR 16.78, 95\% Cl 4.32 to 65.18; Analysis 3.2) showed that incomplete outcome data bias might potentially influence the results.

Visual inspection of the forest plots showed no signs of heterogeneity in a best-worst case scenario. In a worst-best case scenario visual inspection of the forest plots showed that the Frizelle 2004 trial compared to the remaining trials seemed to have an extreme result favouring exercise-based cardiac rehabilitation and the test for statistical heterogeneity was also significant $\left(1^{2}=\right.$ $56 \% ; P=0.08$ ). A post hoc sensitivity analysis showed that the metaanalysis result was not changed significantly when removing the trial of Frizelle 2004 from the analysis (RR 13.50, 95\% Cl 3.24 to 56.25; Analysis 3.3).

\section{Longest available follow-up after the intervention period}

Both the best-worst case meta-analysis (RR $0.48,95 \% \mathrm{Cl} 0.32$ to 0.74; Analysis 5.1) and the worst-best case meta-analysis (RR 2.29, $95 \% \mathrm{Cl} 1.12$ to 4.70 ; Analysis 6.1 ) showed that incomplete outcome data bias might potentially influence the results.

\section{Subgroup analysis}

It was only possible to conduct one subgroup analysis because there were no relevant data for the remaining planned subgroup analyses.

Test for subgroup differences showed no evidence of a difference in the subgroup analysis of exercise-based cardiac rehabilitation intervention only compared to exercise-based cardiac rehabilitation intervention plus any other co-intervention at longest follow-up, $\mathrm{P}=0.60$; Analysis 7.1).

\section{Assessment of clinical significance}

We did not assess the clinical significance of the results on allcause mortality as the thresholds for statistical significance were not crossed at either end of the intervention or at longest available follow-up after the intervention period.

\section{Serious adverse events}

\section{Meta-analysis}

\section{End of intervention}

Three trials with a total of 467 participants and a follow-up ranging from eight weeks to 24 weeks reported results on serious adverse events (Berg 2014; Dougherty 2015; Piotrowicz 2015). Fifty-two exercise-based exercise-based cardiac rehabilitation participants experienced one or more serious adverse event compared with 48 control participants. Only the trials of Berg 2014 and Dougherty 2015 contributed to this meta-analysis as the third study had no events. Meta-analysis of these two trials (356 participants) showed no evidence of a difference (RR $1.05,95 \% \mathrm{Cl} 0.77$ to 1.44 ; quality of evidence: low; Analysis 1.2). See Figure 4 for a detailed description of the serious adverse events.

Figure 4. Table: Serious adverse events at end of intervention.

\begin{tabular}{|c|l|l|l|c|}
\hline $\begin{array}{l}\text { Serious adverse events at } \\
\text { end of intervention }\end{array}$ & Berg $\mathbf{2 0 1 5}$ & Doughterty 2015 & Piotrowicz 2015 & Total events \\
\hline Intervention & $\begin{array}{l}2 \text { deaths } \\
39 \text { hospitalisations }\end{array}$ & 11 hospitalisations & $\begin{array}{l}\text { Reported 0 serious } \\
\text { adverse events }\end{array}$ & 52 \\
\hline Control & $\begin{array}{l}1 \text { death } \\
36 \text { hospitalisations }\end{array}$ & 11 hospitalisations & $\begin{array}{l}\text { Reported 0 serious } \\
\text { adverse events }\end{array}$ & 48 \\
\hline
\end{tabular}




\section{Longest available follow-up after the intervention period}

Three trials with a total of 188 participants and a follow-up ranging from 12 months to 18 months reported results on serious adverse events (Belardinelli 2006; Smolis-Bak 2015; Smolis-Bak 2017). Fourteen exercise-based cardiac rehabilitation participants experienced one or more serious adverse event compared with 23 control participants. Meta-analysis showed no evidence of a difference using a random-effects model (RR $0.84,95 \% \mathrm{Cl} 0.43$ to 1.65; quality of evidence: very low; Analysis 4.2). Using a fixedeffect model there was evidence of a difference favouring exercisebased cardiac rehabilitation (RR $0.81,95 \% \mathrm{Cl} 0.61$ to 1.08 ; quality of evidence: very low; Analysis 4.3). We have chosen to use the result from the fixed-effect model, as it was the most conservative result. See Figure 5 for a detailed description of the serious adverse events.

Figure 5. Table: Serious adverse events at longest available follow-up.

\begin{tabular}{|c|l|l|l|c|}
\hline $\begin{array}{c}\text { Serious adverse events at } \\
\text { longest available follow-up }\end{array}$ & Belardineli 2006 & Smolis-Bak 2015 & Smolis-Bak 2017 & Total events \\
\hline Intervention & Reported 0 serious & $\begin{array}{l}3 \text { deaths } \\
11 \text { hospitalisations }\end{array}$ & $\begin{array}{l}3 \text { deaths } \\
22 \text { hospitalisations }\end{array}$ & 39 \\
\hline Codverse events & $\begin{array}{l}6 \text { deaths } \\
19 \text { hospitalisations }\end{array}$ & 48 \\
\hline
\end{tabular}

\section{Heterogeneity}

\section{End of intervention}

Neither visual inspection of the forest plots nor tests for statistical heterogeneity $\left(1^{2}=0 \% ; P=0.67\right)$ indicated evidence of heterogeneity.

\section{Longest available follow-up after the intervention period}

Both visual inspection of the forest plots and tests for statistical heterogeneity $(12=69 \% ; P=0.04)$ indicated substantial heterogeneity. A post hoc sensitivity analysis showed that the metaanalysis result was not changed significantly when removing the trial of Belardinelli 2006 from the analysis (RR 1.01, 95\% Cl 0.76 to $1.34 ; I^{2}=0 \%, P=0.70$ )

\section{Sensitivity analyses}

\section{End of intervention}

The best-worst case meta-analysis (RR $0.58,95 \% \mathrm{Cl} 0.41$ to 0.82 ; Analysis 2.2) and worst-best case meta-analysis (RR $1.74,95 \% \mathrm{Cl}$ 1.34 to 2.27; Analysis 3.4) showed that incomplete outcome data bias might potentially influence the results.

Visual inspection of the forest plots showed no signs of heterogeneity.

\section{Longest available follow-up after the intervention period}

Two of the three trials did not report any dropouts and we were therefore unable to perform sensitivity analyses.

\section{Subgroup analysis}

It was only possible to conduct two subgroup analyses because there were no relevant data for the remaining planned subgroup analyses.

The test for subgroup differences showed no evidence of a difference in the subgroup analyses for trials with a short follow-up period compared to trials with a longer follow-up period, $P=0.56$; Analysis 7.2. The test for subgroup differences showed no evidence of a difference in the subgroup analyses for trials with an exercise intervention only compared to trials with an exercise intervention plus any other co-intervention at the end of the intervention, $\mathrm{P}=$ 0.67; Analysis 7.3.

\section{Assessment of clinical significance}

We did not assess the clinical significance of the results on serious adverse events as the thresholds for statistical significance was not crossed at either end of the intervention or at longest available follow-up after the intervention period.

\section{Health-related quality of life \\ End of the intervention}

Five trials with a total of 433 participants and a follow-up ranging from eight weeks to 24 weeks reported results on health-related quality of life (Belardinelli 2006; Berg 2014; Frizelle 2004; Piotrowicz 2015; Smolis-Bak 2015); results are summarised in Figure 6. 
Figure 6. Summary of results on health related quality of life at end of intervention and at longest available followup

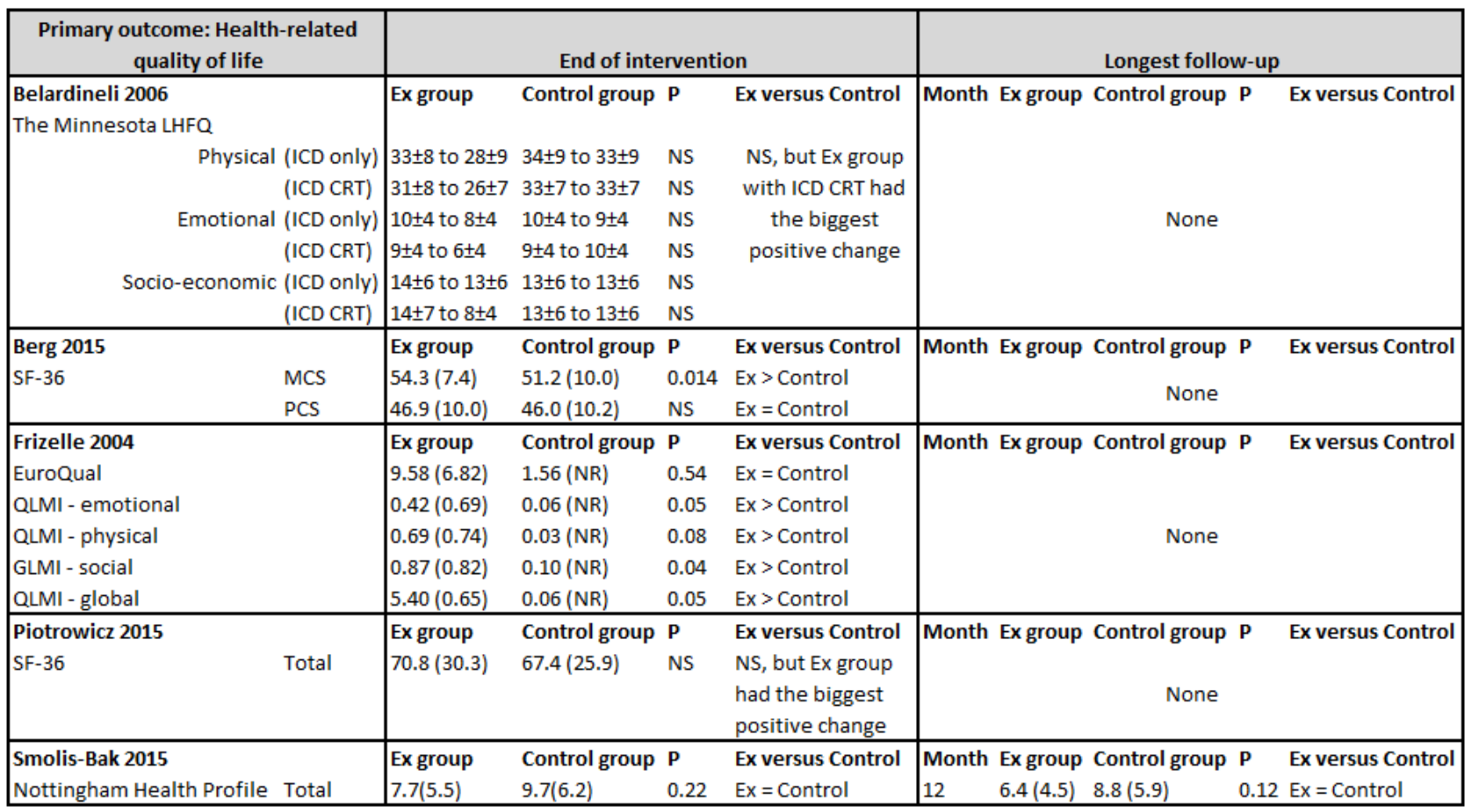

Two of the five trials reported the SF-36 (Berg 2014; Piotrowicz 2015). Berg 2014 showed evidence of a greater improvement in the exercise-based cardiac rehabilitation group than control group on SF-36 Mental Component Score but no difference in Physical Component Score. Piotrowicz 2015 showed no evidence of a difference between total SF-36 score. It was not possible to conduct a meta-analysis on the two trials as Piotrowicz 2015 used a Polish version of the SF-36 and therefore was not comparable to Berg 2014 , who used the original validated version of SF-36.

Smolis-Bak 2015 reported no evidence of a difference between the exercise-based cardiac rehabilitation and control groups on the total Nottingham Health Profile score (Smolis-Bak 2015). Only this trial used the Nottingham Health Profile and meta-analysis was therefore not possible.

Frizelle 2004 reported no evidence of a difference between the exercise-based cardiac rehabilitation and control groups on EuroQol score (Frizelle 2004). Only this trial used the EuroQual and meta-analysis was therefore not possible.

Belardinelli 2006 reported no evidence of a difference between the exercise-based cardiac rehabilitation and control groups on Minnesota Living with Heart Failure Questionnaire Physical, Emotional or Socio-Economic subscores (Belardinelli 2006). Only this trial used the Minnesota Living with Heart Failure Questionnaire and meta-analysis was therefore not possible.

\section{Longest available follow-up after the intervention period}

One trial with a total of 52 participants reported results on healthrelated quality of life at 12 months of follow-up with no evidence of a difference between the exercise-based cardiac rehabilitation and control groups on the total Nottingham Health Profile score
(Smolis-Bak 2015). Only this trial reported results at longest followup and meta-analysis was therefore not possible.

\section{Assessment of clinical significance}

It was not possible to asses the clinical significance of the results on health-related quality of life. The included trials used different health-related quality of life measures and calculating the minimally important difference in health-related quality of life measures is debated (Farivar 2004). Some suggest that this can be done using $0.5 \mathrm{SD}$ and some argue that using $0.3 \mathrm{SD}$ is more accurate. However, no consensus on recommendations exist.

\section{Secondary outcomes}

\section{Exercise-capacity at the end of the intervention}

Meta-analysis

\section{End of the intervention}

Eight trials with a total of 1507 participants and a follow-up ranging from eight weeks to 24 weeks reported results on exercise-capacity. Seven trials reported $\mathrm{VO}_{2}$ peak with a total of 1485 participants (Belardinelli 2006; Berg 2014; Dougherty 2015; Piccini 2013; Piotrowicz 2015; Smolis-Bak 2015; Smolis-Bak 2017). Randomeffects meta-analysis showed evidence of a higher $\mathrm{VO}_{2}$ peak with exercise-based cardiac rehabilitation compared with control at the end of the intervention (mean difference (MD) $2.27,95 \% \mathrm{Cl} 1.07$ to 3.46, quality of evidence: very low; Analysis 1.3). Using a fixed-effect model there was evidence of a difference favouring exercise-based cardiac rehabilitation compared to control (MD 0.91, $95 \% \mathrm{Cl} 0.60$ to 1.21 , quality of evidence: very low; Analysis 1.4). We have chosen to use the result from the fixed-effect model, as it was the most conservative result. 
Consistent with this, Frizelle 2004 reported evidence of a greater improvement in mean shuttle test distance from baseline in the exercise-based cardiac rehabilitation group compared with control group (exercise-based cardiac rehabilitation group: mean changes 85.56, SD 24.13; control group: mean changes 0.32) (Frizelle 2004). Only this trial used the shuttle test and meta-analysis was therefore not possible.

\section{Longest available follow-up after the intervention period}

Two trials with a total of 136 participants reported results on exercise-capacity at 12 months of follow-up with no evidence of a difference between the exercise-based cardiac rehabilitation and control groups (MD $0.83,95 \% \mathrm{Cl}-0.66$ to 2.32 , quality of evidence: very low; Analysis 4.4) (Smolis-Bak 2015; Smolis-Bak 2017).

\section{Heterogeneity}

\section{End of intervention}

Visual inspection of the forest plot did not show any clear signs of heterogeneity. However tests for statistical heterogeneity indicated evidence of heterogeneity $\left(I^{2}=79 \% ; P=0.0002\right)$.

\section{Longest available follow-up after the intervention period}

Both visual inspection of the forest plots and tests for statistical heterogeneity $\left(\mathrm{I}^{2}=89 \% ; \mathrm{P}=0.002\right)$ indicated substantial heterogeneity. A post hoc sensitivity analysis was not possible as there were only two trials.

\section{Assessment of clinical significance}

Our results show that exercise-based cardiac rehabilitation might increase the exercise-capacity in adults with an ICD at the end of the intervention. However, exercise-capacity is a surrogate outcome with questionable clinical relevance, so the clinical significance of this outcome result should be interpreted with caution. Further, based on prior studies a $6 \%$ change in peak $\mathrm{VO}^{2}$ has shown to be clinically meaningful in heart failure patients (Corrá 2006).

\section{ICD antitachycardia pacing}

\section{Meta-analysis}

\section{End of the intervention}

Two trials with a total of 356 participants and a followup ranging from 12 weeks to 24 weeks reported results on antitachycardia pacing (Berg 2014; Dougherty 2015). Thirty-eight exercise-based cardiac rehabilitation participants experienced one or more antitachycardia pacing event(s) compared with 29 control participants. Meta-analysis showed no evidence of a difference (RR $1.26,95 \% \mathrm{Cl} 0.84$ to 1.90 ; quality of evidence: moderate; Analysis $1.5)$.

\section{Longest available follow-up after the intervention period}

One trial with a total of 196 participants reported results on antitachycardia pacing at 45 months of follow-up with no evidence of a difference between the exercise-based cardiac rehabilitation and control groups (Berg 2014). Only this trial reported results at longest follow-up and meta-analysis was therefore not possible.

\section{Heterogeneity \\ End of intervention}

Neither visual inspection of the forest plots nor tests for statistical heterogeneity $\left(I^{2}=0 \% ; P=0.66\right)$ indicated evidence of heterogeneity.

\section{Longest available follow-up after the intervention period}

We were unable to test for statistical heterogeneity as only one trial reported antitachycardia pacing.

\section{Assessment of clinical significance}

The clinical significance of the results for antitachycardia pacing was unclear. The outcome results should be interpreted with caution as we assessed them as high risk of bias and the lack of statistical significance may very well be due to random error and lack of power. But as there was no difference in the risk of requiring antitachycardia pacing between the exercise-based cardiac rehabilitation group and the control group at the end of the intervention, one could argue, that exercise-based cardiac rehabilitation was safe, as it did not increase ventricular heart activity as this would have let to an increase of antitachycardia pacing.

\section{ICD shock}

\section{Meta-analysis}

\section{End of the intervention}

Three trials with a total of 428 participants and a follow-up ranging from eight weeks to 24 weeks reported results on appropriate shock (Berg 2014; Dougherty 2015; Piotrowicz 2015). Thirty-one exercisebased cardiac rehabilitation participants experienced one or more appropriate shocks compared with 25 control participants. Metaanalysis showed no evidence of a difference (RR 0.56, 95\% Cl 0.20 to 1.58; quality of evidence: low; Analysis 1.6).

Two trials with a total of 234 participants and a follow-up ranging from eight weeks to 24 weeks reported results on inappropriate shock (Dougherty 2015; Piotrowicz 2015). One trial reported no inappropriate shock and one trial reported a total of three inappropriate shocks (exercise-based cardiac rehabilitation: 1 inappropriate shock; control: 2 inappropriate shocks). As only one trial reported results at the end of the intervention we were unable to conduct a meta-analysis. Instead we have reported on a single study result, with no evidence of a difference between the exercisebased cardiac rehabilitation group and control group at the end of the intervention (RR $0.60,95 \% \mathrm{Cl} 0.10$ to 3.51 ; quality of evidence: moderate; Analysis 1.7).

\section{Longest available follow-up after the intervention period}

Four trials with a total of 384 participants and a follow-up ranging from 12 months to 45 months reported results on appropriate shock (Belardinelli 2006; Berg 2014; Smolis-Bak 2015; Smolis-Bak 2017). Sixty-one exercise-based cardiac rehabilitation participants experienced one or more appropriate shock(s) compared with 67 control participants. Meta-analysis showed no evidence of a difference using neither a random-effects model (RR $0.28,95 \% \mathrm{Cl}$ 0.05 to 1.65; quality of evidence: very low; Analysis 4.5) nor a fixedeffect model (RR $0.88,95 \% \mathrm{Cl} 0.68$ to 1.13 ; quality of evidence: very low; Analysis 4.6). We have chosen to use the result from the random-effects model, as it was the most conservative result. 
One trial with a total of 1053 participants and a follow-up of 26 months reported results on all shock (Piccini 2013). One hundred and eight exercise-based cardiac rehabilitation participants experienced one or more appropriate shock(s) compared with 113 control participants. As only one trial reported results at longest available follow-up after the intervention period we were unable to perform a meta-analysis. Instead we have reported on a single study result, with no evidence of a difference between the exercisebased cardiac rehabilitation group and control group at longest available follow-up after the intervention period (RR $0.89,95 \% \mathrm{Cl}$ 0.70 to 1.12 ; quality of evidence: very low; Analysis 4.7).

\section{Heterogeneity}

\section{End of intervention}

Neither visual inspection of the forest plots nor tests for statistical heterogeneity $(12=43 \% ; P=0.17)$ indicated evidence of heterogeneity for results on appropriate shock.

We were unable to test for statistical heterogeneity as only one trial reported on inappropriate shock.

\section{Longest available follow-up after the intervention period}

Both visual inspection of the forest plots and tests for statistical heterogeneity $(12=77 \% ; P=0.004)$ indicated evidence of heterogeneity for results on appropriate shock.

We were unable to test for statistical heterogeneity as only one trial reported on all shocks.

\section{Assessment of clinical significance}

The clinical significance of the results on appropriate shock, inappropriate shock and all shocks was unclear. Outcome results should be interpreted with caution as the $95 \% \mathrm{Cl}$ was very wide and we could not rule out any beneficial or harmful effects at this time. But as there was no difference in the risk of requiring an ICD shock between the exercise-based cardiac rehabilitation group and the control group, neither at end of intervention nor at longest available follow-up after the intervention period, one could argue, that exercise-based cardiac rehabilitation was safe, as it did not increase ventricular heart activity as this would have led to an increase of ICD shock.

\section{Non-serious adverse events}

\section{Meta-analysis}

\section{End of the intervention}

Two trials with a total of 271 participants and a follow-up ranging from eight weeks to 24 weeks reported results on the proportion of participants with non-serious adverse events at the end of the intervention (Dougherty 2015; Piotrowicz 2015). Eleven exercisebased cardiac rehabilitation participants experienced one or more serious adverse event compared with one control participants. Meta-analysis showed some evidence of a difference favouring the control group (RR 5.44, $95 \% \mathrm{Cl} 1.01$ to 29.32 ; Analysis 1.8), but the extremely wide $\mathrm{Cls}$, with the lower $\mathrm{Cl}$ very close to one, suggested that the data are compatible with their being no difference between groups.

\section{Longest available follow-up after the intervention period}

No trials reported results on non-serious adverse events after the end of the intervention.

\section{Heterogeneity}

\section{End of the intervention}

Neither visual inspection of the forest plots nor tests for statistical heterogeneity $\left(1^{2}=0 \% ; P=0.80\right)$ indicated evidence of heterogeneity.

\section{Assessment of clinical significance}

The clinical significance of the results on non-serious adverse events was sparse, as only two trials, with a total of 271 participants, reported on this outcome.

\section{Employment \\ Meta-analysis \\ End of intervention}

None of the included trials reported on this outcome at the end of the intervention.

\section{Longest available follow-up after the intervention period}

Only one trial reported results at 12 months of follow-up, and therefore we were unable to perform a meta-analysis. Instead, we have reported on a single trial result, which showed that after one year, $81 \%$ of the patients working before ICD implantation were still employed with no evidence of a difference between the exercisebased cardiac rehabilitation group and control group (Berg 2014).

\section{Assessment of clinical significance}

We did not assess the clinical significance of the results on employment as only one trial reported on this outcome.

\section{Costs and cost-effectiveness}

\section{Meta-analysis}

\section{End of intervention}

None of the included trials reported on this outcome at the end of the intervention.

\section{Longest available follow-up after the intervention period}

Only one trial reported results at 45 months of follow-up, and therefore we were unable to perform a meta-analysis. Instead, we have reported on a single study result, which showed that the rehabilitation programme resulted in a reduction in total attributable direct healthcare costs at 36 months' follow-up. The cost of rehabilitation was USD 335/EUR 276 per patient enrolled in rehabilitation. The total attributable cost of rehabilitation after three years was - USD 6789/- EUR 5593 in favour of exercise-based cardiac rehabilitation (Berg 2014). Only this trial reported results and we were therefore unable to perform a meta-analysis.

\section{Assessment of clinical significance}

We did not assess the clinical significance of the results on costs and cost-effectiveness as only one trial reported on this outcome.

\section{DISCUSSION}

\section{Summary of main results}

This systematic review identified eight randomised controlled trials (RCTs) with a total of 1730 participants, with an implantable cardiac device (ICD) with or without cardiac resynchronisation therapy 
(CRT) function, comparing exercise-based cardiac rehabilitation with no exercise control. All trials and outcome results were at high risk of bias and we assessed the evidence for all outcomes as ranging from very low to moderate quality.

The exercise-based programmes consisted in all eight trials of both aerobic exercise and resistance training or stretching (Belardinelli 2006; Berg 2014; Dougherty 2015; Frizelle 2004; Piccini 2013; Piotrowicz 2015; Smolis-Bak 2015; Smolis-Bak 2017). The dose of exercise training ranged widely across the trials with two to seven sessions per week and a duration of 10 to 60 minutes per session for a period of eight to 26 weeks. In two trials, the exercise-based programme was supplemented by psychoeducational follow-up, either face-to-face or by phone (Berg 2014; Frizelle 2004).

The trials had different approaches to their control group. One trial asked the control group not to start a new exercise programme (Dougherty 2015). The rest of the trials either did not report on this or the control group had no restriction in activity. None of the trials reported any data on the control groups, why we grouped the control groups into a single control throughout the review.

Meta-analysis showed that there was no evidence of a difference in all-cause mortality at the end of the intervention or at the longest available follow-up. There was also no evidence of a difference in serious adverse events between exercise-based cardiac rehabilitation and control at the end of the intervention or at the longest available follow-up. Sensitivity analysis showed that incomplete outcome data bias might potentially influence the results of both all-cause mortality and serious adverse events. Tests for subgroup differences showed no evidence of a difference in trials with a short follow-up period compared to trials with a longer follow-up period, or trials with an exercise intervention only compared to trials with an exercise intervention plus any other cointervention at the end of the intervention, and at longest available follow-up after the intervention period. Given the variation in reported health-related quality of life outcomes, it was not possible to pool data. The five trials reporting health-related quality of life, showed little or no difference at follow-up between exercise-based cardiac rehabilitation and control.

For secondary outcomes, this systematic review demonstrates a potential positive effect of exercise-based cardiac rehabilitation on exercise capacity compared to control at the end of the intervention. However, these effects of exercise-based cardiac rehabilitation are more uncertain at longest available followup after the intervention period. This systematic review also demonstrates that there are uncertain effects of exercise-based cardiac rehabilitation on antitachycardia pacing, appropriate shock, inappropriate shock, all shock, non-serious adverse events, employment and cost-effectiveness at the end of the intervention and at longest available follow-up after the intervention period.

This systematic review demonstrates that exercise-based cardiac rehabilitation might improve short-term exercise capacity compared with control. However, given the lack of evidence it was not possible to definitively assess the effects of exercisebased cardiac rehabilitation on all-cause mortality, serious adverse events, or health-related quality of life. All trials were at high risk of bias so it is highly likely that our results overestimate benefit and underestimate harm.
Our results are summarised in Summary of findings for the main comparison for results at the end of the intervention and Summary of findings 2 for results at longest available follow-up.

\section{Overall completeness and applicability of evidence}

We searched for RCTs irrespective of language, publication year, publication type and publication status. We also searched ClinicalTrials.gov, Controlled-trials.com, and The World Health Organization International Clinical Trials Registry Platform to search for ongoing trials or any that had not yet been published.

There was an insufficient number of trials to assess reporting bias using funnel plots for any of the stated outcomes.

When analysing the effects of exercise-based cardiac rehabilitation on all-cause mortality and serious adverse events, tests were limited to two subgroup analyses: trials with a short follow-up period compared to trials with a longer follow-up period; and trials with exercise intervention only compared to trials with exercise intervention plus any other co-intervention.

Our analyses showed that there was only evidence of a difference favouring exercise-based cardiac rehabilitation, when it comes to the outcome, exercise capacity. However, this finding needs to be interpreted with caution as all trials had a high risk of bias. Exercise-based cardiac rehabilitation might improve short-term exercise capacity compared with control, but there was no evidence of a long-term improvement. This could indicate that exercisebased cardiac rehabilitation did not have any permanent change in exercise behaviour in the included participants and therefore did not have a deferred benefit.

\section{Quality of the evidence}

We used the GRADE approach to assess the quality of evidence of each outcome result (Guyatt 2008). The GRADE assessments showed that the quality of evidence ranged from very low quality to moderate quality. Accordingly, there is a high risk that future trials may overturn the results of this present review. Reasons for the GRADE assessments are given below and are also described in the footnotes of Summary of findings for the main comparison for results at the end of the intervention and of Summary of findings 2 for results at the longest available follow-up.

The lack and quality of the reporting of methods in the majority of included trials made it difficult to assess their risk of bias. This was especially evident in terms of selection bias, performance bias, detection bias, and other bias. We judged the overall risk of bias in all the trials to be 'high risk', as we judged all of the trials to be 'unclear' or 'high risk' in one or more risk of bias domains. Two trials described their methodology in more depth and if we disregarded the bias domain of blinding of participants and personnel, these trails would have a low risk of bias. We assessed the risk of bias as high and downgraded these results by one level if $50 \%$ or lower of the included trials had a high risk of bias, and two levels if more than $50 \%$ of the included trials had a high risk of bias. For a summary on risk of bias, see Figure 2 and Figure 3.

The degree of variability between trials in the results of exercise capacity at the end of the intervention and serious adverse events and ICD shock at longest available follow-up were $50 \%$ to $90 \%$, which might represent substantial heterogeneity. Therefore, we assessed the risk of inconsistency as high and downgraded these 
results by one level. This decreases the validity of our reported results on these outcomes. In the rest of the results, we assessed the risk of inconsistency as not serious, which increases the validity of our reported results.

We assessed the degree of imprecision in the results and downgraded by one level if the number of events to calculate a precise effect estimate was too low or if the $95 \% \mathrm{Cls}$ included both no effect and appreciable harm and appreciable benefit. This was evident in the results of all-cause mortality, serious adverse events, and antitachycardia pacing and shock, and therefore we downgraded results to serious or very serious.

\section{Potential biases in the review process}

\section{Strengths}

This has been the first systematic review of RCTs assessing the impact of exercise-based cardiac rehabilitation for adult patients with an ICD. The review was conducted according to the recommendations of the Cochrane Handbook for Systematic Reviews of Interventions (Higgins 2011a). We followed the peerreviewed published protocol, which predefined participants, interventions, comparisons, and outcomes, with the attention of avoiding biases during review preparation. We performed a comprehensive literature search to identify published and unpublished studies according to our prespecified inclusion and exclusion criteria. We located full text publications of all included trials and conducted the meta-analysis using available data from these trials. We assessed outcomes at two assessment time points (end of the intervention and longest available follow-up). We thoroughly assessed risk of bias for each trial to assess the risks of systematic errors ('bias') (Higgins 2011a). We used sensitivity analyses (best-worst, worst-best) to test the robustness of our results (Higgins 2011a).

\section{Limitations}

Our review has some limitations. Firstly, most trials were relatively small (one trial, Piccini 2013 contributed $65 \%$ of the total data) and reported few clinical events. Secondly, although we contacted authors for missing data or trial information, we obtained a poor response. Thirdly, any searches hold the risk of missing items, e.g. limitations by number of databases, and limits due to search terms and filters. Fourthly, a longer intervention period might affect outcomes, as the follow-up duration and duration of exercise programme might be too short for clinical outcomes. Fiftly, because the trials had different approaches to the control groups, we grouped the control groups into a single control, which might be to much of a simplification.

\section{Agreements and disagreements with other studies or reviews}

We found that exercise-based cardiac rehabilitation increased exercise capacity at the end of the intervention, although results should be interpreted with caution as all trials had high risk of bias and there was evidence of substantial statistical heterogeneity. This finding concurs with previous reviews by Pandey and colleagues and Isaksen and colleagues. Isaksen et al concluded that exercisebased cardiac rehabilitation improves functional capacity in patients with ICDs and Pandey et al concluded that exercise training in patients with ICDs is associated with improved peak oxygen uptake (Isaksen 2012; Pandey 2017). Based on the trials identified in this review, we found no evidence of a difference in the risk of antitachycardia pacing, appropriate shock, inappropriate shock and all shock at the end of the intervention or at longest available follow-up. This does not concur with the review of Pandey et al, who concluded, in pooled analyses using a random-effects model, that exercise training was associated with significantly lower likelihood of ICD shock (Pandey 2017). When it comes to safety regarding inappropriate and appropriate shock during exercise, rehabilitation appears to be safe, as none of the trials included in this review reported any inappropriate or appropriate shocks during exercise. This concurs with both Isaksen et al and Pandey et al (Isaksen 2012; Pandey 2017).

Cochrane Reviews of the effects of exercise-based cardiac rehabilitation have been undertaken for other heart disease indications including heart failure and ischaemic heart disease (Anderson 2016; Taylor 2014). These reviews demonstrate that exercise-based cardiac rehabilitation decreases rates of hospitalisation and increases health-related quality of life. However, the impact of exercise-rehabilitation on these outcomes remains unproven for patients treated with ICD, and should be the focus of future randomised trials and updates of this Cochrane Review.

\section{AUTHORS' CONCLUSIONS}

\section{Implications for practice}

The European Society of Cardiology recommend exercise-based cardiac rehabilitation for patients treated with ICD (Piepoli 2012). In support of this, our systematic review of randomised trials showed evidence in favour of exercise-based rehabilitation (8 to 26 weeks of aerobic training, 2 to 7 days per week and a duration of 10 to 60 minutes per session) on short-term exercise capacity. However, the quality of evidence is low, and there was no evidence to support benefit in terms of mortality, ICD shock, antitachycardia pacing, employment or health-related quality of life.

The majority of trials included in this review were based on cardiac rehabilitation programmes that were of exercise training alone. However, it is widely accepted that contemporary cardiac rehabilitation is a complex intervention and should consist of other elements, including risk factor education and counselling (Anderson 2014) - 'comprehensive cardiac rehabilitation'. Moreover, due to the risk of ICD shock, rehabilitation programmes for ICD patients should contain elements of psychoeducation for shock management.

Based on this review, exercise-based cardiac rehabilitation seems safe, when it comes to ICD shock. Firstly, there was no difference in the risk of requiring an appropriate shock, inappropriate shock or all shock between the exercise-based cardiac rehabilitation group and the control group, neither at end of intervention nor at longest available follow-up after the intervention period. Secondly, all trials reported that their exercise programme was safe, with no ICD shocks during exercise. These results provide reassurance that exercise training in patients with an ICD does not lead to an increased incidence of appropriate shock, inappropriate shock or all shock. However, we still do not know if exercise-based cardiac rehabilitation for patients with ICD is safe in general, due to a small number of non-serious and serious adverse events reported by the trials identified in this review. There was also no information to what happened to ICD leads in the trials, but according to Lampert 
2017 , the estimated lead survival free of definite malfunction (from implantation date) was $95 \%$ at five years among 440 participants in organised sports.

\section{Implications for research}

This systematic review shows that well-designed adequately powered randomised trials are needed in order to assess the impact of exercise-based cardiac rehabilitation on the outcomes that matter most to patients, clinicians and policy makers. These outcomes include all-cause mortality, serious adverse events, health-related quality of life, appropriate shock, inappropriate shock, return to work, and costs and cost-effectiveness (Anderson 2016; Piepoli 2012; Taylor 2014).

New trials need to be conducted with a low risk of bias and a low risk of random errors, further they should be reported in accordance with CONSORT guidelines for non-pharmacological interventions (Boutron 2008). Future clinical trials of exercise-based cardiac rehabilitation in ICD patients should also address the following considerations.
- Address outcomes not present in this review, i.e. ICDs zones or detection times, ICD lead failure and ICD-related complications.

- Generalisability of trial populations, i.e. inclusion of women, people with different ICD types with or without cardiac resynchronisation therapy (CRT) function, both primary and secondary prophylactics ICD.

- Interventions to minimise the risk of ICD shock, antitachycardia pacing and increase exercise capacity and better health-related quality of life.

- Interventions to enhance long-term mortality, costs and costeffectiveness, and adherence, compliance and referral to rehabilitation programmes.

\section{ACK N O WLEDGEMENTS}

We would like to thank the Cochrane Heart Group who ran the literature searches for this review. 


\section{RE F E R E N C E S}

\section{References to studies included in this review}

Belardinelli 2006 \{published data only\}

Belardinellia R, Capestroa F, Misiania A, Scipionea P, Georgioub D. Moderate exercise training improves functional capacity,quality of life, and endothelium-dependent vasodilation in chronic heart failure patients with implantable cardioverter defibrillators and cardiac resynchronization therapy. European Journal of Cardiovascular Prevention and Rehabilitation 2006;13:818-25.

\section{Berg 2014 \{published data only\}}

* Berg SK, Pedersen PU, Zwisler A, Winkel P, Gluud C, Pedersen BD, et al. Comprehensive cardiac rehabilitation improves outcome for patients with implantable cardioverter defibrillator. Findings from the COPE-ICDrandomised clinical trial. European Journal of Cardiovascular Nursing 2015;14:3444

Berg SK, Pedersen PU, Zwisler AD, Winkel P, Gluud C, Pedersen $\mathrm{B}$, et al. Comprehensive cardiac rehabilitation versus treatment as usual for implantable cardioverter defibrillator recipients improves exercise capacity, general health and mental health-mixed methods approach embedding data from a randomised clinical trial with qualitative data. Conference Abstract. 2012.

Berg SK, Svendsen JH, Zwisler AD, Pedersen BD, Preisler P, Siersbæk-Hansen L, et al. COPE-ICD: a randomised clinical trial studying the effects and meaning of a comprehensive rehabilitation programme for ICD recipients - design, intervention and population. BMC Cardiovascular Disorders 2011;11:33.

Christensen AV, Øhlers AA, Zwisler AD, Svendsen JH, Berg SK. Employment status and sick leave after first-time implantable cardioverter defibrillator implantation: results from the COPEICD trial. Journal of Cardiovascular Nursing 2017;32(5):448-54. [DOI: 10.1097/JCN.0000000000000366]

\section{Dougherty 2015 \{published data only\}}

* Dougherty C, Glenny R, Burr R, Flo G, Kudenchuk P. Prospective randomized trial of moderately strenuous aerobic exercise after an implantable cardioverter defibrillator. Circulation 2015;131:1835-42.

Dougherty C, Glenny R, Kudenchuk P, Malinick T, Flo G. Testingan exercise intervention to improve aerobic conditioning and autonomic function after an implantable cardioverter defibrillator (ICD). Pacing and Clinical Electrophysiology 2010;33:1-8

Dougherty CM, Glenny R, Kudenchuk PJ, Flo GL, Burr RL. Aerobic exercise training after an ICD: Primary results of the antiarrhythmic effects of exercise after an ICD trial. Conference Abstract. 2011.

Dougherty CM, Glenny R, Kudenchuk PJ, Flo PL, Burr R. Aerobic exercise training after an ICD: Primary results of the antiarrhythmic effects of exercise after an ICD trial. Conference Abstract. 2013.
Flo G, Glenny R, Kudenchuk P, Dougherty C. Development and safety of an exercise testing protocol for participants with primary or secondary ICD indication. Cardiopulmonary Physical Therapy Journal 2012;23:16-22.

Goldman T, Dougherty CM, Burr RL, Kudenchuk PJ. Aerobic exercise improves heart rate recovery after an ICD. Conference Abstract. 2013

Frizelle 2004 \{published data only\}

Frizelle D, Lewin R, Kaye G, Hargreaves C, Hasney K, Beaumont $C$, et al. Cognitive-behavioural rehabilitation programme for patients with an implanted cardioverter defibrillator: a pilot study. British Journal of Health Psychology 2004;9:381-92.

\section{Piccini 2013 \{published data only\}}

Piccini J, Hellkamp A, Whellan D, Ellis S, Keteyian S, Kraus W, et al. Exercise training and implantable cardioverter defibrillator shocks in patients with heart failure: results from HF-ACTION. JACC: Heart Failure 2013;1:142-8.

Piotrowicz 2015 \{published data only\}

Piotrowicz E, Zielinski T, Bodalski R, Rywik T, DobraszkiewiczWasilewska B, Sobieszczanska-Małek M, et al. Home-based tele monitored Nordic walking training is well accepted, safe, effective and has high adherence among heart failure patients, including those with cardiovascular implantable electronic devices: a randomised controlled study. European Journal of Preventive Cardiology 2015;22:1368-77.

\section{Smolis-Bak 2015 \{published data only\}}

Smolis-Bąk E, Dąbrowski R, Piotrowicz E, Chwyczko T, Dobraszkiewicz-Wasilewska B, Kowalik I, et al. Hospital-based and tele monitoring guided home-based training programs: Effects on exercise tolerance and quality of life in patients with heart failure (NYHA class III) and cardiac resynchronization therapy: a randomised, prospective observation. International Journal of Cardiology 2015;199:442-7.

\section{Smolis-Bak 2017 \{published data only\}}

Smolis-Bąk E, Rymuzav H, Kazimierska B, Kowalik I, Chwyczko T, Borowiec A, et al. Improvement of exercise tolerance in cardiopulmonary testing with sustained safety after regular training in outpatients with systolic heart failure (NYHA III)and an implantable cardioverter-defibrillator. Prospective 18-month randomized study. Archives of Medical Science 2017;13:1094101. [DOI: 10.5114/aoms.2016.61938]

\section{References to studies excluded from this review}

Dougherty 2004 \{published data only\}

Cynthia M, Dougherty G, Pyper P, Frasz HA. Description of a nursing intervention program after an implantable cardioverter defibrillator. Heart and Lung 2004;33(3):183-90.

Dunbar 2009 \{published data only\}

Dunbar SB, Langberg JL, Reilly CM, Viswanathan B, McCarty F, Culler SD, et al. Effect of a psychoeducational intervention on 
depression, anxiety, and health resource use in implantable cardioverter defibrillator patients. PACE 2009;32:1259-71.

\section{Edelman 2006 \{published data only\}}

Edelman S, Lemon J, Kirkness A. Educational intervention for patients with automatic implantable cardioverter defibrillators. Australian Journal of Advanced Nursing 2007;24(3):26-32.

\section{Fichet 2003 \{published data only\}}

Fitchet A, Doherty PJ, Bundy C, Bell W, Fitzpatrick AP, Garratt CJ. Comprehensive cardiac rehabilitation programme for implantable cardioverter-defibrillator patients:a randomised controlled trial. Heart 2003;89:155-60.

\section{Klempfner 2015 \{published data only\}}

Klempfner R, Kamerman T, Schwammenthal E, Nahshon A, Hay I, Goldenberg I, et al. Efficacy of exercise training in symptomatic patients with hypertrophic cardiomyopathy: Results of a structured exercise training program in a cardiac rehabilitation center. European Journal of Preventive Cardiology 2015;22:13-9.

\section{Lewin 2007 \{published data only\}}

Lewin RJ, Coulton S, Frizelle DJ, Kaye G, Cox H. A brief cognitive behavioural preimplantation and rehabilitation programme for patients receiving an implantable cardioverter-defibrillator improves physical health and reduces psychological morbidity and unplanned readmissions. Heart 2009;95:63-9.

\section{Michitaka 2017 \{published data only\}}

Kato M, Masuda T, Ogano M, Hotta K, Takagi H, Tanaka S, et al. Stretching exercises improve vascular endothelial dysfunction through attenuation of oxidative stress in chronic heart failure patients with an implantable cardioverter defibrillator. Journal of Cardiopulmonary Rehabilitation and Prevention 2017;37:130-8. [DOI: 10.1097/HCR.0000000000000229]

Rakhshan 2017 \{published data only\}

Rakhshan M, Ansari L, Molazem Z, Zare N. Complications of heart rhythm management devices after cardiac rehabilitation program. Clinical Nurse Specialist 2017;31(3):E1-6. [DOI: 10.1097/NUR.0000000000000293]

Russell 2015 \{published data only\}

Russell DC, Smith TL, Krahn DD, Graskamp P, Singh D, Kolden GG, et al. Effects of cognitive behavioral stress management on negative mood and cardiac autonomic activity in ICD recipients. PACE 2015;38:951-65.

Toise 2014 \{published data only\}

Toise SC, Sears SF, Schoenfeld MH, Blitzer ML, Marieb MA, Drury $\mathrm{JH}$, et al. Psychosocial and cardiac outcomes of yoga for ICD patients: a randomized clinical control trial. PACE 2014;37:48-62.

\section{Vanhees 2004 \{published data only\}}

Vanhees L, Kornaat M, Defoor J, Aufdemkampe G, Schepers D, Stevens A, et al. Effect of exercise training in patients with an implantable cardioverter defibrillator. European Heart Journal 2004;25:1120-6.

\section{References to studies awaiting assessment}

Chrysohoou 2015 \{published data only\}

Chrysohoou C, Angelis A, Tsitsinakis G, Spetsioti S, Nasis I, Tsiachris $D$, et al. Cardiovascular effects of high-intensity interval aerobic training combined with strength exercise in patients with chronic heart failure: a randomised phase III clinical trial. International Journal of Cardiology 2015;179:26974.

\section{Weretka 2010 \{published data only\}}

Weretka S, Paape H, Thieliant J, Stellos K, Braun M, Weig HJ, et al. Beneficial effects of exercise training in patients with implantable cardioverter-defibrillators (BETA): a prospective randomised study. Conference Abstract. 2010.

\section{References to ongoing studies}

NCT03544489 \{unpublished data only\}

NCT03544489. Implementing exercise after an (ICD) (E-ICD). clinicaltrials.gov/ct2/show/NCT03544489 (first posted 1 June 2018).

\section{Additional references}

\section{Adamopoulos 1993}

Adamopoulos S, Coats AJ, Brunotte F, Arnolda L, Meyer T, Thompson $\mathrm{CH}$, et al. Physical training improves skeletal muscle metabolism in patients with chronic heart failure. Journal of the American College of Cardiology 1993;21(5):1101-6.

\section{Anderson 2014}

Anderson LJ, Taylor RS. Cardiac rehabilitation for people with heart disease: an overview of Cochrane systematic reviews. International Journal of Cardiology 2014;177(2):348-61.

\section{Anderson 2016}

Anderson L, Thompson DR, Oldridge N, Zwisler AD, Rees K, Martin N, et al. Exercise-based cardiac rehabilitation for coronary heart disease. Cochrane Database of Systematic Reviews 2016, Issue 1. [DOI: 10.1002/14651858.CD001800.pub3]

\section{Belardinelli 1995}

Belardinelli R, Georgiou D, Scocco V, Barstow TJ, Purcaro A. Low intensity exercise training in patients with chronic heart failure. Journal of the American College of Cardiology 1995;26(4):97582.

\section{Boutron 2008}

Boutron I, Moher D, Altman DG, Schultz KF, Ravaud P. Extending the CONSORT statement to randomised trials of nonpharmacologic treatment: explanation and elaboration. Annals of Internal Medicine 2008;148(4):295-309.

\section{Brooks 1996}

Brooks R. EuroQual: the current state of play. Health Policy 1996;37:53-72. 


\section{Coats 1992}

Coats AJ, Adamopoulos S, Radaelli A, McCance A, Meyer TE, Bernardi L, et al. Controlled trial of physical training in chronic heart failure. Exercise performance, haemodynamics, ventilation, and autonomic function. Circulation 1992;85(6):2119-31.

\section{Corrá 2006}

Corrà U, Mezzani A, Bosimini E, Giannuzzi P. Prognostic value of time-related changes of cardiopulmonary exercise testing indices in stable chronic heart failure: a pragmatic and operative scheme. European Journal of Cardiovascular Prevention and Rehabilitation 2006;13(2):186-92. [DOI: 10.1097/01.hjr.0000189807.22224.54]

\section{Davids 2005}

Davids JS, McPherson CA, Earley C, Batsford WP, Lampert R. Benefits of cardiac rehabilitation in patients with implantable cardioverter defibrillators: a patient survey. Archives of Physical Medicine and Rehabilitation 2005;86(10):1924-8.

\section{Deeks 2011}

Deeks JJ, Higgins JP, Altman DG, editor(s). Chapter 9: Analysing data and undertaking meta-analyses. In: Higgins JP, Green S, editor(s). Cochrane Handbook for Systematic Reviews of Interventions Version 5.1.0 (updated March 2011). The Cochrane Collaboration, 2011. Available from handbook.cochrane.org. Chichester: John Wiley \& Sons.

\section{Demets 1987}

Demets DL. Methods for combining randomised clinical trials: strengths and limitations. Statistics in Medicine 1987;6(3):34150.

\section{DerSimonian 1986}

DerSimonian R, Laird N. Meta-analysis in clinical trials. Controlled Clinical Trials 1987;7(3):177-88.

\section{Dougherty 2005}

Dougherty CM, Thompsen EA, Lewis FM. Long-term outcomes of a telephone intervention after an ICD. Pacing and Clinical Electrophysiology 2005;28(11):1157-67.

\section{Dougherty 2008}

Dougherty CM, Glenny R, Kudenchuk PJ. Aerobic exercise improves fitness and heart rate variability after an implantable cardioverter defibrillator. Journal of Cardiopulmonary Rehabilitation and Prevention 2008;28(5):307-11.

\section{Dunbar 2012}

Dunbar SB, Dougherty CM, Sears SF, Carroll DL, Goldstein NE, Mark DB, et al. Educational and psychological interventions to improve outcomes for recipients of implantable cardioverter defibrillators and their families. A scientific statement from the American Heart Association. Circulation 2012;126(17):2146-72.

\section{Egger 1997}

Egger M, Smith GD, Schneider M, Minder C. Bias in meta-analysis detected by a simple, graphical test. BMJ 1997;315:629-34.

\section{Fan 2009}

Fan S, Lyon CE, Savage PD, Ozonoff A, Ades PA, Balady GJ. Outcomes and adverse events among patients with implantable cardiac defibrillators in cardiac rehabilitation: a case-controlled study. Journal of Cardiopulmonary Rehabilitation and Prevention 2009;29(1):40-3.

\section{Farivar 2004}

Farivar SS, Liu H, Hays RD. Half standard deviation estimate of the minimally important difference in HRQOL scores?. Expert Review of Pharmacoeconomics \& Outcomes Research 2004;4(5):515-23.

\section{Fitchet 2003}

Fitchet A, Doherty PJ, Bundy C, Bell W, Fitzpatrick AP, Garratt CJ. Comprehensive cardiac rehabilitation programme for implantable cardioverter-defibrillator patients: a randomised controlled trial. Heart 2003;89(2):155-60.

\section{Gersh 2011}

Gersh BJ, Maron BJ, Bonow RO, Dearani JA, Fifer MA, Link MS, et al. 2011 ACCF/AHA guideline for the diagnosis and treatment of hypertrophic cardiomyopathy: a report of the American College of Cardiology Foundation/American Heart Association Task Force on Practice Guidelines. Circulation 2011;124(24):e783831.

\section{Guyatt 2008}

Guyatt GH, Oxman AD, Vist GE, Kunz R, Falck-Ytter Y, AlonsoCoello $P$, et al. GRADE: an emerging consensus on rating quality of evidence and strength of recommendations. $B M J$ 2008;336:924-6.

\section{Higgins 2011a}

Higgins JP, Green S, editor(s). Cochrane Handbook for Systematic Reviews of Interventions Version 5.1.0 (updated March 2011). The Cochrane Collaboration, 2011. Available from handbook.cochrane.org.

\section{Higgins 2011b}

Higgins JP, Altman DG, Sterne JA. Chapter 8: Assessing risk of bias in included studies. In: Higgins JP, Green S, editor(s). Cochrane Handbook for Systematic Reviews of Interventions Version 5.1.0 (updated March 2011). The Cochrane Collaboration, 2011. Available from handbook.cochrane.org.

\section{ICH-GCP 2015}

US Department of Health and Human Services. International Conference on Harmonisation. Guideline for technical requirements for registration of pharmaceuticals for human use. Guideline for Good Clinical Practice E6(R2) 2015.

\section{Irvine 2011}

Irvine J, Firestone J, Ong L, Cribbie R, Dorian P, Harris L, et al. A randomised controlled trial of cognitive behavior therapy tailored to psychological adaptation to an implantable cardioverter defibrillator. Psychosomatic Medicine 2011;73(3):226-33. 


\section{Isaksen 2012}

Isaksen K, Morken IM, Munk PS, Larsen AI. Exercise training and cardiac rehabilitation in patients with implantable cardioverter defibrillators: a review of current literature focusing on safety, effects of exercise training, and the psychological impact of programme participation. European Journal of Preventive Cardiology 2012;19(4):804-12.

\section{Jessup 2009}

Jessup M, Abraham WT, Casey DE, Feldman AM, Francis GS, Ganiats TG, et al. 2009 focused update: ACCF/AHA guidelines for the diagnosis and management of heart failure in adults: a report of the American College of Cardiology Foundation/ American Heart Association Task Force on Practice Guidelines: developed in collaboration with the International Society for Heart and Lung Transplantation. Circulation 2009;119(14):19772016.

\section{Kirkfeldt 2014}

Kirkfeldt RE, Johansen JB, Nohr EA, Jørgensen OD, Nielsen JC. Complications after cardiac implantable electronic device implantations: an analysis of a complete, nationwide cohort in Denmark. European Heart Journal 2014;35(18):1186-94.

\section{Kuck 2014}

Kuck KH, Hindricks G, Padeletti L, Raatikainen P, Anar DO. The EHRA White Book 2014. The current status of cardiac electrophysiology in ESC member countries. www.escardio.org/ static_file/Escardio/Subspecialty/EHRA/publications/ehrawhite-book-2014.pdf (accessed 24 July 2015).

\section{Lampert 2017}

Lampert R, Olshansky B, Heidbuchel H, Lawless C, Saarel E, Ackerman M, et al. Safety of sports for athletes with implantable cardioverter-defibrillators - long-term results of a prospective multinational registry. Circulation 2017;135:23.

\section{Lefebvre 2011}

Lefebvre C, Manheimer E, Glanville J. Chapter 6: Searching for studies. In: Higgins JP, Green S, editor(s). Cochrane Handbook for Systematic Reviews of Interventions Version 5.1.0 (updated March 2011). The Cochrane Collaboration, 2011. Available from handbook.cochrane.org.

\section{Lemon 2004}

Lemon J, Edelman S, Kirkness A. Avoidance behaviours in patients with implantable cardioverter defibrillators. Heart Lung 2004;33(3):176-82.

\section{Lewin 2009}

Lewin RJ, Coulton S, Frizelle DJ, Kaye G, Cox H. A brief cognitive behavioural preimplantation and rehabilitation programme for patients receiving an implantable cardioverter-defibrillator improves physical health and reduces psychological morbidity and unplanned readmissions. Heart 2009;95(1):63-9.

\section{Lichtman 2008}

Lichtman JH, Bigger JT Jr, Blumenthal JA, Frasure-Smith N, Kaufman PG, Lespérance $F$, et al. Depression and coronary heart disease: recommendations for screening, referral, and treatment: a science advisory from the American
Heart Association Prevention Committee of the Council on Cardiovascular Nursing, Council on Clinical Cardiology, Council on Epidemiology and Prevention, and Interdisciplinary Council on Quality of Care and Outcomes Research: endorsed by the American Psychiatric Association. Circulation 2008;118(17):1768-75.

\section{Magyar-Russell 2011}

Magyar-Russell G, Thombs BD, Cai JX, Baveja T, Kuhl EA, Singh PP, et al. The prevalence of anxiety and depression in adults with implantable cardioverter defibrillators: a systematic review. Journal of Psychosomatic Research 2011;71(4):223-31.

\section{Mark 2008}

Mark DB, Anstrom KJ, Sun JL, Clapp-Channing NE, Tsiatis AA, Davidson-Ray L, et al. Quality of life with defibrillator therapy or amiodarone in heart failure. New England Journal of Medicine 2008;359(10):999-1008.

\section{Mozaffarian 2015}

Mozaffarian D, Benjamin EJ, Go AS, Arnett DK, Blaha MJ, Cushman M, et al. Heart disease and stroke statistics-2015 update: a report from the American Heart Association. Circulation 2015;131(4):e29-e322.

\section{Niemeijer 2015}

Niemeijer M, Berg M, Leening M, Hofman A, Franco O, Deckers J, et al. Declining incidence of sudden cardiac death from 19902010 in a general middle-aged and elderly population: the Rotterdam Study. Heart Rhythm 2015;12(1):123-9.

\section{O'Connor 2009}

O'Connor CM, Whellan DJ, Lee KL, Keteyian SJ, Cooper LS, Ellis SJ, et al. Efficacy and safety of exercise training in patients with chronic heart failure: HF-ACTION randomised controlled trial. JAMA 2009;301(14):1439-50.

\section{Pandey 2017}

Pandey A, Parashar A, Moore C, Ngo C, Salahuddin U, Bhargava $M$, et al. Safety and efficacy of exercise training in patients with an implantable cardioverter-defibrillator. JACC: Clinical Electrophysiology 2017;3(2):117-26.

\section{Pedersen 2007}

Pedersen SS, van den Broek KC, Sears SF Jr. Psychological intervention following implantation of an implantable defibrillator: a review and future recommendations. Pacing and Clinical Electrophysiology 2007;30(12):1546-54.

\section{Piepoli 2010}

Piepoli MF, Corrà U, Benzer W, Bjarnason-Wehrens B, Dendale $\mathrm{P}$, Gaita D, et al. Secondary prevention through cardiac rehabilitation: from knowledge to implementation. A position paper from the Cardiac Rehabilitation Section of the European Association of Cardiovascular Prevention and Rehabilitation. European Journal of Cardiovascular Prevention and Rehabilitation 2010;17(1):1-17.

\section{Piepoli 2012}

Piepoli MF, Corrà U, Adamopoulos S, Benzer W, BjarnasonWehrens B, Cupples M, et al. Secondary prevention in the 
clinical management of patients with cardiovascular diseases. Core components, standards and outcome measures for referral and delivery: a policy statement from the cardiac rehabilitation section of the European Association for Cardiovascular Prevention \& Rehabilitation. Endorsed by the Committee for Practice Guidelines of the European Society of Cardiology. European Journal of Preventive Cardiology 2014;21(6):664-81.

\section{Ponikowski 2016}

Ponikowski P, Voors AA, Anker SD, Bueno H, Cleland JG, Coats AJ, et al. 2016 ESC guidelines for the diagnosis and treatment of acute and chronic heart failure. European Heart Journal 2016;18(8):891-975.

\section{Rector 1992}

Rector TS, Cohn JN. Assessment of patient outcome with the Minnesota Living with Heart Failure questionnaire: reliability and validity during a randomized, doubleblind, placebo-controlled of Pimobendan. American Heart Journal 1992;124(4):1017-25.

\section{Review Manager 2014 [Computer program]}

Nordic Cochrane Centre, The Cochrane Collaboration. Review Manager 5 (RevMan 5). Version 5.3. Copenhagen: Nordic Cochrane Centre, The Cochrane Collaboration, 2014.

\section{Risom 2017}

Risom SS, Zwisler AD, Johansen PP, Sibilitz KL, Lindschou J, Taylor RS, et al. Exercise-based cardiac rehabilitation for adults with atrial fibrillation. Cochrane Database of Systematic Reviews 2017, Issue 2. [DOI: 10.1002/14651858.CD011197.pub2]

\section{Savović 2012}

Savović J, Jones H, Altman D, Harris R, Jüni P, Pildal J, et al. Influence of reported study design characteristics on intervention effect estimates from randomised controlled trials: combined analysis of meta epidemiological studies. Health Technology Assessment Journal 2012;16(35):1-82.

\section{Schron 2002}

Schron EB, Exner DV, Yao Q, Jenkins LS, Steinberg JS, Cook JR, et al. Quality of life in the antiarrhythmics versus implantable defibrillators trial: impact of therapy and influence of adverse symptoms and defibrillator shocks. Circulation 2002;105(5):589-94.

\section{Scott 2009}

Scott PA, Turner NG, Chungh A, Morgan JM, Roberts PR. Varying implantable cardioverter defibrillator referral patterns from implanting and non-implanting hospitals. Europace 2009;11(8):1048-51.

\section{Sibilitz 2016}

Sibilitz KL, Berg SK, Tang LH, Risom SS, Gluud C, Lindschou J, et al. Exercise-based cardiac rehabilitation for adults after heart valve surgery. Cochrane Database of Systematic Reviews 2016, Issue 3. [DOI: 10.1002/14651858.CD010876.pub2]

\section{Sullivan 1988}

Sullivan MJ, Higginbotham MB, Cobb FR. Exercise training in patients with severe left ventricular dysfunction. Hemodynamic and metabolic effects. Circulation 1988;78(3):506-15.

\section{Taylor 2014}

Taylor RS, Sagar VA, Davies EJ, Briscoe S, Coats AJ, Dalal H, et al. Exercise-based rehabilitation for heart failure. Cochrane Database of Systematic Reviews 2014, Issue 4. [DOI: 10.1002/14651858.CD003331.pub4]

\section{Thomas 2001}

Thomas SA, Friedmann E, Kelley FJ. Living with an implantable cardioverter-defibrillator: a review of the current literature related to psychosocial factors. AACN Clinical Issues 2001;12(1):156-63.

\section{Thorlund 2009}

Thorlund K, Devereux PJ, Wetterslev J, Guyatt G, Ioannidis JP, Thabane $L$, et al. Can trial sequential monitoring boundaries reduce spurious inferences from meta-analyses?. International Journal of Epidemiology 2009;38(1):276-86.

\section{Thorlund 2011}

Thorlund K, Engstrøm J, Wetterslev J, Brok J, Imberger G, Gluud C. User manual for Trial Sequential Analysis (TSA). www.ctu.dk/tsa/files/tsa_manual.pdf (accessed 24 July 2015).

\section{Tracy 2012}

Tracy CM, Epstein AE, Darbar D, DiMarco JP, Dunbar SB, Estes NA 3rd, et al. 2012 ACCF/AHA/HRS focused update of the 2008 guidelines for device-based therapy of cardiac rhythm abnormalities: a report of the American College of Cardiology Foundation/American Heart Association Task Force on Practice Guidelines. Journal of the American College of Cardiology 2012;60(14):1297-313.

\section{TSA 2011 [Computer program]}

Copenhagen Trial Unit, Centre for Clinical Intervention Research. Trial Sequential Analysis (TSA). Copenhagen: Copenhagen Trial Unit, Centre for Clinical Intervention Research, 2011.

\section{Ware 1992}

Ware JE Jr, Sherbourne CD. The MOS 36-item short-form health survey (SF-36). I. Conceptual framework and item selection. Medical Care 1992;30:473-83.

\section{Wetterslev 2008}

Wetterslev J, Thorlund K, Brok J, Gluud C. Trial sequential analysis may establish when firm evidence is reached in cumulative meta-analysis. Journal of Clinical Epidemiology 2008;61(1):64-75.

\section{Wetterslev 2009}

Wetterslev J, Thorlund K, Brok J, Gluud C. Estimating required information size by quantifying diversity in random-effects model meta-analysis. BMC Medical Research Methodology 2009;9:86. 


\section{Wilson 1996}

Wilson JR, Groves J, Rayos G. Circulatory status and response to cardiac rehabilitation in patients with heart failure. Circulation 1996;94(7):1567-72.

\section{Wood 2008}

Wood L, Egger M, Gluud LL, Schulz KF, Jüni P, Altman DG, et al. Empirical evidence of bias in treatment effect estimates in controlled trials with different interventions and outcomes: meta-epidemiological study. BMJ 2008;336(7644):601-5.

\section{Yancy 2013}

Yancy CW, Jessup M, Bozkurt B, Butler J, Casey DE Jr, Drazner MH, et al. 2013 ACCF/AHA guideline for the

\section{CHARACTERISTICS OF STUDIES}

Characteristics of included studies [ordered by study ID] management of heart failure: a report of the American College of Cardiology Foundation/American Heart Association Task Force on Practice Guidelines. Circulation 2013;128(16):240-327.

\section{References to other published versions of this review Nielsen 2015}

Nielsen KM, Zwisler A-D, Taylor RS, Svendsen JH, Lindschou J, Anderson L, et al. Exercise-based cardiac rehabilitation for adult patients with an implantable cardioverter defibrillator. Cochrane Database of Systematic Reviews 2015, Issue 8. [DOI: 10.1002/14651858.CD011828]

* Indicates the major publication for the study

Belardinelli 2006

\begin{tabular}{|c|c|}
\hline Methods & Parallel group RCT with cross-over \\
\hline Participants & $\begin{array}{l}\text { N Randomised: } 52 \text { (avoided training group 22; exercise group 30). No information about patients lost } \\
\text { to follow-up } \\
\text { Profile: heart failure patients with ICD (primary indication 63.5\%). CRT-D: exercise group 12; usual care } \\
\text { group 10) } \\
\text { Age: } 55+/-10 \text { years } \\
\text { Male: } 100 \% \\
\text { White: NS } \\
\text { Inclusion criteria } \\
\text { - Stable CHF patients in NYHA functional class II and III } \\
\text { - Without hospital admission or change in medications in the last } 3 \text { months } \\
\text { - No evidence of ICD discharge } \\
\text { Exclusion criteria } \\
\text { - Decompensated CHF } \\
\text { - Uncontrolled hypertension or diabetes mellitus } \\
\text { - Severe respiratory disease } \\
\text { - Significant anaemia (or haemoglobin of less than } 10 \mathrm{~g} / \mathrm{dL} \text { ) } \\
\text { - Renal insufficiency (creatinine greater than } 2 \mathrm{mg} / \mathrm{dL} \text { ) } \\
\text { - Inability to exercise }\end{array}$ \\
\hline
\end{tabular}

Interventions

\section{Exercise}

- Total duration: 8 weeks

- Aerobic/resistance/mix: the intervention included a mix of stretching exercises and aerobic training

- Frequency: 3 days per week (for 8 weeks)

- Duration: 1 hour class (8 weeks)

- Intensity:aerobic training was done at $60 \%$ of peak $\mathrm{VO}_{2}$

- Modality: group training at the hospital consisted of the following: 15 minutes stretching, 40 minutes cycling, and 5 minutes recovery 
Belardinelli 2006 (Continued)

- Setting: hospital gym

- Other: ns

\section{Control}

- Control group were asked to be sedentary

\begin{tabular}{ll}
\hline Outcomes & Peak VO 2 \\
& - QoL (Minnesota Quality of Life) \\
& - Mortality \\
& - Readmission \\
& $\cdot$ Shock \\
& $\cdot$ LVEF \\
& NYHA \\
\hline Country and setting & Italy, single-centre trial, with a hospital setting \\
\hline Follow-up & -8 weeks (exercise capacity, LVEF, NYHA, QoL) \\
\hline Notes & 18 months (mortality, shock, readmission) \\
\hline
\end{tabular}

\section{Risk of bias}

\begin{tabular}{|c|c|c|}
\hline Bias & Authors' judgement & Support for judgement \\
\hline $\begin{array}{l}\text { Random sequence genera- } \\
\text { tion (selection bias) }\end{array}$ & Unclear risk & $\begin{array}{l}\text { Randomisation was performed using a table of random numbers, however } \\
\text { there were } 30 \text { patients in the intervention group and only } 22 \text { patients in the } \\
\text { control group }\end{array}$ \\
\hline $\begin{array}{l}\text { Allocation concealment } \\
\text { (selection bias) }\end{array}$ & Unclear risk & No information. Waiting response from author \\
\hline $\begin{array}{l}\text { Blinding of participants } \\
\text { and personnel (perfor- } \\
\text { mance bias) } \\
\text { All outcomes }\end{array}$ & High risk & No blinding because of the nature of exercise-based cardiac rehabilitation \\
\hline $\begin{array}{l}\text { Blinding of outcome as- } \\
\text { sessment (detection bias) } \\
\text { All outcomes }\end{array}$ & Unclear risk & No information. Waiting response from author \\
\hline $\begin{array}{l}\text { Incomplete outcome data } \\
\text { (attrition bias) } \\
\text { All outcomes }\end{array}$ & Unclear risk & There was no information about dropouts or withdrawals \\
\hline $\begin{array}{l}\text { Selective reporting (re- } \\
\text { porting bias) }\end{array}$ & High risk & Design paper not published. No hierarchy of outcomes \\
\hline Performance bias & Unclear risk & No information about co-intervention. Waiting response from author \\
\hline $\begin{array}{l}\text { Groups balanced at base- } \\
\text { line bias }\end{array}$ & Unclear risk & $\begin{array}{l}\text { Patients well matched at baseline, however there were } 30 \text { patients in the inter- } \\
\text { vention group and only } 22 \text { patients in the control group }\end{array}$ \\
\hline Intention-to-treat analysis & Low risk & Analyses were conducted according to an intention-to-treat analysis \\
\hline
\end{tabular}


Belardinelli 2006 (Continued)
For-profit bias
Unclear risk
No report on their source of funding

Berg 2014

\begin{tabular}{ll}
\hline Methods & Parallel group RCT \\
\hline Participants & N Randomised: 196 (usual care group 97; exercise group 99). 52 patients were lost to follow-up (usual \\
& care group 26; exercise group 26) \\
& $\begin{array}{l}\text { Profile: patients with ICD (primary indication 66\%, secondary indication 34\%). Heart failure: usual care } \\
\text { group 73 (75.3\%); exercise group } 76 \text { (76.8\%) }\end{array}$
\end{tabular}

Age: 57.2; SD: 13 years

Male: $79.1 \%$

White: NS

\section{Inclusion criteria}

- First time ICD implant

- Agreed to participate in the entire programme

- Randomised prior to hospital discharge

\section{Exclusion criteria}

- Less than 18 years of age

- Diagnosed with a psychiatric disease or a somatic disease where the disease per se or its recovery might have influenced the outcome

- Assessed to not understand the study instructions

- No permission by their treating physician to participate in the exercise programme

- Patients already enrolled in clinical trials that prohibited additional participation in trials

\section{Interventions $\quad$ Exercise:}

- Total duration: 12 weeks

- Aerobic/resistance/mix: the intervention included a mix of resistance training and aerobic training

- Frequency: 2 days per week (for 12 weeks)

- Duration: 1 hour class (12 weeks)

- Intensity: resistance training was done at $60 \%$ to $80 \%$ of one-repetition maximum, and aerobic exercise at $50 \%$ to $80 \%$ of estimated maximum heart rate

- Modality: group training at the hospital consisted of the following: 10 minutes warm-up, 8 minutes biking, 8 minutes walking/jogging/running, 8 minutes individual aerobic endurance training e.g. step, stairway or running and resistance training of the major muscle groups. The session ended with a 10minute cool down and relaxation period. Home training was individually planned

- Setting: home or in hospital, as chosen by the patient

- Other: one year of psychoeducational follow-up focusing on modifiable factors associated with poor outcomes. Nine consultations with a cardiac nurse face-to-face (mean 60 minutes) or by phone (mean 30 minutes), as chosen by the patient

\section{Control:}

- Control group were not denied local rehabilitation

$\begin{array}{ll}\text { Outcomes } & \text { Peak } \mathrm{VO}_{2} \\ \text { - } & \text { General health measured by SF-36 } \\ \text { - } & \text { Mental health (SF-36) }\end{array}$


Berg 2014 (Continued)

- ICD therapies

- Hospitalisations

- Attributable direct costs

- Employment status

- Death

\begin{tabular}{ll}
\hline Country and setting & Denmark, single-centre trial, with a home or hospital setting \\
\hline Follow-up & - End of treatment $\left(\mathrm{VO}_{2}, \mathrm{SF}-36\right.$, death, serious adverse event and ICD therapies) \\
& - 45 months (death and ICD therapies) \\
\hline Notes &
\end{tabular}

\section{Risk of bias}

\begin{tabular}{|c|c|c|}
\hline Bias & Authors' judgement & Support for judgement \\
\hline $\begin{array}{l}\text { Random sequence genera- } \\
\text { tion (selection bias) }\end{array}$ & Low risk & Computer random-number generator with voice response \\
\hline $\begin{array}{l}\text { Allocation concealment } \\
\text { (selection bias) }\end{array}$ & Low risk & Independent randomisation unit \\
\hline $\begin{array}{l}\text { Blinding of participants } \\
\text { and personnel (perfor- } \\
\text { mance bias) } \\
\text { All outcomes }\end{array}$ & High risk & No blinding because of the nature of exercise-based cardiac rehabilitation \\
\hline $\begin{array}{l}\text { Blinding of outcome as- } \\
\text { sessment (detection bias) } \\
\text { All outcomes }\end{array}$ & Low risk & Blinded outcome assessment \\
\hline $\begin{array}{l}\text { Incomplete outcome data } \\
\text { (attrition bias) } \\
\text { All outcomes }\end{array}$ & Low risk & $\begin{array}{l}\text { Number and reason for dropout was described and sensitivity analyses per- } \\
\text { formed for primary outcomes }\end{array}$ \\
\hline $\begin{array}{l}\text { Selective reporting (re- } \\
\text { porting bias) }\end{array}$ & Low risk & $\begin{array}{l}\text { Design paper published (Berg 2014). Outcome described in methods are re- } \\
\text { ported in results }\end{array}$ \\
\hline Performance bias & Unclear risk & $\begin{array}{l}\text { Patients in the usual care group were not denied local rehabilitation, but there } \\
\text { were no data on wether they received local rehabilitation }\end{array}$ \\
\hline $\begin{array}{l}\text { Groups balanced at base- } \\
\text { line bias }\end{array}$ & Low risk & Patients well matched at baseline \\
\hline Intention-to-treat analysis & Low risk & $\begin{array}{l}\text { Analyses were conducted according to an intention-to-treat analysis as well as } \\
\text { sensitivity analyses. }\end{array}$ \\
\hline For-profit bias & Low risk & Reported on their source of funding with conflicts of interest \\
\hline
\end{tabular}

Methods $\quad$ Parallel group RCT


Dougherty 2015 (Continued)

Participants
N Randomised: 160 (usual care group 76; exercise group 84). 18 patients were lost to follow-up (usual care group 10; exercise group 8)

Profile: patients with ICD (primary indication 43\%, secondary indication 57\%). Heart failure: usual care group $78.9 \%$; exercise group $84.4 \%$

Age: $55+/-22$ years

Male: $77.5 \%$

White: $84.4 \%$

\section{Inclusion criteria:}

- ICD implantation for either primary or secondary prevention of sudden cardiac arrest

- English proficient and provided informed consent

- Taking $\beta$-blocker medication

- Willing to complete the exercise program and all follow-ups

\section{Exclusion criteria:}

- Clinical co morbidities that impaired cognitive or physical functioning

- Short Blessed score $>6$ representing cognitive dysfunction

- Age $<21$ years

- Alcohol Use Disorders Identification Test score $\geq 4$ for alcohol use indicating excessive alcohol consumption

- Unstable angina, myocardial infarction, ICD shock, or heart surgery within the previous 3 months

- Concurrent participation in an exercise program $\geq 60 \mathrm{~min} / 5$ days per week

- Cardiac rhythm other than normal sinus rhythm, pacemaker dependence, or a cardiac resynchronisation therapy device

- Sustained ventricular arrhythmias at baseline cardiopulmonary exercise testing

Interventions

\section{Exercise:}

- Total duration: 24 week

- Aerobic/resistance/mix: the intervention included 2 phases, phase one: an 8-week aerobic training component; phase two: a 16-week aerobic maintenance component

- Frequency: 5 days pr week (for 8 week); 150 minutes pr week (for 16 week)

- Duration: 1 hour class (8 week); 150 minutes pr week (16 week)

- Intensity: week 1 to $2,60 \%$ to $65 \%$ of heart rate reserve; Week 3 to $4,70 \%$ to $75 \%$ of heart rate reserve; and week 5 to $8,80 \%$ to $85 \%$ of heart rate reserve. The target heart rate during home exercise was tailored to fall below the ICD rate threshold for tachycardia detection by at least 20 beats pr minute; week 9-24 home walking at $80 \%$ of heart rate reserve

- Modality: walking

- Setting: home

- Other: weekly telephone contacts

\section{Control:}

- Control group were requested not to start a new exercise program or change their exercise patterns for the duration of the study

$\begin{array}{ll}\text { Outcomes } & \text { Peak } \mathrm{CO}_{2} \\ & \text { - ICD therapies } \\ & \text { - Hospitalisation } \\ \text { - Musculoskeletal symptoms } & \text { Death }\end{array}$


Dougherty 2015 (Continued)

Country and setting USA, single centre trial (10 outpatient settings), with a home setting intervention.

\begin{tabular}{ll}
\hline Follow-up $\quad$ End of intervention \\
\hline Notes
\end{tabular}

\section{Risk of bias}

\begin{tabular}{|c|c|c|}
\hline Bias & Authors' judgement & Support for judgement \\
\hline $\begin{array}{l}\text { Random sequence genera- } \\
\text { tion (selection bias) }\end{array}$ & Low risk & Computer random-number generator \\
\hline $\begin{array}{l}\text { Allocation concealment } \\
\text { (selection bias) }\end{array}$ & Low risk & Data manager informed the study nurse of intervention group allocation \\
\hline $\begin{array}{l}\text { Blinding of participants } \\
\text { and personnel (perfor- } \\
\text { mance bias) } \\
\text { All outcomes }\end{array}$ & High risk & No blinding because of the nature of exercise-based cardiac rehabilitation \\
\hline $\begin{array}{l}\text { Blinding of outcome as- } \\
\text { sessment (detection bias) } \\
\text { All outcomes }\end{array}$ & Unclear risk & The statistician was not blinded to the group assignment. \\
\hline $\begin{array}{l}\text { Incomplete outcome data } \\
\text { (attrition bias) } \\
\text { All outcomes }\end{array}$ & Low risk & $\begin{array}{l}\text { Number and reason for dropout was described. Consort diagram presented. } \\
\text { Regression imputations for all of the missing data were simulated for both } \\
\text { groups, with no statistically significant changes in outcomes discovered at any } \\
\text { time point. }\end{array}$ \\
\hline $\begin{array}{l}\text { Selective reporting (re- } \\
\text { porting bias) }\end{array}$ & Low risk & $\begin{array}{l}\text { Design paper published (Dougherty 2015). Outcome described in methods are } \\
\text { reported in results }\end{array}$ \\
\hline Performance bias & Low risk & No co-interventions are delivered \\
\hline $\begin{array}{l}\text { Groups balanced at base- } \\
\text { line bias }\end{array}$ & Low risk & No baseline difference between groups \\
\hline Intention-to-treat analysis & Low risk & Analyses were conducted according to an intention-to-treat analysis \\
\hline For-profit bias & Low risk & Reported on their source of funding with conflicts of interest \\
\hline
\end{tabular}

Frizelle 2004

\begin{tabular}{ll}
\hline Methods & Parallel group RCT (pilot trial) \\
\hline Participants & N Randomised: 22 (control group (waiting list) 10; exercise group 12). None lost to follow-up \\
Profile: Patients with ICD \\
Age: Exercise group 60.4 yeas SD 10.13 versus control group 62.8 years SD 4.66 \\
Male: NS \\
White: NS \\
Inclusion criteria:
\end{tabular}

Exercise-based cardiac rehabilitation for adult patients with an implantable cardioverter defibrillator (Review) 
Frizelle 2004 (Continued)

- Patients that had undergone implantation of an ICD for treatment of uncontrolled ventricular arrhythmia due to chronic heat disease (included patients who had undergone coronary artery bypass graft surgery or other cardiac surgery prior to ICD implantation)

\section{Exclusion criteria:}

- Patients who were awaiting CABG and/or heart transplantation surgery or who had recently experienced acute MI

- Patients with idiopathic aetiology of ventricular arrhythmia;

- Patients with other complicating medical conditions that would make co-operation difficult or impossible

- Patients unable to understand English

\section{Exercise:}

- Total duration: 12 weeks

- Aerobic/resistance/mix: a simple, low impact, self-paced, largely home-based exercise programme

- Frequency: 7 days per week (for 12 week)

- Duration: 10 minutes

- Intensity: patients set their own baseline for how many of each set of exercises they could complete within the allocated time

- Modality: ns

- Setting: 6 sessions at the out-patient clinic, rest done at home.

- Other: psycho-education based on cognitive-behavioural therapy ( 6 group sessions face to face, 1 telephone follow up)

\section{Control:}

- Control group received routine care including any scheduled visits to ICD patient clinics or their own doctor

\begin{tabular}{ll}
\hline Outcomes & - Anxiety \\
& - Quality of life \\
& - Perceived health state \\
\hline Country and setting & England, single-centre trial, with 6 sessions at an outpatient clinic setting; rest done in home setting \\
\hline Follow-up & End of intervention, no long term follow-up because of cross-over \\
\hline Notes &
\end{tabular}

\section{Risk of bias}

\begin{tabular}{lll}
\hline Bias & Authors' judgement & Support for judgement \\
\hline $\begin{array}{l}\text { Random sequence genera- } \\
\text { tion (selection bias) }\end{array}$ & Unclear risk & No information. Waiting response from author \\
\hline $\begin{array}{l}\text { Allocation concealment } \\
\text { (selection bias) }\end{array}$ & Unclear risk & No information. Waiting response from author \\
\hline $\begin{array}{l}\text { Blinding of participants } \\
\text { and personnel (perfor- } \\
\text { mance bias) } \\
\text { All outcomes }\end{array}$ & High risk & No blinding because of the nature of exercise-based cardiac rehabilitation \\
\hline
\end{tabular}


Frizelle 2004 (Continued)

Blinding of outcome as- Unclear risk No information. Waiting response from author sessment (detection bias)

All outcomes

\begin{tabular}{lll}
\hline $\begin{array}{l}\text { Incomplete outcome data } \\
\text { (attrition bias) } \\
\text { All outcomes }\end{array}$ & Low risk & Number and reason for dropout was described \\
\hline $\begin{array}{l}\text { Selective reporting (re- } \\
\text { porting bias) }\end{array}$ & Unclear risk & Outcome described in methods are reported in results \\
\hline Performance bias & Unclear risk & No information about co-intervention. Waiting response from author \\
\hline $\begin{array}{l}\text { Groups balanced at base- } \\
\text { line bias }\end{array}$ & Low risk & No baseline difference between groups \\
\hline Intention-to-treat analysis & Low risk & Analyses were conducted according to an intention-to-treat analysis \\
\hline For-profit bias & Unclear risk & No report on their source of funding \\
\hline
\end{tabular}

Piccini 2013

\begin{tabular}{ll}
\hline Methods & Parallel group RCT (secondary analysis of a subgroup of the HF-ACTION trial) \\
\hline Participants & N Randomised: 1053 (usual care group 507; exercise group 546). No information about patients lost to \\
follow-up & Profile: patients with heat failure and ICD (CRT-D: exercise group 41\% (224); usual care group 42\% \\
$(211)$ ) & Age: median 61 years \\
Male: $77 \%$ \\
White: $69 \%$ \\
Inclusion criteria: \\
- Patients with HF (NYHA functional class II - IV) \\
- LVEF $\leq 35 \%$ \\
Exclusion criteria: \\
- Unable to exercise \\
- Already engaged in a routine exercise programme (> 1 session/week) \\
- Major cardiovascular event in the prior six weeks \\
ICD tachycardia detection limit was set below the target heart rate for exercise training
\end{tabular}

Interventions

\section{Exercise:}

- Total duration: 4 years

- Aerobic/resistance/mix: the intervention included 2 phases, phase one: an 12-week aerobic training component; phase two: a continuous aerobic maintenance component up to 4 years

- Frequency: 3 days pr week (for 12 week); 5 days pr week (for up to 4 years)

- Duration: 15 to $35 \mathrm{~min} / \mathrm{session}$

- Intensity: $60-70 \%$ of target heart rate

- Modality: walking, treadmill or cycle ergometer 
Piccini 2013 (Continued)

- Setting: outpatient clinic and home

- Other: ns

\section{Control:}

- Control group had no restriction in activity

\begin{tabular}{ll}
\hline Outcomes & $\cdot \begin{array}{l}\text { ICD shocks } \\
\text { VO }\end{array}$ \\
\hline Country and setting & USA, multicentre trial, with an outpatient clinic and home setting \\
\hline Follow-up & $\cdot 12$ week (primary outcome) \\
\hline Notes & 4 years \\
\hline
\end{tabular}

\section{Risk of bias}

\begin{tabular}{|c|c|c|}
\hline Bias & Authors' judgement & Support for judgement \\
\hline $\begin{array}{l}\text { Random sequence genera- } \\
\text { tion (selection bias) }\end{array}$ & High risk & This is a subgroup analysis of a larger trial including HF patients \\
\hline $\begin{array}{l}\text { Allocation concealment } \\
\text { (selection bias) }\end{array}$ & Low risk & Patients are randomised using an interactive voice response \\
\hline $\begin{array}{l}\text { Blinding of participants } \\
\text { and personnel (perfor- } \\
\text { mance bias) } \\
\text { All outcomes }\end{array}$ & High risk & No blinding because of the nature of exercise-based cardiac rehabilitation \\
\hline $\begin{array}{l}\text { Blinding of outcome as- } \\
\text { sessment (detection bias) } \\
\text { All outcomes }\end{array}$ & Unclear risk & Insufficiently described \\
\hline $\begin{array}{l}\text { Incomplete outcome data } \\
\text { (attrition bias) } \\
\text { All outcomes }\end{array}$ & Unclear risk & Inclompleate information \\
\hline $\begin{array}{l}\text { Selective reporting (re- } \\
\text { porting bias) }\end{array}$ & Unclear risk & $\begin{array}{l}\text { Post hoc analyses of a larger RCT, the outcome described in methods are re- } \\
\text { ported in results }\end{array}$ \\
\hline Performance bias & Unclear risk & No restriction in activity in control group \\
\hline $\begin{array}{l}\text { Groups balanced at base- } \\
\text { line bias }\end{array}$ & Low risk & Patients well matched at baseline \\
\hline Intention-to-treat analysis & Low risk & Analyses were conducted according to an intention-to-treat analysis \\
\hline For-profit bias & Low risk & Reported on their source of funding with conflicts of interest \\
\hline
\end{tabular}

Piotrowicz 2015

\begin{tabular}{ll}
\hline Methods $\quad$ Parallel group RCT \\
\hline
\end{tabular}


Piotrowicz 2015 (Continued)

Participants
N Randomised: 111 (control group 34, exercise group 77). 4 patients were lost to follow-up (control group 2, exercise group 2)

Profile: patients with heart failure (67.3 with ICD).

Age: exercise group 54.4 yeas SD 10.9 versus control group 62.1 years SD 12.5

Male: $88.8 \%$

White: NS

\section{Inclusion criteria:}

- Any aetiology of left ventricular systolic HF (as defined in the European Society of Cardiology guidelines) diagnosed at least for three months

- LVEF $40 \%$ on echocardiography

- Classified as NYHA class II or III

- Clinically stable and receiving an optimal and stable medication regimen for at least four week before enrolment

- Had no contraindications to exercise training

- Were able to undergo home-based cardiac tele rehabilitation

\section{Exclusion criteria:}

- Unstable angina

- A history of an acute coronary syndrome within the last month

- Coronary artery bypass grafting within the last two months

- Initiation of CRT-P or cardiac CRT-D within the last six months

- Implantation of a pacemaker and/or ICD within the last six weeks

- Symptomatic and/or exercise-induced cardiac arrhythmia or conduction disturbance

- Valvular or congenital heart disease requiring surgical treatment

- Hypertrophic cardiomyopathy

- Severe pulmonary hypertension or other severe pulmonary disease

- Uncontrolled hypertension

- Anaemia (haemoglobin $10.0 \mathrm{~g} / \mathrm{dL}$ )

- Acute and/or decompensated noncardiac disease

- Physical disability related to severe musculoskeletal or neurological problems

- Acute or chronic inflammatory disease

- Severe psychiatric disorder

- Patient refusal to participate

\section{Exercise:}

- Total duration: 8 week

- Aerobic/resistance/mix: aerobic (Nordic walking)

- Frequency: 5 days pr week (for 8 week)

- Duration: 25-60 minutes depending on baseline $\mathrm{VO}_{2}$ (8 week)

- Intensity: ns

- Modality: home-based Nordic walking

- Setting: home

- Other: no

\section{Control:}

- Control group were not provided with a formal exercise training prescription and did not perform supervised rehabilitation 
Piotrowicz 2015 (Continued)

\begin{tabular}{|c|c|c|}
\hline Outcomes & \multicolumn{2}{|c|}{ 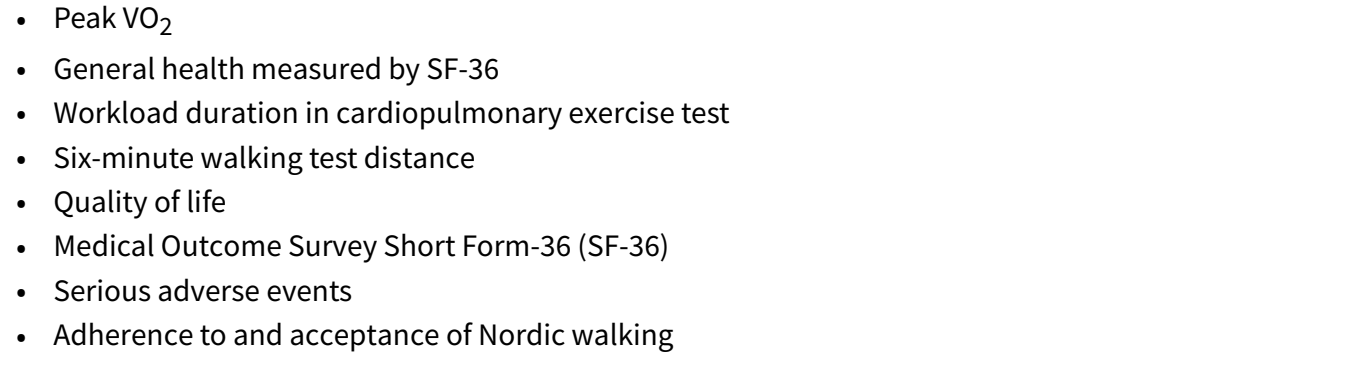 } \\
\hline Country and setting & \multicolumn{2}{|c|}{ Poland, Single-centre trial, with a home setting } \\
\hline Follow-up & \multicolumn{2}{|l|}{ - 8 weeks } \\
\hline \multicolumn{3}{|l|}{ Notes } \\
\hline \multicolumn{3}{|l|}{ Risk of bias } \\
\hline Bias & Authors' judgement & Support for judgement \\
\hline $\begin{array}{l}\text { Random sequence genera- } \\
\text { tion (selection bias) }\end{array}$ & Low risk & Random number table \\
\hline $\begin{array}{l}\text { Allocation concealment } \\
\text { (selection bias) }\end{array}$ & Unclear risk & No information on concealment \\
\hline $\begin{array}{l}\text { Blinding of participants } \\
\text { and personnel (perfor- } \\
\text { mance bias) } \\
\text { All outcomes }\end{array}$ & High risk & No blinding because of the nature of exercise-based cardiac rehabilitation \\
\hline $\begin{array}{l}\text { Blinding of outcome as- } \\
\text { sessment (detection bias) } \\
\text { All outcomes }\end{array}$ & Unclear risk & No information \\
\hline $\begin{array}{l}\text { Incomplete outcome data } \\
\text { (attrition bias) } \\
\text { All outcomes }\end{array}$ & Low risk & Number and reason for dropout was described \\
\hline $\begin{array}{l}\text { Selective reporting (re- } \\
\text { porting bias) }\end{array}$ & High risk & LVEF was not reported after intervention as described in the methods section. \\
\hline Performance bias & Low risk & No co-interventions are delivered \\
\hline $\begin{array}{l}\text { Groups balanced at base- } \\
\text { line bias }\end{array}$ & High risk & High risk of bias due to large age difference in the two groups. \\
\hline Intention-to-treat analysis & Low risk & Analyses were conducted according to an intention-to-treat analysis \\
\hline For-profit bias & Low risk & Reported on their source of funding with conflicts of interest \\
\hline
\end{tabular}

Methods Parallel group RCT


Smolis-Bak 2015 (Continued)

Participants
N Randomised: 52 (control group 26; exercise group 26). No information about patients lost to follow-up

Profile: advanced heart failure (NYHA III) with CRT-D

Age: $60+/-8.5$ years (exercise group); $65.1+/-8.2$ (control group)

Male: 25 (96.1\%) (exercise group); 22 (84.6\%) (control group)

White: NS

\section{Inclusion criteria:}

- CHF of Ischaemic origin or another etiology

- NYHA class III

- LVEF below 35\%

- Planned implantation of a CRT-D device

- Controlled hypertension, diabetes and other metabolic disorders

- Capacity to perform treadmill exercise test

- Absence of complex arrhythmia

\section{Exclusion criteria:}

- Acute or uncontrolled disorders other than CHF

- Severe mobility impairment

- Severe musculoskeletal conditions which preclude physical rehabilitation (orthopaedic, neurological)

- Planned cardiac surgery or percutaneous coronary interventions

- Cardiac surgery or coronary angioplasty within last 3 months

- Acute coronary syndrome

- Stroke or TIA within last six months

- Venous thrombosis or pulmonary embolism the past; significant valve and pulmonary diseases.

\section{Exercise:}

- Total duration: 11 week

- Aerobic/resistance/mix: the intervention included a mix of active exercises of small and subsequently larger muscle groups of the lower and upper limbs, respiratory exercises and range of motion exercises of the shoulder joint on the implantation side

- Frequency: 5 days per week

- Duration: ns

- Intensity: the mean differences between the resting heart rate and the peak heart rate for the homebased exercise training were $10.5 \pm 2.3 \%$ during the first training session and $8.7 \pm 1.7 \%$ during the last training session while the mean rating of perceived exertion on the 10-point Borg scale was 2.9 \pm 1.2 .

- Modality: group training at the hospital consisted of the following; 15 minutes stretching, 40 minutes cycling and 5 minutes recovery

- Setting: hospital Rehabilitation Unit (3 weeks on average) and at home with tele monitoring (8 week on average).

- Other: ns

\section{Control:}

- Control group had no rehabilitation after discharge from hospital 
Smolis-Bak 2015 (Continued)

- Standard echocardiography

- Beck Depression Inventory

- QoL (Nottingham Health Profile)

\begin{tabular}{ll}
\hline Country and setting & Poland. Single centre trial, with a hospital and a home setting \\
\hline Follow-up & - End of intervention \\
& - 12 months \\
\hline Notes & \\
\hline
\end{tabular}

\section{Risk of bias}

\begin{tabular}{|c|c|c|}
\hline Bias & Authors' judgement & Support for judgement \\
\hline $\begin{array}{l}\text { Random sequence genera- } \\
\text { tion (selection bias) }\end{array}$ & Unclear risk & $\begin{array}{l}\text { Patients were randomly allocated, but there is no information on how this was } \\
\text { done. Waiting response from author }\end{array}$ \\
\hline $\begin{array}{l}\text { Allocation concealment } \\
\text { (selection bias) }\end{array}$ & Unclear risk & No information on concealment \\
\hline $\begin{array}{l}\text { Blinding of participants } \\
\text { and personnel (perfor- } \\
\text { mance bias) } \\
\text { All outcomes }\end{array}$ & High risk & No blinding because of the nature of exercise-based cardiac rehabilitation \\
\hline $\begin{array}{l}\text { Blinding of outcome as- } \\
\text { sessment (detection bias) } \\
\text { All outcomes }\end{array}$ & Unclear risk & No information. Waiting response from author \\
\hline $\begin{array}{l}\text { Incomplete outcome data } \\
\text { (attrition bias) } \\
\text { All outcomes }\end{array}$ & Unclear risk & No information. Waiting response from author \\
\hline $\begin{array}{l}\text { Selective reporting (re- } \\
\text { porting bias) }\end{array}$ & Low risk & Outcome described in methods are reported in results. \\
\hline Performance bias & Unclear risk & No information about co-intervention. Waiting response from author \\
\hline $\begin{array}{l}\text { Groups balanced at base- } \\
\text { line bias }\end{array}$ & High risk & High risk of bias due to large age difference in the two groups. \\
\hline Intention-to-treat analysis & Low risk & Analyses were conducted according to an intention-to-treat analysis \\
\hline For-profit bias & Low risk & Reported on their source of funding with conflicts of interest \\
\hline
\end{tabular}

Smolis-Bak 2017

Methods Parallel group RCT

Participants N Randomised: 84 (control group 43; exercise group 41). 12 patients were lost to follow-up (control group 5, exercise group 7)

Profile: SHF and NYHA III with ICD

Age: $63.7+/-9.5$ years (exercise group); $61.1+/-9.7$ (control group) 
Smolis-Bak 2017 (Continued)

Male: 36 (87.8\%) (exercise group); 40 (93.0\%) (control group)

White: NS

\section{Inclusion criteria:}

- SHF of ischaemic or non-ischaemic etiology

- Implanted ICD

- Low LVEF ( $\leq 35 \%)$

- Controlled hypertension and diabetes

\section{Exclusion criteria:}

- Resynchronisation therapy

- Possible indications for CRT in the future (left bundle branch block, QRS > $150 \mathrm{~ms}$ )

- Severe musculoskeletal conditions which preclude physical rehabilitation (orthopaedic, neurological)

- Planned cardiac surgery or percutaneous coronary interventions, cardiac surgery or coronary angioplasty within the last 3 months

- Acute coronary syndromes, stroke or transient ischaemic attack within the last 6 months

- Venous thrombosis or pulmonary embolism in the past

- Significant valvular disease

- History of malignancy

Interventions

\section{Exercise:}

- Total duration: 6 months

- Aerobic/resistance/mix: ICD-exercise patients underwent interval workouts with a cycloergometer and conditioning exercises with elements of resistance exercises

- Frequency: 3 days pr week

- Duration: cycloergometer training lasted on average 30 minutes. Resistance training lasted from 5 to 10 minutes

- Intensity: cycloergometer training with a speed of 55 to 64 revolutions per minute. Resistance training with a load of up to $50 \%$ of muscle strength. During the working phase lasting 1 minutes, the patients performed $10-12$ repetitions in one cycle.

- Setting: outpatient setting

- Other: ns

\section{Control:}

- Control group received standard systolic heart failure care

\begin{tabular}{ll}
\hline Outcomes & - Cardiopulmonary exercise testing \\
& $\cdot$ Standard echocardiographic examination \\
& 6-minute walk test \\
\hline Country and setting & Poland. Single-centre trial, with an outpatient setting \\
\hline Follow-up & - End of intervention \\
\hline Notes & 12 months \\
\hline Risk of bias & Authors' judgement Support for judgement \\
\hline Bias &
\end{tabular}


Smolis-Bak 2017 (Continued)

Random sequence genera- Unclear risk Patients were randomly allocated, but there is no information on how this was tion (selection bias) done.

\begin{tabular}{|c|c|c|}
\hline $\begin{array}{l}\text { Allocation concealment } \\
\text { (selection bias) }\end{array}$ & Unclear risk & No information on concealment \\
\hline $\begin{array}{l}\text { Blinding of participants } \\
\text { and personnel (perfor- } \\
\text { mance bias) } \\
\text { All outcomes }\end{array}$ & High risk & No blinding because of the nature of exercise-based cardiac rehabilitation \\
\hline $\begin{array}{l}\text { Blinding of outcome as- } \\
\text { sessment (detection bias) } \\
\text { All outcomes }\end{array}$ & Unclear risk & No information \\
\hline $\begin{array}{l}\text { Incomplete outcome data } \\
\text { (attrition bias) } \\
\text { All outcomes }\end{array}$ & Unclear risk & $\begin{array}{l}\text { Reasons for dropouts and withdrawals were not described. There was no infor- } \\
\text { mation about any methods being used to handle missing data. }\end{array}$ \\
\hline $\begin{array}{l}\text { Selective reporting (re- } \\
\text { porting bias) }\end{array}$ & Low risk & Outcome described in methods are reported in results. \\
\hline Performance bias & Low risk & Co-intervention was delivered equally to both groups \\
\hline $\begin{array}{l}\text { Groups balanced at base- } \\
\text { line bias }\end{array}$ & Low risk & Patients well matched at baseline \\
\hline Intention-to-treat analysis & Low risk & Analyses were conducted according to an intention-to-treat analysis \\
\hline For-profit bias & Low risk & Reported on their source of funding with conflicts of interest \\
\hline
\end{tabular}

CHF: systolic heart failure; CRT: cardiac resynchronisation therapy; CRT-D: cardiac resynchronisation therapy with defibrillator; CRT-P: cardiac resynchronisation therapy with pacing; ESC: European Society of Cardiology; HF: heart failure; ICD: implantable cardioverter defibrillator; LVEF: left ventricular ejection fraction; NYHA: New York Heart Association; NS: not stated; QoL: quality of life; RCT: randomised controlled trial; SD: standard deviation; SF-36: Short Form-36 Health Survey; SHF: systolic heart failure; TIA: transient ischaemic attack; QRS: QRS complex; VF: ventricular fibrillation; VO2: estimated oxygen consumption; VT: ventricular tachycardia.

Characteristics of excluded studies [ordered by study ID]

\begin{tabular}{|c|c|}
\hline Study & Reason for exclusion \\
\hline Dougherty 2004 & A randomised controlled design was not used \\
\hline Dunbar 2009 & Intervention was not exercise-based \\
\hline Edelman 2006 & Intervention was not exercise-based \\
\hline Fichet 2003 & A randomised controlled design was not used \\
\hline Klempfner 2015 & A randomised controlled design was not used \\
\hline Lewin 2007 & Intervention was not exercise-based \\
\hline Michitaka 2017 & Intervention was not exercise-based \\
\hline
\end{tabular}




\begin{tabular}{ll}
\hline Study & Reason for exclusion \\
\hline Rakhshan 2017 & No relevant outcomes reported and authors did not respond to query about measured outcomes \\
\hline Russell 2015 & Intervention was not exercise-based \\
\hline Toise 2014 & Intervention was not exercise-based \\
\hline Vanhees 2004 & A randomised controlled design was not used \\
\hline
\end{tabular}

Characteristics of studies awaiting assessment [ordered by study ID]

Chrysohoou 2015

\begin{tabular}{ll}
\hline Methods & Randomised controlled trial \\
\hline Participants & $\begin{array}{l}\text { Patients with chronic heart failure, } 72 \text { completed the study (exercise training group, } \mathrm{n}=33,63+/-9 \\
\text { years, } 88 \% \text { men, and control group, } \mathrm{n}=39,56+/-11 \text { years, } 82 \% \text { men) }\end{array}$ \\
\hline Interventions & High-intensity interval aerobic training combined with strength exercise \\
\hline Outcomes & - Pulse wave velocity \\
& - MLHFQ \\
& - 6 -minute walk \\
& Peak oxygen uptake \\
& Peak power \\
The number of ICD patients in the trial were below $50 \%$, and so we contacted the author to get sep- \\
arated data on the ICD population. The author has not returned our request.
\end{tabular}

Weretka 2010

\begin{tabular}{ll}
\hline Methods & Prospective, randomised study \\
\hline Participants & $\begin{array}{l}\text { Fifty-three patients implanted with ICDs were randomised to exercise or to control arms and fol- } \\
\text { lowed up for } 6 \text { months }\end{array}$ \\
\hline Interventions & Exercise training \\
\hline Outcomes & Ejection fraction \\
& -6 -minute walk \\
& - VO2 \\
\hline
\end{tabular}

Notes

It was not possible to find anything else except the conference abstract from the main search

Emv/Vp: ; MLHFQ: Minnesota Living with Heart Failure Questionnaire; ICD: implantable cardioverter defibrillator.

Characteristics of ongoing studies [ordered by study ID] 
NCT03544489

\begin{tabular}{ll}
\hline Trial name or title & Implementing exercise after an (ICD) (E-ICD) \\
\hline Methods & A randomised controlled trial \\
\hline Participants & 90 participants \\
\hline Interventions & Home walking exercise \\
\hline Outcomes & $\bullet$ Daily activity \\
\hline Starting date & General health \\
\hline Contact information & Cynthia M Dougherty, Professor, University of Washington \\
\hline Notes & Not yet recruiting \\
\hline
\end{tabular}

DATA AND ANALYSES

Comparison 1. Exercise-based cardiac rehabilitation versus control at the end of the intervention

\begin{tabular}{|c|c|c|c|c|}
\hline Outcome or subgroup title & No. of studies & $\begin{array}{l}\text { No. of partici- } \\
\text { pants }\end{array}$ & Statistical method & Effect size \\
\hline 1 All-cause mortality & 1 & 196 & $\begin{array}{l}\text { Risk Ratio (M-H, Random, 95\% } \\
\mathrm{Cl} \text { ) }\end{array}$ & $1.96[0.18,21.26]$ \\
\hline 2 Serious adverse events & 2 & 356 & $\begin{array}{l}\text { Risk Ratio (M-H, Random, 95\% } \\
\mathrm{Cl} \text { ) }\end{array}$ & $1.05[0.77,1.44]$ \\
\hline $\begin{array}{l}3 \text { Exercise capacity }\left(\mathrm{VO}_{2} \text { peak) }\right. \\
\text { (random-effects model) }\end{array}$ & 7 & 1485 & $\begin{array}{l}\text { Mean Difference (IV, Random, } \\
95 \% \mathrm{CI} \text { ) }\end{array}$ & $2.27[1.07,3.46]$ \\
\hline $\begin{array}{l}4 \text { Exercise capacity }\left(\mathrm{VO}_{2} \text { peak) }\right. \\
\text { (fixed-effect model) }\end{array}$ & 7 & 1485 & $\begin{array}{l}\text { Mean Difference (IV, Fixed, 95\% } \\
\mathrm{CI} \text { ) }\end{array}$ & $0.91[0.60,1.21]$ \\
\hline 5 ICD, antitachycardia pacing & 2 & 356 & $\begin{array}{l}\text { Risk Ratio (M-H, Random, 95\% } \\
\mathrm{Cl} \text { ) }\end{array}$ & $1.26[0.84,1.90]$ \\
\hline 6 ICD, appropriate shock & 3 & 428 & $\begin{array}{l}\text { Risk Ratio (M-H, Random, 95\% } \\
\mathrm{CI} \text { ) }\end{array}$ & $0.56[0.20,1.58]$ \\
\hline $7 \mathrm{ICD}$, inappropriate shock & 1 & 160 & Risk Ratio (M-H, Fixed, 95\% Cl) & $0.60[0.10,3.51]$ \\
\hline 8 Non-serious adverse events & 2 & 271 & $\begin{array}{l}\text { Risk Ratio (M-H, Random, 95\% } \\
\mathrm{Cl})\end{array}$ & $5.44[1.01,29.32]$ \\
\hline
\end{tabular}


Analysis 1.1. Comparison 1 Exercise-based cardiac rehabilitation versus control at the end of the intervention, Outcome 1 All-cause mortality.

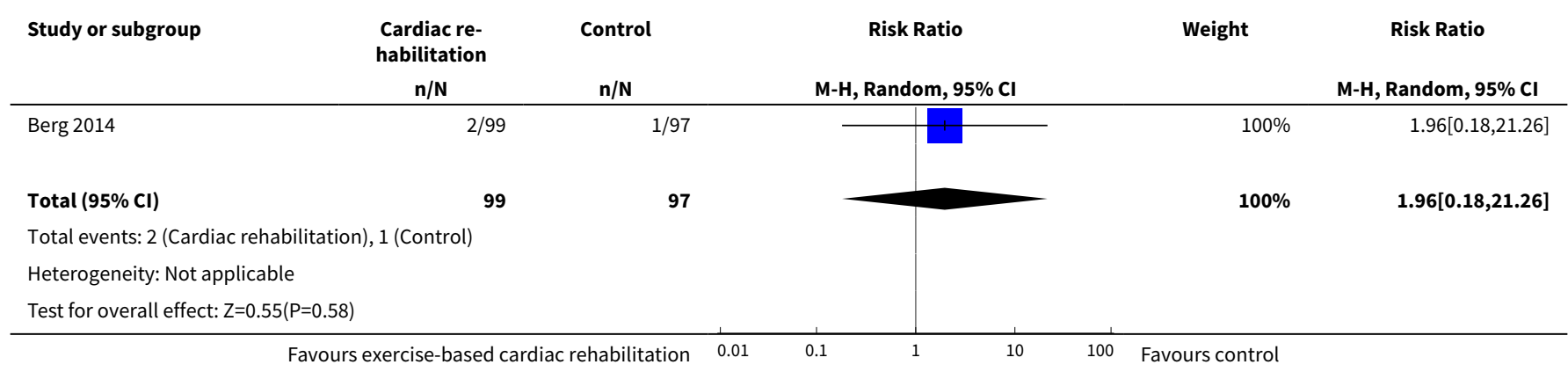

Analysis 1.2. Comparison 1 Exercise-based cardiac rehabilitation versus control at the end of the intervention, Outcome 2 Serious adverse events.

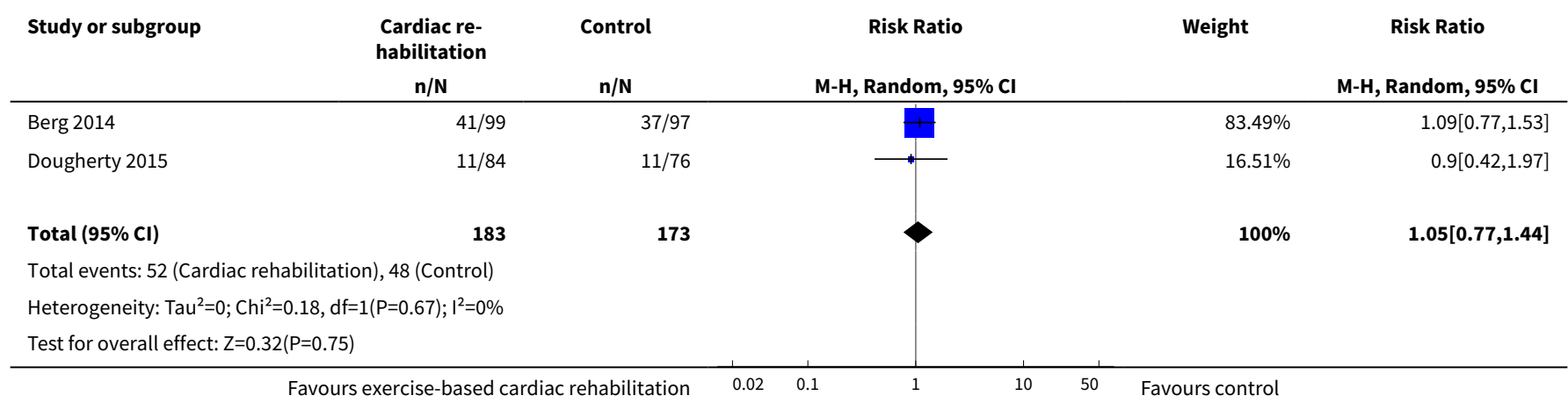

Analysis 1.3. Comparison 1 Exercise-based cardiac rehabilitation versus control at the end of the intervention, Outcome 3 Exercise capacity $\left(\mathrm{VO}_{2}\right.$ peak) (random-effects model).

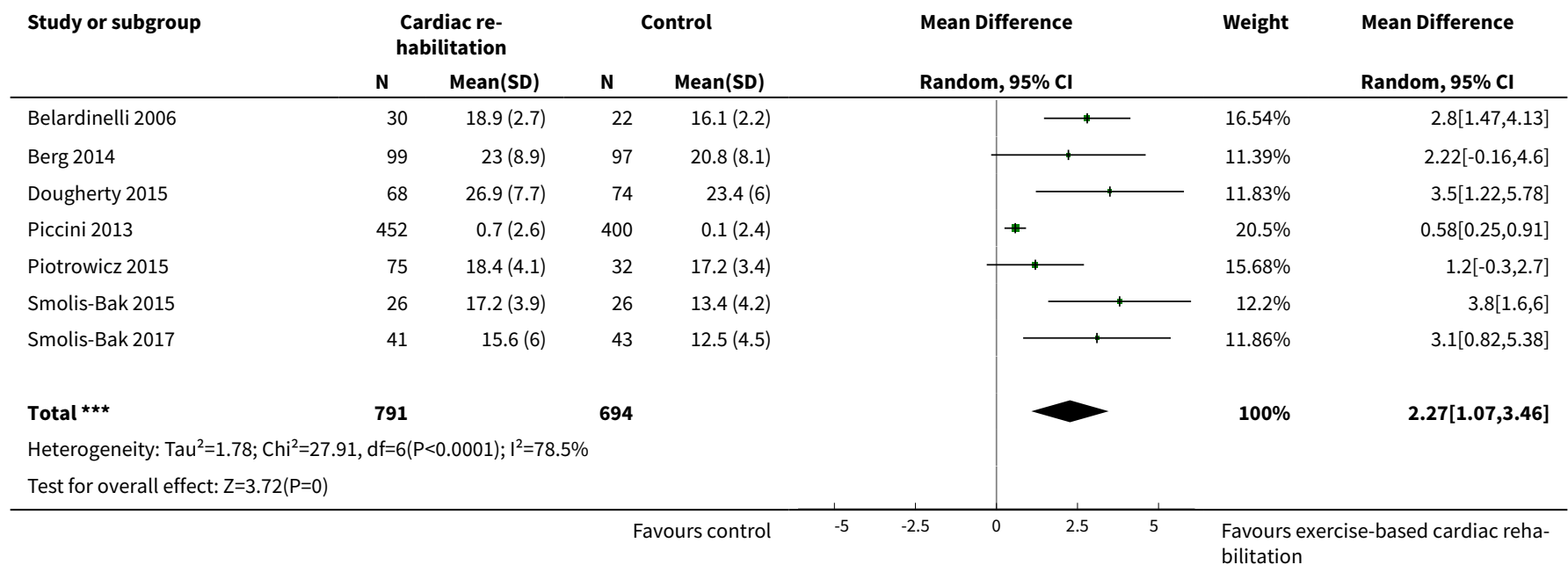


Analysis 1.4. Comparison 1 Exercise-based cardiac rehabilitation versus control at the end of the intervention, Outcome 4 Exercise capacity $\left(\mathrm{VO}_{2}\right.$ peak) (fixed-effect model).

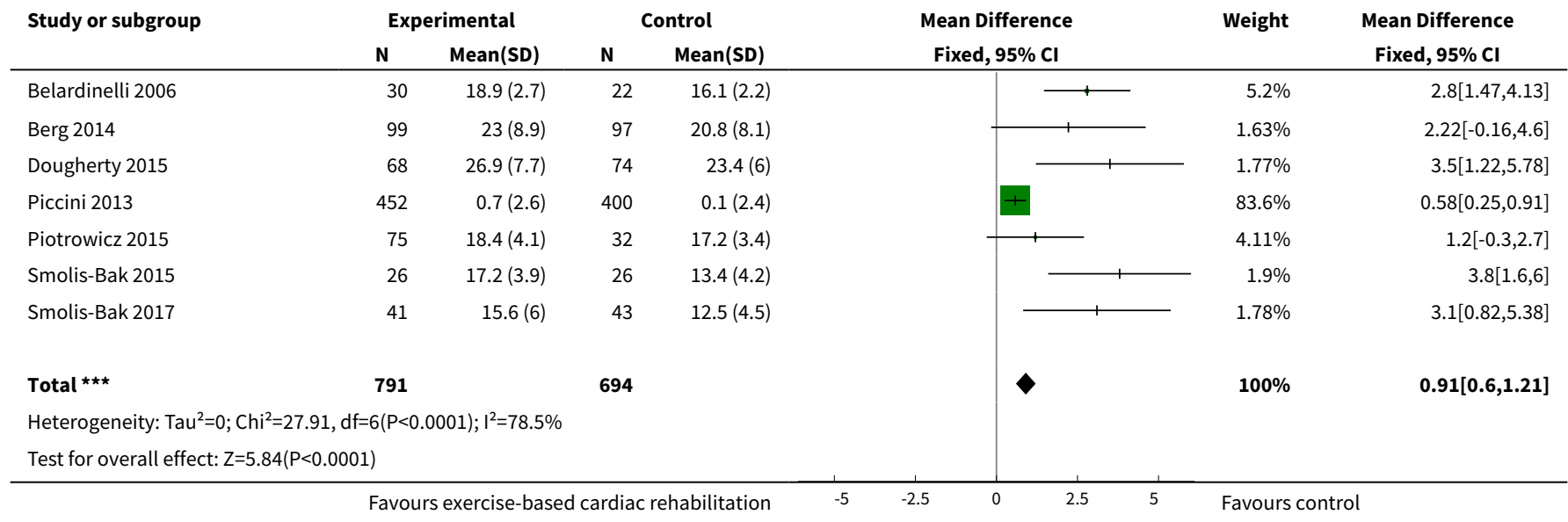

Analysis 1.5. Comparison 1 Exercise-based cardiac rehabilitation versus control at the end of the intervention, Outcome 5 ICD, antitachycardia pacing.

\begin{tabular}{|c|c|c|c|c|c|}
\hline Study or subgroup & $\begin{array}{c}\text { Cardiac re- } \\
\text { habilitation } \\
n / N\end{array}$ & $\begin{array}{l}\text { Control } \\
n / N\end{array}$ & $\begin{array}{c}\text { Risk Ratio } \\
\text { M-H, Random, } 95 \% \mathrm{Cl} \\
\end{array}$ & Weight & $\begin{array}{c}\text { Risk Ratio } \\
\text { M-H, Random, 95\% Cl }\end{array}$ \\
\hline Berg 2014 & $34 / 99$ & $27 / 97$ & & $94.03 \%$ & $1.23[0.81,1.88]$ \\
\hline Dougherty 2015 & $4 / 84$ & $2 / 76$ & $1+$ & $5.97 \%$ & $1.81[0.34,9.6]$ \\
\hline Total $(95 \% \mathrm{Cl})$ & 183 & 173 & & $100 \%$ & $1.26[0.84,1.9]$ \\
\hline \multicolumn{6}{|c|}{ Heterogeneity: $\operatorname{Tau}^{2}=0 ; \mathrm{Chi}^{2}=0.19, \mathrm{df}=1(\mathrm{P}=0.66) ; \mathrm{I}^{2}=0 \%$} \\
\hline Test for overall effect & & & & & \\
\hline
\end{tabular}

Analysis 1.6. Comparison 1 Exercise-based cardiac rehabilitation versus control at the end of the intervention, Outcome 6 ICD, appropriate shock.

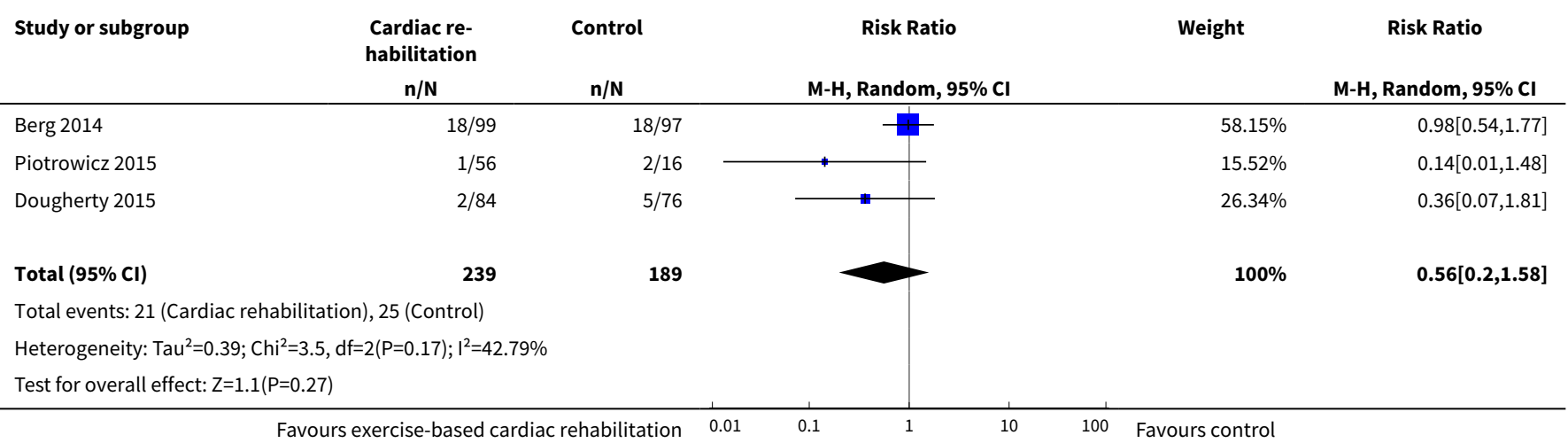


Analysis 1.7. Comparison 1 Exercise-based cardiac rehabilitation versus control at the end of the intervention, Outcome 7 ICD, inappropriate shock.

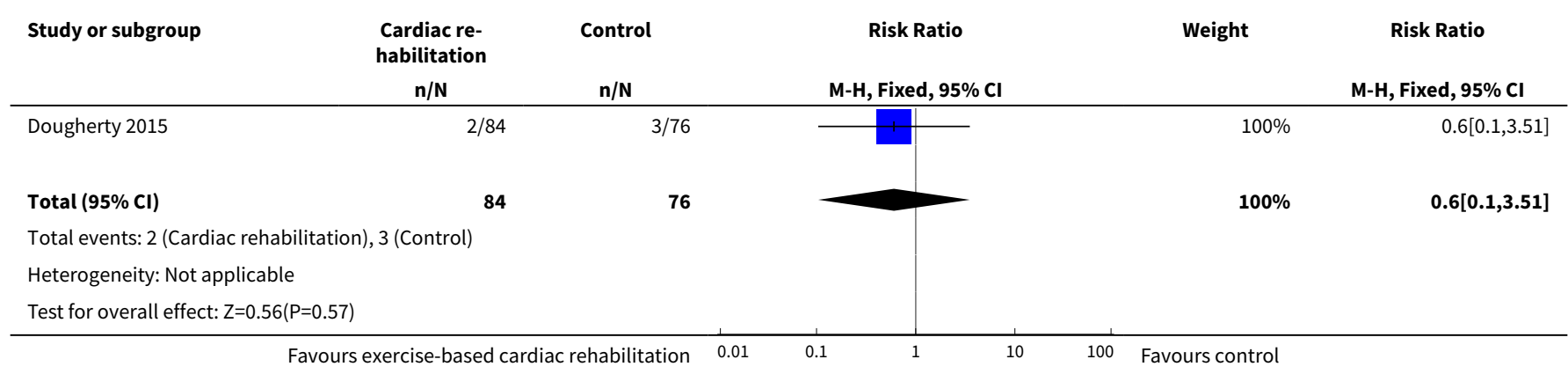

Analysis 1.8. Comparison 1 Exercise-based cardiac rehabilitation versus control at the end of the intervention, Outcome 8 Non-serious adverse events.

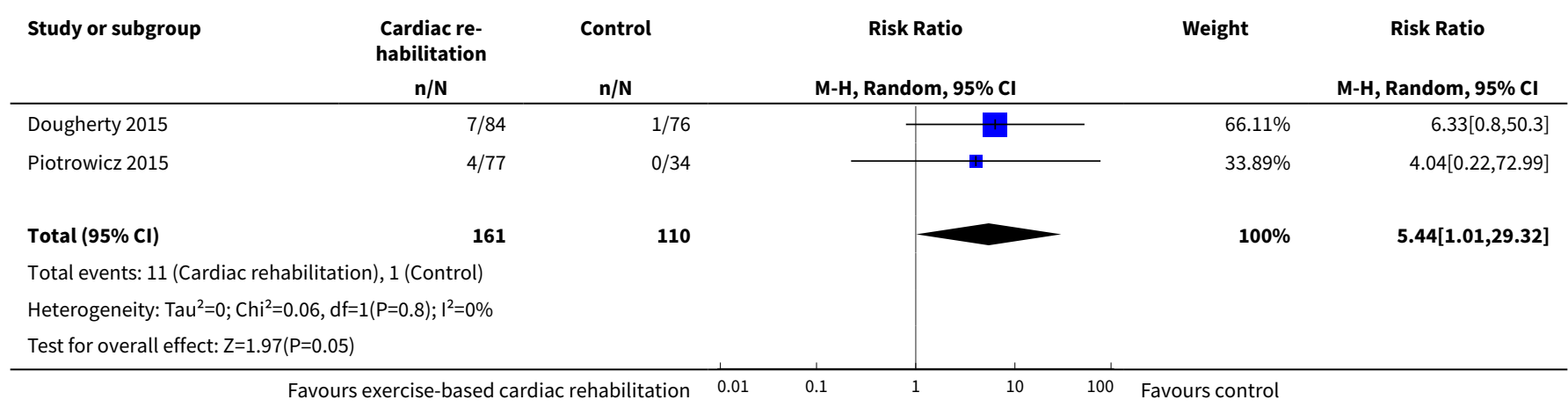

Comparison 2. Exercise-based cardiac rehabilitation versus control at the end of the intervention (best-worst case meta-analysis)

\begin{tabular}{lllll}
\hline Outcome or subgroup title & No. of studies & $\begin{array}{l}\text { No. of partici- } \\
\text { pants }\end{array}$ & Statistical method & Effect size \\
\hline 1 All-cause mortality & 3 & 467 & Risk Ratio (M-H, Random, 95\% Cl) & $0.07[0.02,0.22]$ \\
\hline 2 Serious adverse events & 3 & 467 & Risk Ratio (M-H, Random, 95\% Cl) & $0.58[0.41,0.82]$ \\
\hline
\end{tabular}

Analysis 2.1. Comparison 2 Exercise-based cardiac rehabilitation versus control at the end of the intervention (best-worst case meta-analysis), Outcome 1 All-cause mortality.

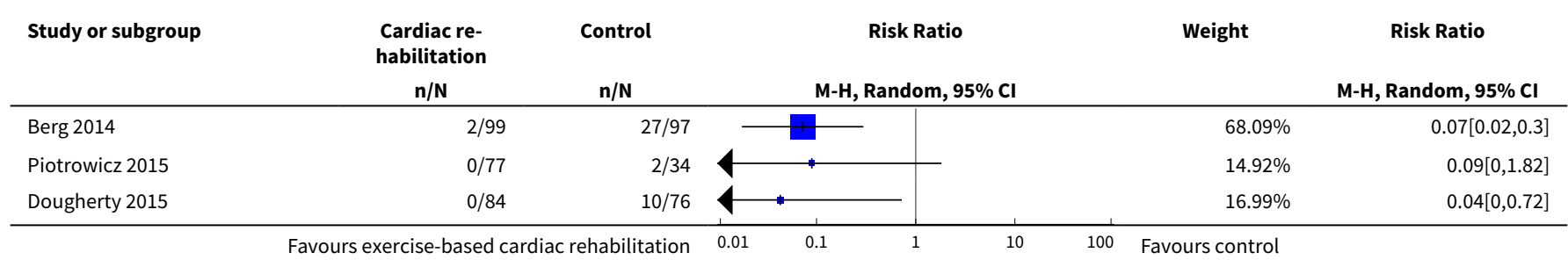




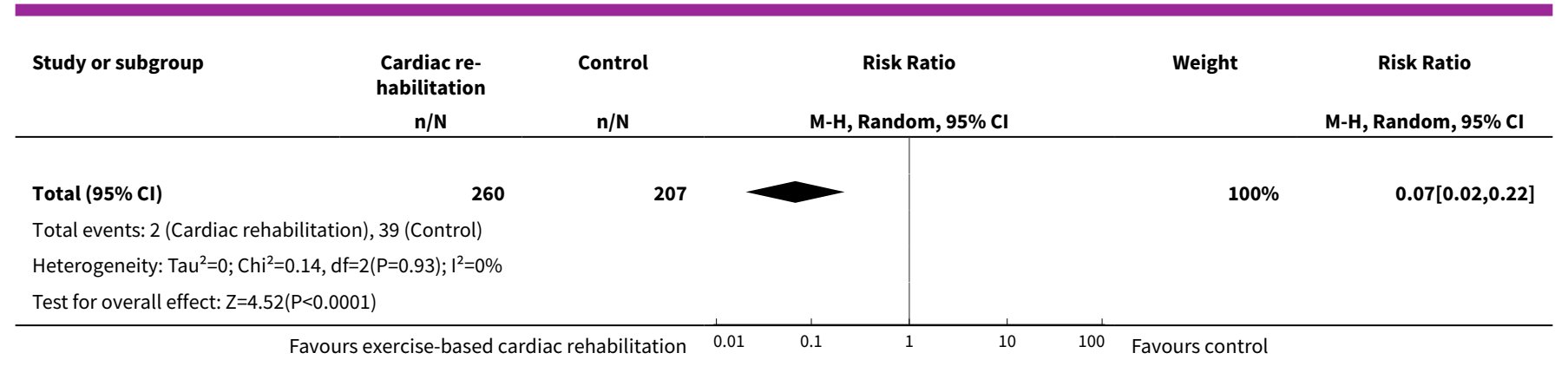

Analysis 2.2. Comparison 2 Exercise-based cardiac rehabilitation versus control at the end of the intervention (best-worst case meta-analysis), Outcome 2 Serious adverse events.

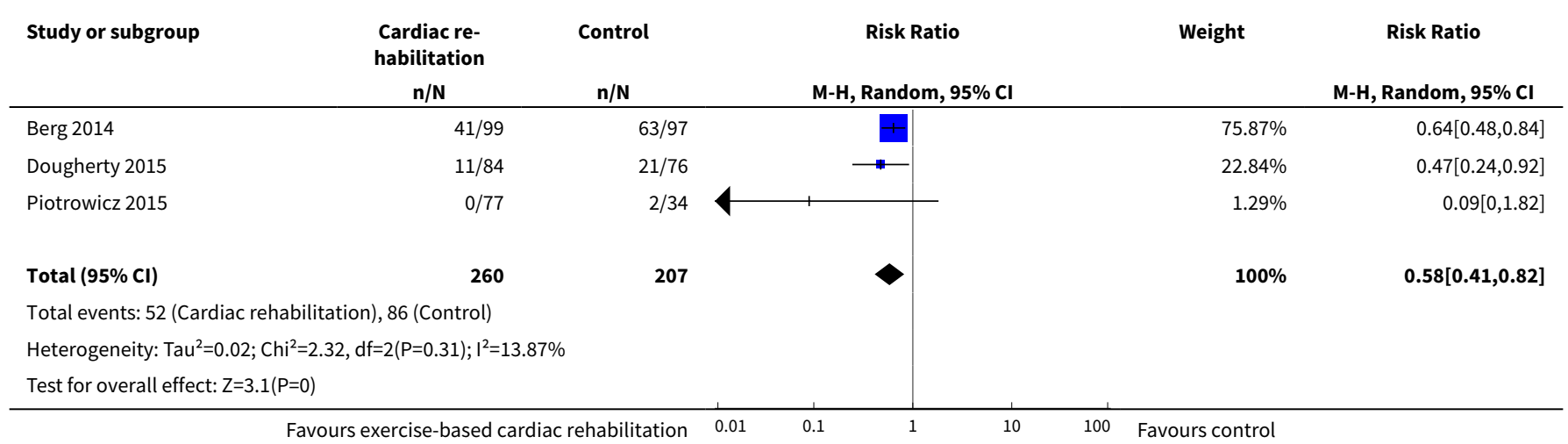

Comparison 3. Exercise-based cardiac rehabilitation versus control at the end of the intervention (worst-best case meta-analysis)

\begin{tabular}{lllll}
\hline Outcome or subgroup title & No. of studies & $\begin{array}{l}\text { No. of partici- } \\
\text { pants }\end{array}$ & Statistical method & Effect size \\
\hline $\begin{array}{l}1 \text { All-cause mortality (random-ef- } \\
\text { fects model) }\end{array}$ & 3 & 467 & $\begin{array}{l}\text { Risk Ratio (M-H, Random, 95\% } \\
\text { Cl) }\end{array}$ & $13.50[3.24,56.25]$ \\
\hline $\begin{array}{l}2 \text { All-cause mortality (fixed-effect } \\
\text { model) }\end{array}$ & 3 & 467 & Risk Ratio (M-H, Fixed, 95\% Cl) & $16.78[4.32,65.18]$ \\
\hline 3 All-cause mortality & 3 & 467 & $\begin{array}{l}\text { Risk Ratio (M-H, Random, 95\% } \\
\text { Cl) }\end{array}$ & $13.50[3.24,56.25]$ \\
\hline 4 Serious adverse events & 3 & 467 & $\begin{array}{l}\text { Risk Ratio (M-H, Random, 95\% } \\
\text { Cl) }\end{array}$ & $1.74[1.34,2.27]$ \\
\hline
\end{tabular}


Analysis 3.1. Comparison 3 Exercise-based cardiac rehabilitation versus control at the end of the intervention (worst-best case meta-analysis), Outcome 1 All-cause mortality (random-effects model).

\begin{tabular}{|c|c|c|c|c|c|}
\hline \multirow[t]{2}{*}{ Study or subgroup } & $\begin{array}{l}\text { Cardiac re- } \\
\text { habilitation }\end{array}$ & Control & Risk Ratio & Weight & \multirow[t]{2}{*}{$\begin{array}{c}\text { Risk Ratio } \\
\text { M-H, Random, } 95 \% \mathrm{Cl}\end{array}$} \\
\hline & $n / N$ & $\mathbf{n} / \mathbf{N}$ & \multicolumn{2}{|l|}{ M-H, Random, $95 \% \mathrm{Cl}$} & \\
\hline Berg 2014 & $28 / 99$ & $1 / 97$ & & $52.2 \%$ & $27.43[3.81,197.69]$ \\
\hline Dougherty 2015 & $8 / 84$ & $0 / 76$ & & $25.32 \%$ & $15.4[0.9,262.39]$ \\
\hline Piotrowicz 2015 & $2 / 77$ & $0 / 34$ & $\longrightarrow$ & $22.47 \%$ & $2.24[0.11,45.52]$ \\
\hline \multicolumn{6}{|c|}{ Total events: 38 (Cardiac rehabilitation), 1 (Control) } \\
\hline \multicolumn{6}{|c|}{ Heterogeneity: $\operatorname{Tau}^{2}=0 ; \mathrm{Chi}^{2}=1.96, \mathrm{df}=2(\mathrm{P}=0.38) ; \mathrm{I}^{2}=0 \%$} \\
\hline Test for overall effect & & & & & \\
\hline
\end{tabular}

Analysis 3.2. Comparison 3 Exercise-based cardiac rehabilitation versus control at the end of the intervention (worst-best case meta-analysis), Outcome 2 All-cause mortality (fixed-effect model).

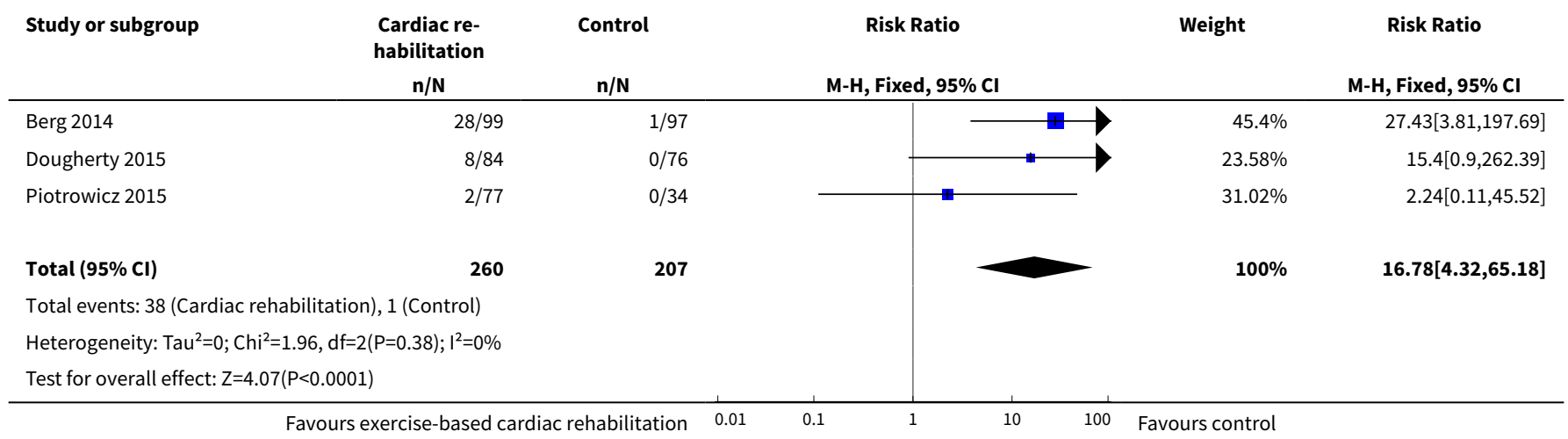

Analysis 3.3. Comparison 3 Exercise-based cardiac rehabilitation versus control at the end of the intervention (worst-best case meta-analysis), Outcome 3 All-cause mortality.

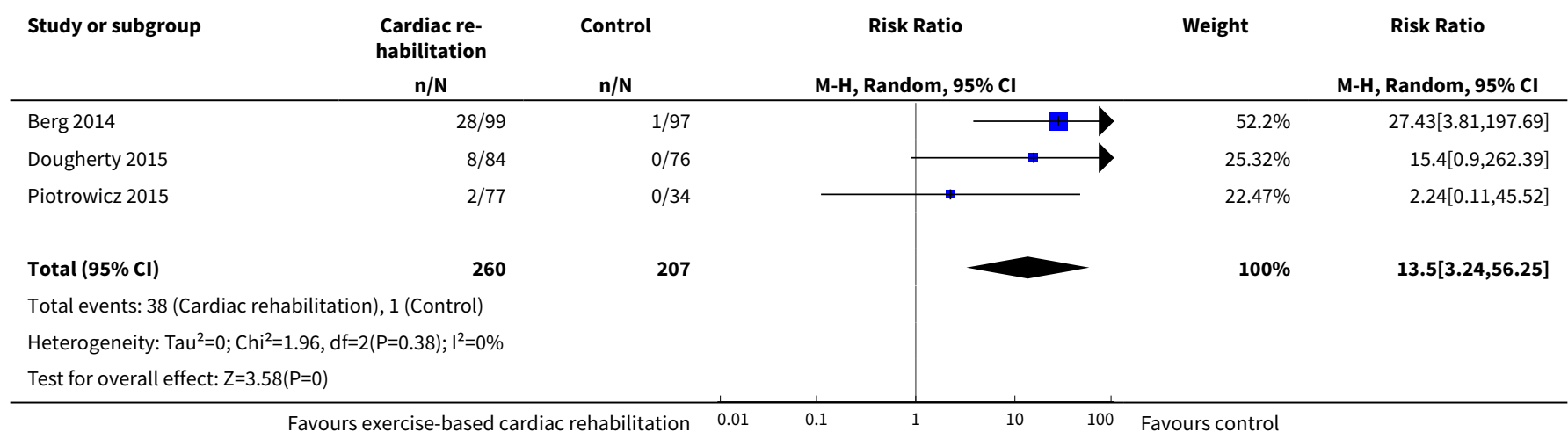


Analysis 3.4. Comparison 3 Exercise-based cardiac rehabilitation versus control at the end of the intervention (worst-best case meta-analysis), Outcome 4 Serious adverse events.

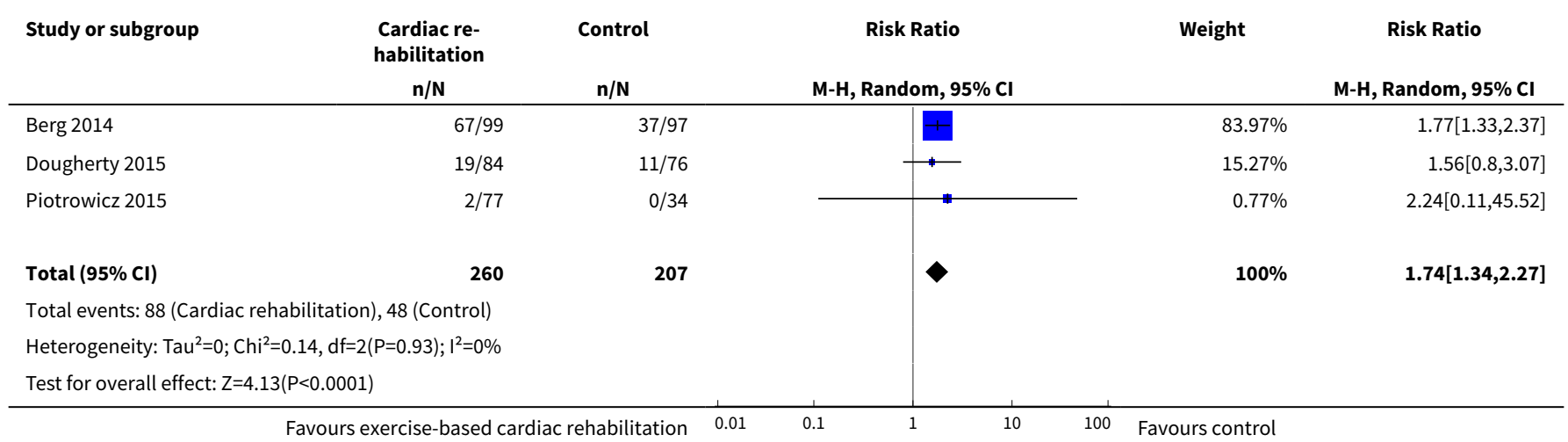

\section{Comparison 4. Exercise-based cardiac rehabilitation versus control at longest follow-up}

\begin{tabular}{|c|c|c|c|c|}
\hline Outcome or subgroup title & No. of studies & $\begin{array}{l}\text { No. of partici- } \\
\text { pants }\end{array}$ & Statistical method & Effect size \\
\hline 1 All-cause mortality & 3 & 332 & $\begin{array}{l}\text { Risk Ratio (M-H, Random, } \\
95 \% \mathrm{Cl})\end{array}$ & $1.18[0.65,2.14]$ \\
\hline $\begin{array}{l}2 \text { Serious adverse events (random-ef- } \\
\text { fects model) }\end{array}$ & 3 & 188 & $\begin{array}{l}\text { Risk Ratio (M-H, Random, } \\
95 \% \mathrm{Cl})\end{array}$ & $0.84[0.43,1.65]$ \\
\hline $\begin{array}{l}3 \text { Serious adverse events (fixed-effect } \\
\text { model) }\end{array}$ & 3 & 188 & $\begin{array}{l}\text { Risk Ratio (M-H, Fixed, 95\% } \\
\mathrm{Cl})\end{array}$ & $0.81[0.61,1.08]$ \\
\hline 4 Exercise capacity $\left(\mathrm{VO}_{2}\right.$ peak) & 2 & 136 & $\begin{array}{l}\text { Mean Difference (IV, Fixed, } \\
95 \% \mathrm{Cl})\end{array}$ & $0.83[-0.66,2.32]$ \\
\hline $\begin{array}{l}5 \text { ICD, appropriate shock (random-ef- } \\
\text { fects model) }\end{array}$ & 4 & 384 & $\begin{array}{l}\text { Risk Ratio (M-H, Random, } \\
95 \% \mathrm{Cl})\end{array}$ & $0.28[0.05,1.65]$ \\
\hline $\begin{array}{l}6 \text { ICD, appropriate shock (fixed-effect } \\
\text { model) }\end{array}$ & 4 & 384 & $\begin{array}{l}\text { Risk Ratio (M-H, Fixed, 95\% } \\
\text { Cl) }\end{array}$ & $0.88[0.68,1.13]$ \\
\hline 7 ICD, all shocks & 1 & & $\begin{array}{l}\text { Risk Ratio (M-H, Random, } \\
95 \% \mathrm{Cl})\end{array}$ & Subtotals only \\
\hline
\end{tabular}

Analysis 4.1. Comparison 4 Exercise-based cardiac rehabilitation versus control at longest follow-up, Outcome 1 All-cause mortality.

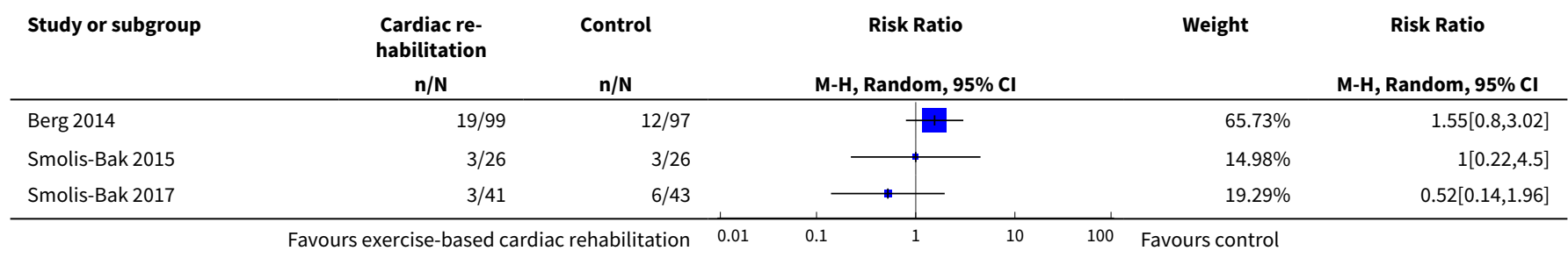




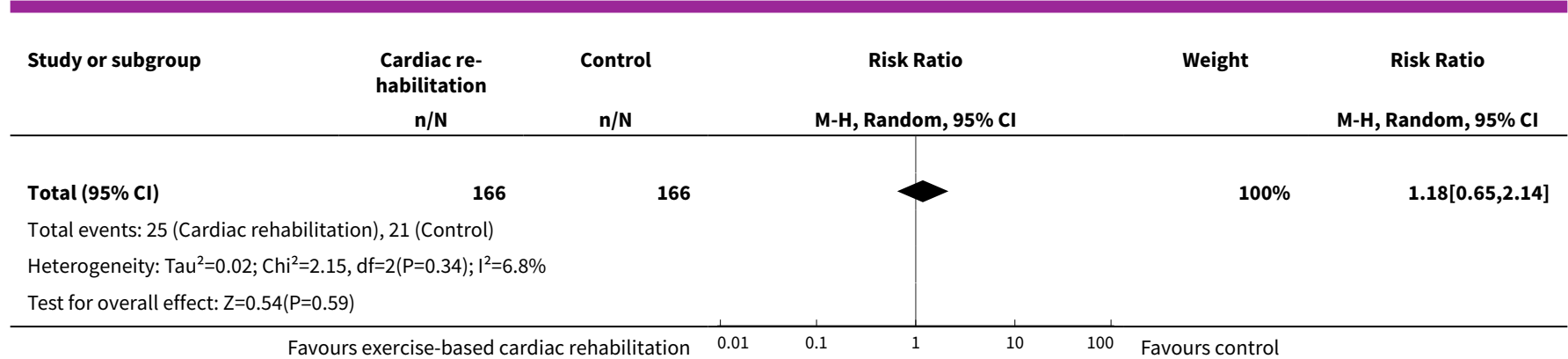

Analysis 4.2. Comparison 4 Exercise-based cardiac rehabilitation versus control at longest follow-up, Outcome 2 Serious adverse events (random-effects model).

\begin{tabular}{|c|c|c|c|c|c|}
\hline \multirow[t]{2}{*}{ Study or subgroup } & $\begin{array}{l}\text { Cardiac re- } \\
\text { habilitation }\end{array}$ & \multirow{2}{*}{$\begin{array}{l}\text { Control } \\
n / N\end{array}$} & Risk Ratio & \multirow[t]{2}{*}{ Weight } & \multirow{2}{*}{$\begin{array}{c}\text { Risk Ratio } \\
\text { M-H, Random, } 95 \% \mathrm{Cl}\end{array}$} \\
\hline & $n / N$ & & M-H, Random, 95\% Cl & & \\
\hline Belardinelli 2006 & $0 / 30$ & $8 / 22$ & - & $5.24 \%$ & $0.04[0,0.72]$ \\
\hline Smolis-Bak 2015 & $14 / 26$ & $15 / 26$ & - & $44.64 \%$ & $0.93[0.57,1.52]$ \\
\hline Smolis-Bak 2017 & $25 / 41$ & $25 / 43$ & & $50.12 \%$ & $1.05[0.74,1.49]$ \\
\hline Total $(95 \% \mathrm{Cl})$ & 97 & 91 & & $100 \%$ & $0.84[0.43,1.65]$ \\
\hline \multicolumn{6}{|c|}{ Total events: 39 (Cardiac rehabilitation), 48 (Control) } \\
\hline \multicolumn{6}{|c|}{ Heterogeneity: $\operatorname{Tau}^{2}=0.2 ; \mathrm{Chi}^{2}=6.48, \mathrm{df}=2(\mathrm{P}=0.04) ; \mathrm{I}^{2}=69.15 \%$} \\
\hline Test for overall effec & & & & & \\
\hline
\end{tabular}

Analysis 4.3. Comparison 4 Exercise-based cardiac rehabilitation versus control at longest follow-up, Outcome 3 Serious adverse events (fixed-effect model).

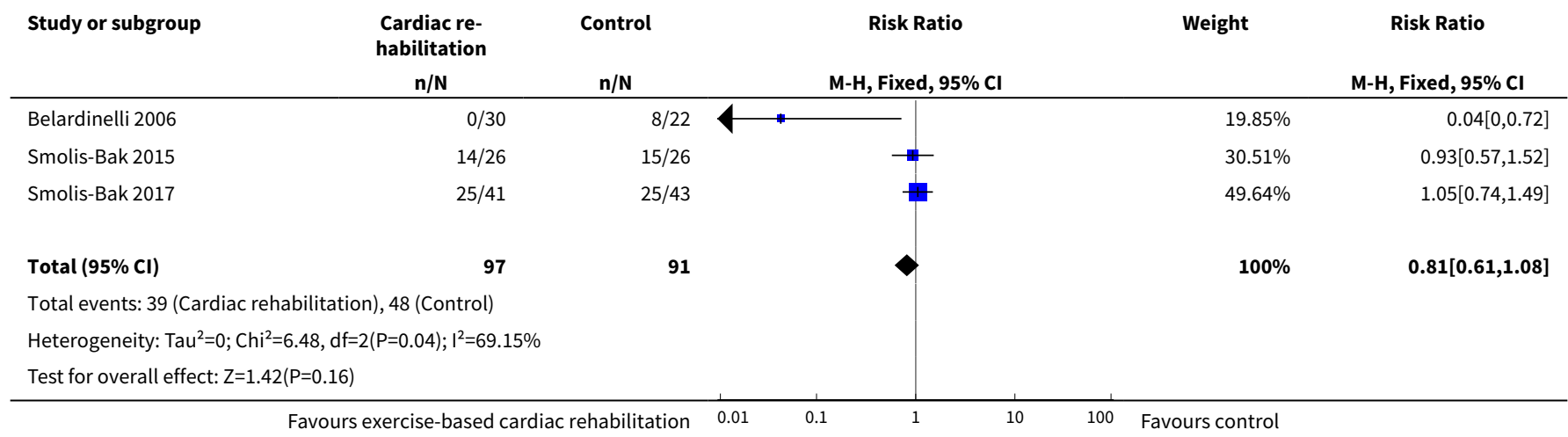


Analysis 4.4. Comparison 4 Exercise-based cardiac rehabilitation versus control at longest follow-up, Outcome 4 Exercise capacity $\left(\mathrm{VO}_{2}\right.$ peak).

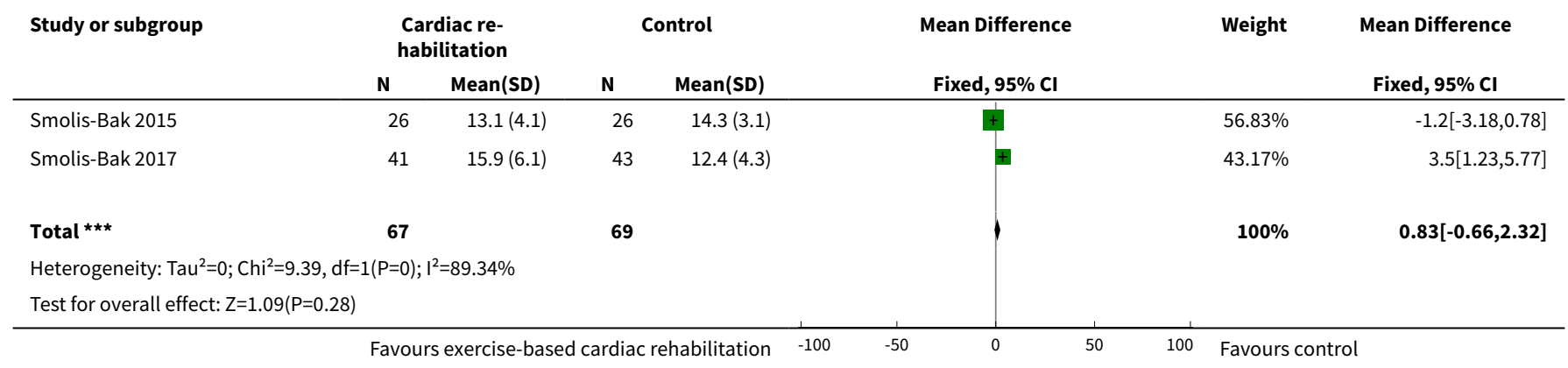

Analysis 4.5. Comparison 4 Exercise-based cardiac rehabilitation versus control at longest follow-up, Outcome 5 ICD, appropriate shock (random-effects model).

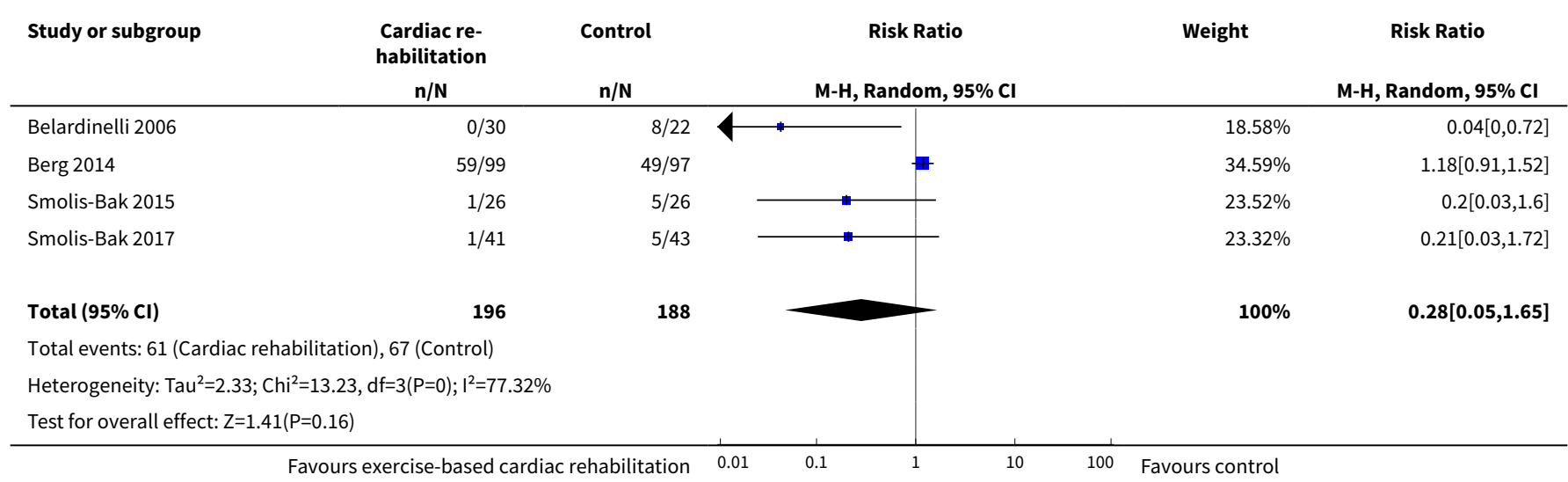

Analysis 4.6. Comparison 4 Exercise-based cardiac rehabilitation versus control at longest follow-up, Outcome 6 ICD, appropriate shock (fixed-effect model).

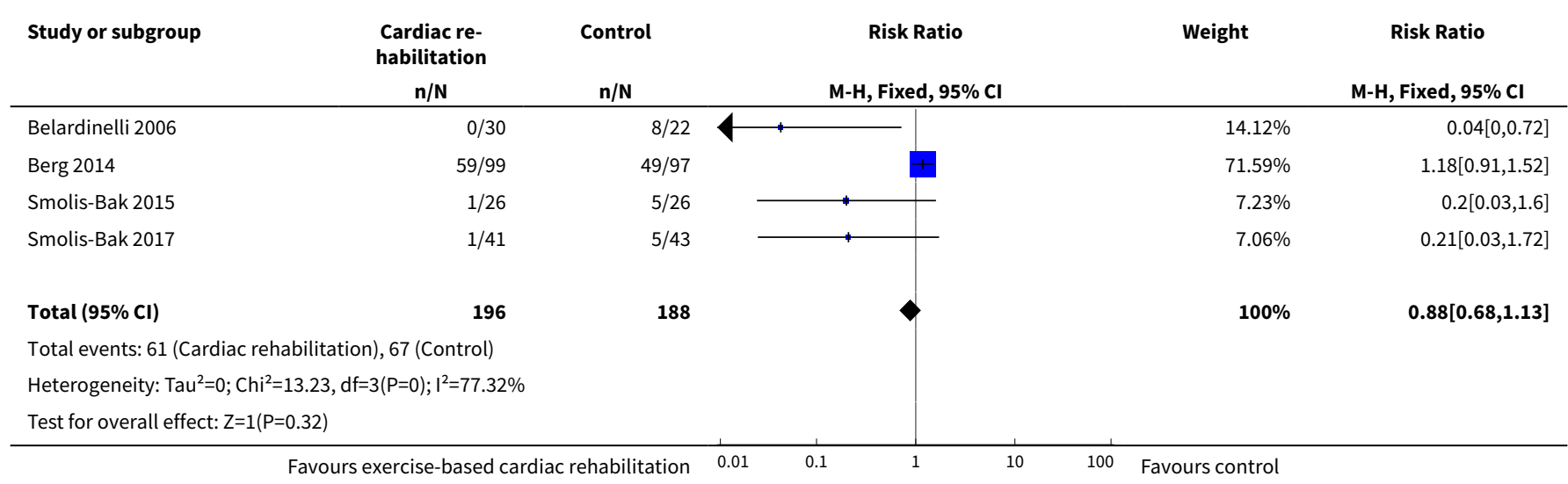


Analysis 4.7. Comparison 4 Exercise-based cardiac rehabilitation versus control at longest follow-up, Outcome 7 ICD, all shocks.

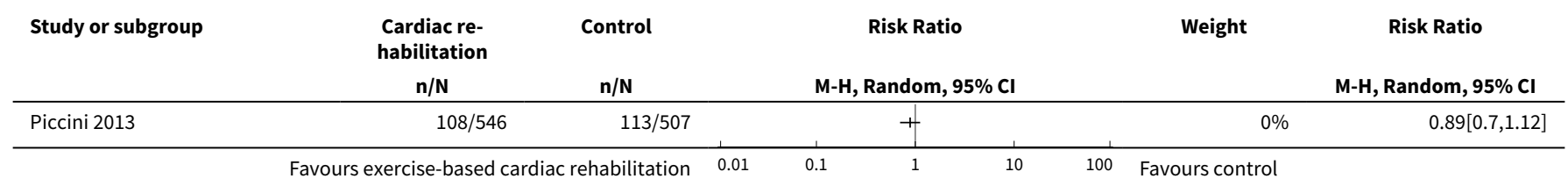

Comparison 5. Exercise-based cardiac rehabilitation versus control at longest follow-up (best-worst case metaanalysis)

\begin{tabular}{lllll}
\hline Outcome or subgroup title & No. of studies & $\begin{array}{l}\text { No. of partici- } \\
\text { pants }\end{array}$ & Statistical method & Effect size \\
\hline 1 All-cause mortality & 4 & 384 & Risk Ratio (M-H, Random, 95\% Cl) & $0.48[0.32,0.74]$ \\
\hline 2 Serious adverse events & 3 & 188 & Risk Ratio (M-H, Fixed, 95\% Cl) & $0.71[0.55,0.93]$ \\
\hline
\end{tabular}

Analysis 5.1. Comparison 5 Exercise-based cardiac rehabilitation versus control at longest follow-up (best-worst case meta-analysis), Outcome 1 All-cause mortality.

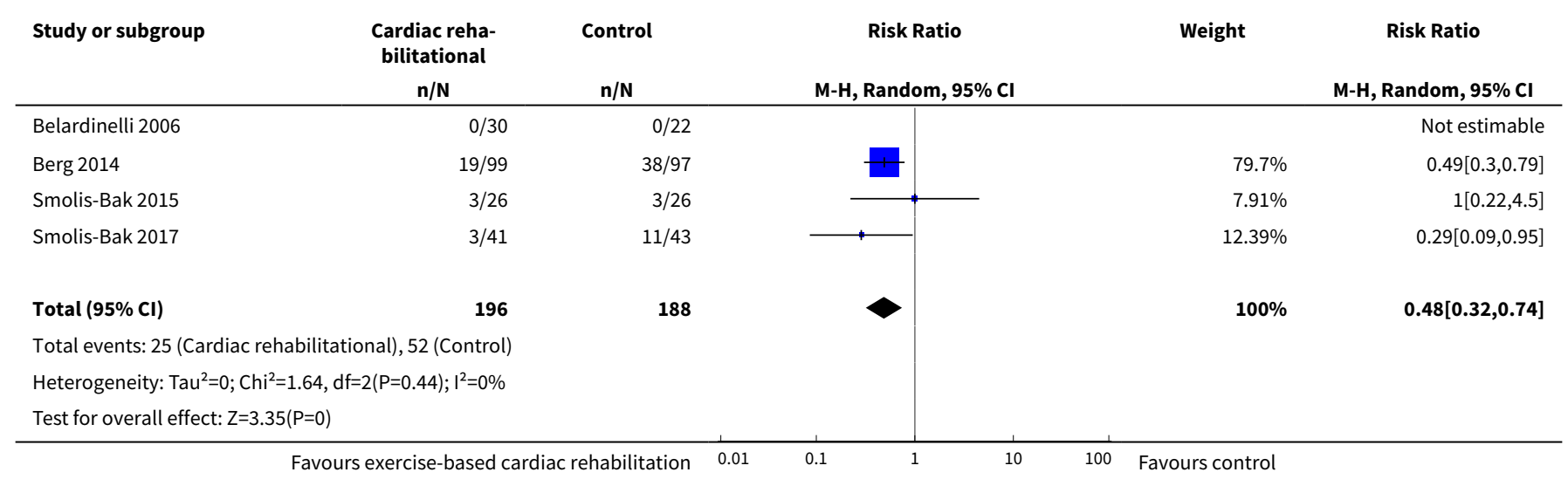

Analysis 5.2. Comparison 5 Exercise-based cardiac rehabilitation versus control at longest follow-up (best-worst case meta-analysis), Outcome 2 Serious adverse events.

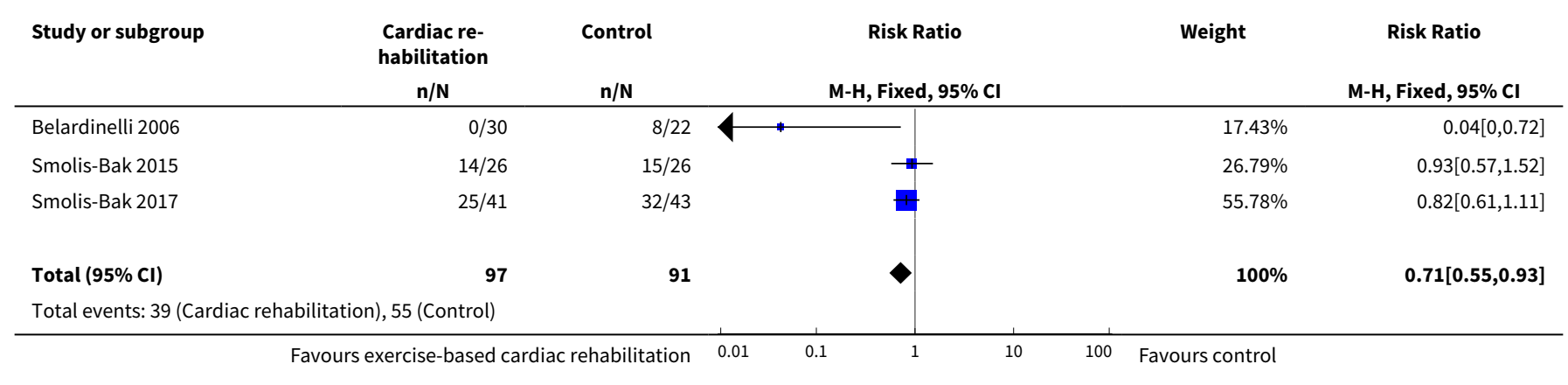




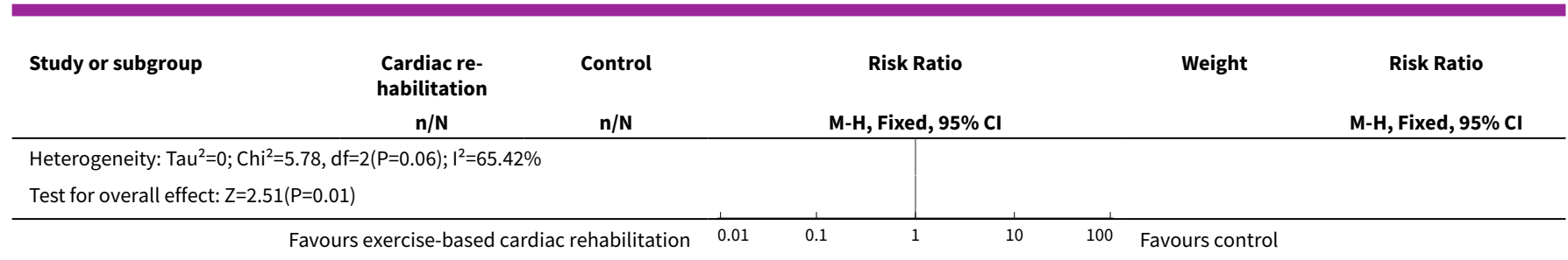

Comparison 6. Exercise-based cardiac rehabilitation versus control at longest follow-up (worst-best case metaanalysis)

\begin{tabular}{lllll}
\hline Outcome or subgroup title & No. of studies & $\begin{array}{l}\text { No. of partici- } \\
\text { pants }\end{array}$ & Statistical method & Effect size \\
\hline 1 All-cause mortality & 4 & 384 & $\begin{array}{l}\text { Risk Ratio (M-H, Random, 95\% } \\
\text { Cl) }\end{array}$ & 2.29 [1.12, 4.70] \\
\hline $\begin{array}{l}\text { 2 Serious adverse events (ran- } \\
\text { dom-effects model) }\end{array}$ & 3 & 188 & $\begin{array}{l}\text { Risk Ratio (M-H, Random, 95\% } \\
\text { Cl) }\end{array}$ & $0.89[0.42,1.89]$ \\
\hline $\begin{array}{l}\text { 3 Serious adverse events (fixed-ef- } \\
\text { fect model) }\end{array}$ & 3 & 188 & Risk Ratio (M-H, Fixed, 95\% Cl) & $0.71[0.55,0.93]$ \\
\hline
\end{tabular}

Analysis 6.1. Comparison 6 Exercise-based cardiac rehabilitation versus control at longest follow-up (worst-best case meta-analysis), Outcome 1 All-cause mortality.

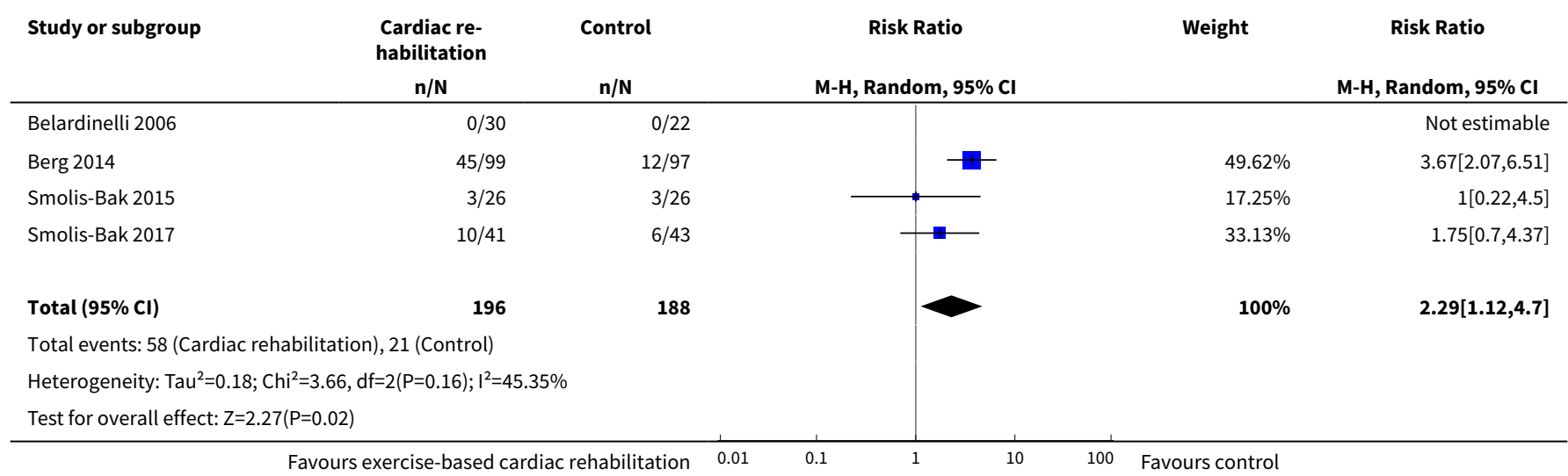

Analysis 6.2. Comparison 6 Exercise-based cardiac rehabilitation versus control at longest followup (worst-best case meta-analysis), Outcome 2 Serious adverse events (random-effects model).

\begin{tabular}{|c|c|c|c|c|c|}
\hline \multirow[t]{2}{*}{ Study or subgroup } & $\begin{array}{l}\text { Cardiac re- } \\
\text { habilitation }\end{array}$ & Control & Risk Ratio & Weight & Risk Ratio \\
\hline & $n / N$ & $n / N$ & M-H, Random, $95 \% \mathrm{Cl}$ & & M-H, Random, $95 \% \mathrm{Cl}$ \\
\hline Belardinelli 2006 & $0 / 30$ & $8 / 22$ & - & $6.33 \%$ & $0.04[0,0.72]$ \\
\hline Smolis-Bak 2015 & $14 / 26$ & $15 / 26$ & $\rightarrow$ & $44.18 \%$ & $0.93[0.57,1.52]$ \\
\hline Smolis-Bak 2017 & $30 / 41$ & $25 / 43$ & & $49.49 \%$ & $1.26[0.92,1.72]$ \\
\hline
\end{tabular}

$\begin{array}{lllllll}\text { Favours exercise-based cardiac rehabilitation } & 0.01 & 0.1 & 1 & 10 & 100 & \text { Favours control }\end{array}$ 


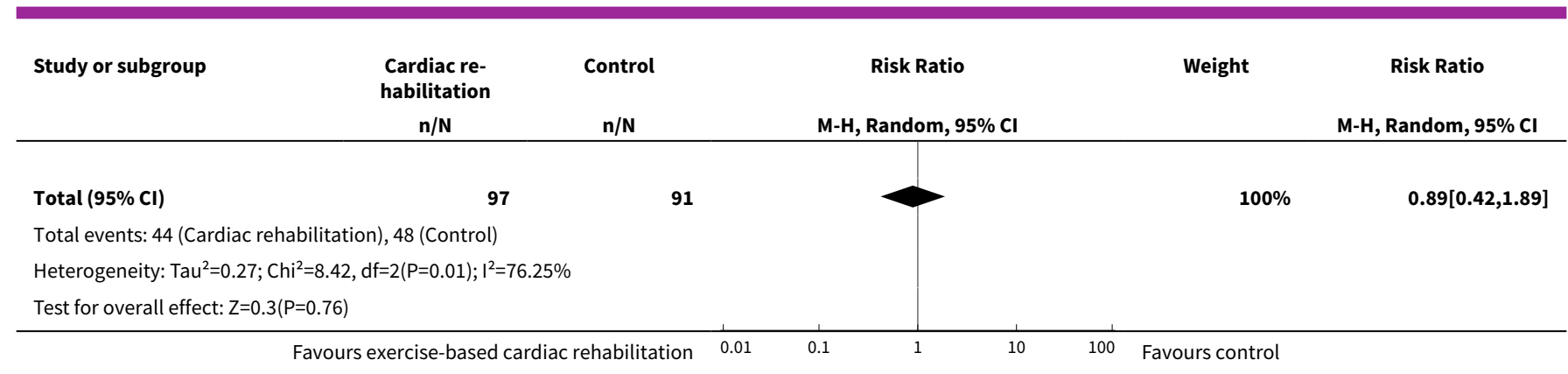

\section{Analysis 6.3. Comparison 6 Exercise-based cardiac rehabilitation versus control at longest follow- up (worst-best case meta-analysis), Outcome 3 Serious adverse events (fixed-effect model).}

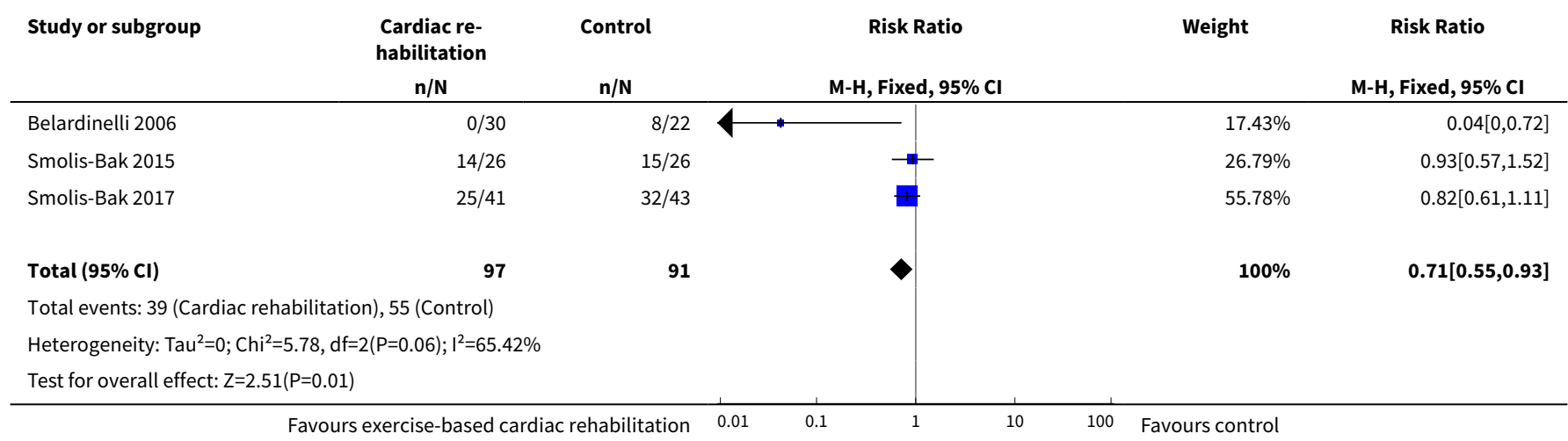

\section{Comparison 7. Subgroup analysis}

\begin{tabular}{|c|c|c|c|c|}
\hline Outcome or subgroup title & No. of studies & $\begin{array}{l}\text { No. of partici- } \\
\text { pants }\end{array}$ & Statistical method & Effect size \\
\hline $\begin{array}{l}1 \text { All-cause mortality: exercise intervention } \\
\text { only compared to exercise intervention } \\
\text { plus any other co-intervention at longest } \\
\text { follow-up }\end{array}$ & 2 & 248 & $\begin{array}{l}\text { Risk Ratio (M-H, Random, } \\
95 \% \mathrm{CI})\end{array}$ & $1.44[0.79,2.65]$ \\
\hline 1.1 Exercise intervention only & 1 & 52 & $\begin{array}{l}\text { Risk Ratio (M-H, Random, } \\
95 \% \mathrm{Cl})\end{array}$ & $1.0[0.22,4.50]$ \\
\hline $\begin{array}{l}\text { 1.2 Exercise intervention plus any other co- } \\
\text { intervention }\end{array}$ & 1 & 196 & $\begin{array}{l}\text { Risk Ratio (M-H, Random, } \\
95 \% \mathrm{Cl})\end{array}$ & $1.55[0.80,3.02]$ \\
\hline 2 Serious adverse events: follow-up & 5 & 544 & $\begin{array}{l}\text { Risk Ratio (M-H, Random, } \\
95 \% \mathrm{Cl})\end{array}$ & $0.99[0.74,1.30]$ \\
\hline 2.1 Follow-up less than six months & 2 & 356 & $\begin{array}{l}\text { Risk Ratio (M-H, Random, } \\
95 \% \mathrm{Cl})\end{array}$ & $1.05[0.77,1.44]$ \\
\hline 2.2 Follow-up six months or more & 3 & 188 & $\begin{array}{l}\text { Risk Ratio (M-H, Random, } \\
95 \% \mathrm{Cl})\end{array}$ & $0.84[0.43,1.65]$ \\
\hline
\end{tabular}




\begin{tabular}{lllll}
\hline Outcome or subgroup title & No. of studies & $\begin{array}{l}\text { No. of partici- } \\
\text { pants }\end{array}$ & Statistical method & Effect size \\
\hline $\begin{array}{l}\text { 3 Serious adverse events: exercise inter- } \\
\text { vention only compared to exercise inter- } \\
\text { vention plus any other co-intervention at } \\
\text { end of intervention }\end{array}$ & 2 & 356 & $\begin{array}{l}\text { Risk Ratio (M-H, Random, } \\
95 \% \mathrm{Cl})\end{array}$ & $1.05[0.77,1.44]$ \\
\hline 3.1 Exercise intervention only & 1 & 160 & $\begin{array}{l}\text { Risk Ratio (M-H, Random, } \\
95 \% \mathrm{Cl})\end{array}$ & $0.90[0.42,1.97]$ \\
\hline $\begin{array}{l}3.2 \text { Exercise intervention plus any other co- } \\
\text { intervention }\end{array}$ & 1 & 196 & $\begin{array}{l}\text { Risk Ratio (M-H, Random, } \\
95 \% \mathrm{Cl})\end{array}$ \\
\hline
\end{tabular}

Analysis 7.1. Comparison 7 Subgroup analysis, Outcome 1 All-cause mortality: exercise intervention only compared to exercise intervention plus any other co-intervention at longest follow-up.

\begin{tabular}{|c|c|c|c|c|c|}
\hline Study or subgroup & $\begin{array}{c}\text { Cardiac re- } \\
\text { habilitation } \\
n / N\end{array}$ & $\begin{array}{c}\text { Control } \\
\mathrm{n} / \mathrm{N} \\
\end{array}$ & $\begin{array}{c}\text { Risk Ratio } \\
\text { M-H, Random, } 95 \% \mathrm{Cl} \\
\end{array}$ & Weight & $\begin{array}{c}\text { Risk Ratio } \\
\text { M-H, Random, } 95 \% \mathrm{Cl}\end{array}$ \\
\hline \multicolumn{6}{|c|}{ 7.1.1 Exercise intervention only } \\
\hline Smolis-Bak 2015 & $3 / 26$ & $3 / 26$ & - & $16.38 \%$ & $1[0.22,4.5]$ \\
\hline Subtotal $(95 \% \mathrm{Cl})$ & 26 & 26 & & $16.38 \%$ & $1[0.22,4.5]$ \\
\hline \multicolumn{6}{|c|}{ Total events: 3 (Cardiac rehabilitation), 3 (Control) } \\
\hline \multicolumn{6}{|c|}{ Heterogeneity: Not applicable } \\
\hline \multicolumn{6}{|c|}{ Test for overall effect: Not applicable } \\
\hline \multicolumn{6}{|c|}{ 7.1.2 Exercise intervention plus any other co-intervention } \\
\hline Berg 2014 & $19 / 99$ & $12 / 97$ & - & $83.62 \%$ & $1.55[0.8,3.02]$ \\
\hline Subtotal $(95 \% \mathrm{Cl})$ & 99 & 97 & & $83.62 \%$ & $1.55[0.8,3.02]$ \\
\hline \multicolumn{6}{|c|}{ Total events: 19 (Cardiac rehabilitation), 12 (Control) } \\
\hline \multicolumn{6}{|c|}{ Heterogeneity: $\operatorname{Tau}^{2}=0 ; C h i^{2}=0, d f=0(P<0.0001) ; I^{2}=100 \%$} \\
\hline \multicolumn{6}{|c|}{ Test for overall effect: $Z=1.29(P=0.2)$} \\
\hline Total $(95 \% \mathrm{Cl})$ & 125 & 123 & & $100 \%$ & $1.44[0.79,2.65]$ \\
\hline \multicolumn{6}{|c|}{ Total events: 22 (Cardiac rehabilitation), 15 (Control) } \\
\hline \multicolumn{6}{|c|}{ Heterogeneity: $\mathrm{Tau}^{2}=0 ; \mathrm{Chi}^{2}=0.27, \mathrm{df}=1(\mathrm{P}=0.6) ; \mathrm{I}^{2}=0 \%$} \\
\hline \multicolumn{6}{|c|}{ Test for overall effect: $\mathrm{Z}=1.18(\mathrm{P}=0.24)$} \\
\hline \multicolumn{6}{|c|}{ Test for subgroup differences: $\mathrm{Ch}^{2}=0.27, \mathrm{df}=1(\mathrm{P}=0.6), \mathrm{I}^{2}=0 \%$} \\
\hline
\end{tabular}

Analysis 7.2. Comparison 7 Subgroup analysis, Outcome 2 Serious adverse events: follow-up.

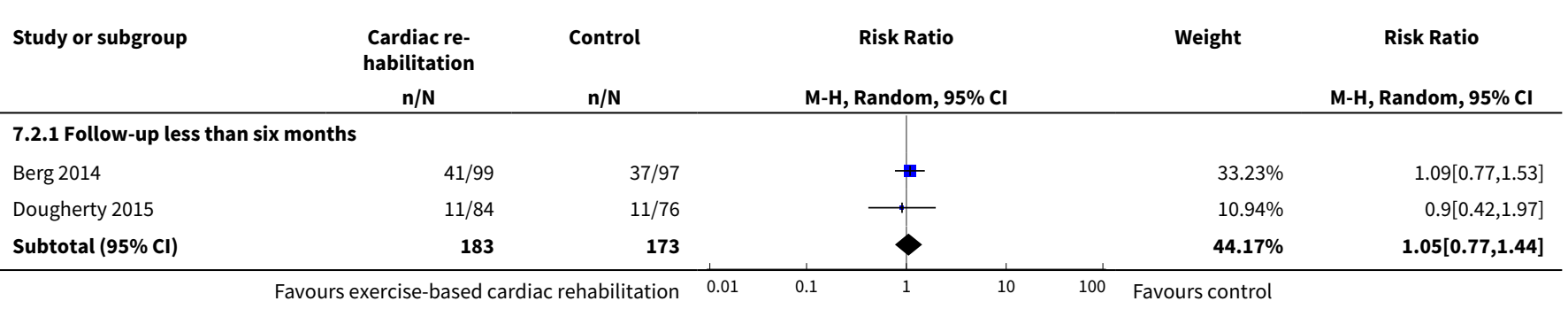




\begin{tabular}{|c|c|c|c|c|c|}
\hline Study or subgroup & $\begin{array}{c}\text { Cardiac re- } \\
\text { habilitation } \\
n / N\end{array}$ & $\mathrm{n} / \mathrm{N}$ & M-H, Random, $95 \% \mathrm{Cl}$ & Weight & $\begin{array}{c}\text { Risk Ratio } \\
\text { M-H, Random, } 95 \% \mathrm{CI}\end{array}$ \\
\hline \multicolumn{6}{|c|}{ Total events: 52 (Cardiac rehabilitation), 48 (Control) } \\
\hline \multicolumn{6}{|c|}{ Heterogeneity: $\mathrm{Tau}^{2}=0 ; \mathrm{Chi}^{2}=0.18, \mathrm{df}=1(\mathrm{P}=0.67) ; \mathrm{I}^{2}=0 \%$} \\
\hline \multicolumn{6}{|c|}{ Test for overall effect: $\mathrm{Z}=0.32(\mathrm{P}=0.75)$} \\
\hline \multicolumn{6}{|c|}{ 7.2.2 Follow-up six months or more } \\
\hline Belardinelli 2006 & $0 / 30$ & $8 / 22$ & & $0.99 \%$ & $0.04[0,0.72]$ \\
\hline Smolis-Bak 2015 & $14 / 26$ & $15 / 26$ & & $22.32 \%$ & $0.93[0.57,1.52]$ \\
\hline Smolis-Bak 2017 & $25 / 41$ & $25 / 43$ & 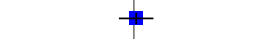 & $32.52 \%$ & $1.05[0.74,1.49]$ \\
\hline Subtotal $(95 \% \mathrm{CI})$ & 97 & 91 & & $55.83 \%$ & $0.84[0.43,1.65]$ \\
\hline \multicolumn{6}{|c|}{ Total events: 39 (Cardiac rehabilitation), 48 (Control) } \\
\hline \multicolumn{6}{|c|}{ Heterogeneity: $\mathrm{Tau}^{2}=0.2 ; \mathrm{Chi}^{2}=6.48, \mathrm{df}=2(\mathrm{P}=0.04) ; \mathrm{I}^{2}=69.15 \%$} \\
\hline \multicolumn{6}{|c|}{ Test for overall effect: $Z=0.5(P=0.62)$} \\
\hline Total $(95 \% \mathrm{CI})$ & 280 & 264 & & $100 \%$ & $0.99[0.74,1.3]$ \\
\hline \multicolumn{6}{|c|}{ Total events: 91 (Cardiac rehabilitation), 96 (Control) } \\
\hline \multicolumn{6}{|c|}{ Heterogeneity: $\mathrm{Tau}^{2}=0.03 ; \mathrm{Chi}^{2}=5.83, \mathrm{df}=4(\mathrm{P}=0.21) ; \mathrm{I}^{2}=31.45 \%$} \\
\hline \multicolumn{6}{|c|}{ Test for overall effect: $Z=0.1(P=0.92)$} \\
\hline Test for subgroup diff & $5, \mathrm{df}=1(\mathrm{P}=0.56)$ & & & & \\
\hline
\end{tabular}

\section{Analysis 7.3. Comparison 7 Subgroup analysis, Outcome 3 Serious adverse events: exercise intervention only compared to exercise intervention plus any other co-intervention at end of intervention.}

\begin{tabular}{|c|c|c|c|c|c|}
\hline Study or subgroup & $\begin{array}{c}\text { Cardiac re- } \\
\text { habilitation } \\
\mathbf{n} / \mathbf{N}\end{array}$ & $\begin{array}{l}\text { Control } \\
\mathbf{n} / \mathbf{N}\end{array}$ & $\begin{array}{c}\text { Risk Ratio } \\
\text { M-H, Random, } 95 \% \mathrm{Cl}\end{array}$ & Weight & $\begin{array}{c}\text { Risk Ratio } \\
\text { M-H, Random, } 95 \% \mathrm{CI}\end{array}$ \\
\hline \multicolumn{6}{|c|}{ 7.3.1 Exercise intervention only } \\
\hline Dougherty 2015 & $11 / 84$ & $11 / 76$ & & $16.51 \%$ & $0.9[0.42,1.97]$ \\
\hline Subtotal $(95 \% \mathrm{Cl})$ & 84 & 76 & & $16.51 \%$ & $0.9[0.42,1.97]$ \\
\hline \multicolumn{6}{|c|}{ Total events: 11 (Cardiac rehabilitation), 11 (Control) } \\
\hline \multicolumn{6}{|c|}{ Test for overall effect: $Z=0.25(P=0.8)$} \\
\hline \multicolumn{6}{|c|}{ 7.3.2 Exercise intervention plus any other co-intervention } \\
\hline Berg 2014 & $41 / 99$ & $37 / 97$ & & $83.49 \%$ & $1.09[0.77,1.53]$ \\
\hline Subtotal $(95 \% \mathrm{Cl})$ & 99 & 97 & & $83.49 \%$ & $1.09[0.77,1.53]$ \\
\hline \multicolumn{6}{|c|}{ Total events: 41 (Cardiac rehabilitation), 37 (Control) } \\
\hline \multicolumn{6}{|c|}{ Test for overall effect: $\mathrm{Z}=0.47(\mathrm{P}=0.64)$} \\
\hline Total $(95 \% \mathrm{Cl})$ & 183 & 173 & & $100 \%$ & $1.05[0.77,1.44]$ \\
\hline \multicolumn{6}{|c|}{ Total events: 52 (Cardiac rehabilitation), 48 (Control) } \\
\hline \multicolumn{6}{|c|}{ Heterogeneity: $\mathrm{Tau}^{2}=0 ; \mathrm{Chi}^{2}=0.18, \mathrm{df}=1(\mathrm{P}=0.67) ; \mathrm{I}^{2}=0 \%$} \\
\hline \multicolumn{6}{|c|}{ Test for overall effect: $Z=0.32(P=0.75)$} \\
\hline Test for subgroup dif & $8, \mathrm{df}=1(\mathrm{P}=0.67)$, & & & & \\
\hline
\end{tabular}




\section{A P P E N D I C E S}

\section{Appendix 1. Search strategies}

\section{CENTRAL}

\#1 MeSH descriptor: [Exercise] explode all trees

\#2 exercis*

\#3 MeSH descriptor: [Exercise Therapy] explode all trees

\#4 MeSH descriptor: [Exercise Tolerance] this term only

\#5 MeSH descriptor: [Sports] explode all trees

\#6 sport*

\#7 MeSH descriptor: [Physical Exertion] this term only

\#8 exertion

\#9 MeSH descriptor: [Physical Fitness] this term only

\#10 (fitness or fitter or fit)

\#11 MeSH descriptor: [Physical Education and Training] explode all trees

\#12 (muscle ${ }^{\star}$ near/3 (train* or activ*))

\#13 (train* near/5 (strength* or aerobic ${ }^{\star}$ or exercise*))

\#14 ((aerobic or resistance) near/3 (train* or $\left.\operatorname{activ}^{\star}\right)$ )

\#15 (physical ${ }^{\star}$ near/5 (fit ${ }^{\star}$ or train* or therap* or activ $^{\star}$ or strength or endur ${ }^{\star}$ or exert ${ }^{\star}$ or capacit $\left.{ }^{\star}\right)$ )

\#16 ((exercise* or fitness) near/3 (treat* or interven* or program or train* or physical or activ*))

\#17 MeSH descriptor: [Rehabilitation] this term only

\#18 MeSH descriptor: [Rehabilitation Centers] this term only

\#19 rehabilitat*

\#20 MeSH descriptor: [Dance Therapy] this term only

\#21 kinesiotherap*

\#22 danc*

\#23 (("lifestyle" or life-style or "life style") near/5 activ*)

\#24 (("lifestyle" or life-style or "life style") near/5 physical*)

\#25 ((lifestyle or life-style or "life style") near/5 (intervent* or program* or treatment $\left.{ }^{\star}\right)$ )

\#26 walk*

\#27 run*

\#28 jog*

\#29 MeSH descriptor: [Patient Education as Topic] this term only

\#30 (patient* ${ }^{*}$ near/5 educat ${ }^{\star}$ )

$\# 31 \# 1$ or $\# 2$ or \#3 or \#4 or \#5 or \#6 or \#7 or \#8 or \#9 or \#10 or \#11 or \#12 or \#13 or \#14 or \#15 or \#16 or \#17 or \#18 or \#19 or \#20 or \#21 or $\# 22$ or \#23 or \#24 or \#25 or \#26 or \#27 or \#28 or \#29 or \#30 
\#32 MeSH descriptor: [Defibrillators, Implantable] this term only

\#33 (implantable near/2 defibrill ${ }^{\star}$ )

\#34 (cardioverter near/2 defibrill ${ }^{\star}$ )

\#35 ICD

\#36 ICD-CRT

\#37 \#32 or \#33 or \#34 or \#35 or \#36

\#38 \#31 and \#37

\section{MEDLINE Ovid}

1. exp Exercise/

2. exercis ${ }^{\star} . t w$.

3. exp Exercise Therapy/

4. Exercise Tolerance/

5. exp Sports/

6. sport ${ }^{\star} . t w$

7. Physical Exertion/

8. exertion.tw.

9. Physical Fitness/

10. (fitness or fitter or fit).tw.

11. exp "Physical Education and Training"/

12. $\left(\right.$ muscle $^{\star} \operatorname{adj} 3\left(\operatorname{train}^{\star}\right.$ or $\left.\left.\operatorname{activ}^{\star}\right)\right)$.tw.

13. (train* $\operatorname{adj} 5$ (strength ${ }^{\star}$ or aerobic ${ }^{\star}$ or exercise $\left.\left.{ }^{\star}\right)\right)$. tw.

14. ((aerobic or resistance) adj3 (train ${ }^{\star}$ or $\left.\left.\operatorname{activ}^{\star}\right)\right) . t w$.

15. (physical ${ }^{\star}$ adj5 ( fit $^{\star}$ or train ${ }^{\star}$ or therap ${ }^{\star}$ or activ $^{\star}$ or strength or endur ${ }^{\star}$ or exert ${ }^{\star}$ or capacit $\left.{ }^{\star}\right)$ ).tw.

16. ((exercise ${ }^{\star}$ or fitness) adj3 (treat* or interven* or program* or train* or physical or activ $\left.\left.{ }^{\star}\right)\right) . t w$.

17. Rehabilitation/

18. Rehabilitation Centers/

19. rehabilitat*.tw.

20. Dance Therapy/

21. kinesiotherap*.tw.

22. danc*.tw.

23. (("lifestyle" or life-style) adj5 activ*).tw.

24. (("lifestyle" or life-style) adj5 physical $\left.{ }^{\star}\right)$.tw.

25. ((lifestyle or life-style) adj5 (intervent ${ }^{\star}$ or program ${ }^{\star}$ or treatment $\left.\left.{ }^{\star}\right)\right)$. .tw.

26. walk*.tw.

27. run*.tw.

Exercise-based cardiac rehabilitation for adult patients with an implantable cardioverter defibrillator (Review) 
28. jog*.tw.

29. Patient Education as Topic/

30. patient $^{\star}$ adj5 educat $\left.{ }^{\star}\right)$. tw.

31. or/1-30

32. Defibrillators, Implantable/

33. (implantable adj2 defibrill*).tw.

34. (cardioverter adj2 defibrill $\left.{ }^{\star}\right)$.tw.

35. ICD.tw

36. ICD-CRT.tw.

37. or $/ 32-36$

38. randomized controlled trial.pt.

39. controlled clinical trial.pt.

40. randomized.ab.

41. placebo.ab.

42. drug therapy.fs.

43. randomly.ab.

44. trial.ab.

45. groups.ab.

46.38 or 39 or 40 or 41 or 42 or 43 or 44 or 45

47. exp animals/ not humans.sh.

48. 46 not 47

49. 31 and 37 and 48

\section{Embase Ovid}

1. exp exercise/

2. exercis ${ }^{\star}$. tw

3. exp kinesiotherapy/

4. exercise tolerance/

5. exp sport/

6. sport ${ }^{\star} . t w$.

7. exertion.tw.

8. fitness/

9. (fitness or fitter or fit).tw.

10. physical education/

11. (muscle ${ }^{\star} \operatorname{adj} 3\left(\operatorname{train}^{\star}\right.$ or $\left.\left.\operatorname{activ}^{\star}\right)\right)$.tw.

12. (train* adj5 (strength* or aerobic* or exercise $\left.\left.{ }^{\star}\right)\right)$. tw.

Exercise-based cardiac rehabilitation for adult patients with an implantable cardioverter defibrillator (Review) 
13. ((aerobic or resistance) adj3 (train ${ }^{\star}$ or $\left.\left.\operatorname{activ}^{\star}\right)\right) . t w$.

14. (physical ${ }^{\star}$ adj5 (fit* or train $^{\star}$ or therap* or activ $^{\star}$ or strength or endur ${ }^{\star}$ or exert* or capacit $\left.^{\star}\right)$ ).tw.

15. ((exercise ${ }^{\star}$ or fitness) adj3 (treat* or interven $^{\star}$ or program ${ }^{\star}$ or train* or physical or activ $\left.{ }^{\star}\right)$ ).tw.

16. rehabilitation/

17. rehabilitation center/

18. rehabilitat*.tw.

19. dance therapy/

20. kinesiotherap*.tw.

21. danc ${ }^{\star}$.tw.

22. (("lifestyle" or life-style) adj5 activ*).tw.

23. (("lifestyle" or life-style) adj5 physical $\left.{ }^{\star}\right)$.tw.

24. ((lifestyle or life-style) adj5 (intervent ${ }^{\star}$ or program or treatment $\left.\left.^{\star}\right)\right)$. .tw.

25. walk*.tw.

26. run*.tw.

27. jog*.tw.

28. patient education/

29. (patient $^{\star}$ adj5 educat $\left.{ }^{\star}\right)$. tw.

30. or/1-29

31. implantable cardioverter defibrillator/

32. (implantable adj2 defibrill*).tw.

33. (cardioverter adj2 defibrill $\left.{ }^{\star}\right)$.tw.

34. ICD.tw.

35. ICD-CRT.tw.

36. or/31-35

37.30 and 36

38. random\$.tw.

39. factorial\$s.tw.

40. crossover\$.tw.

41. cross over\$.tw.

42. cross-over\$.tw.

43. placebo\$.tw.

44. (doubl\$ adj blind\$).tw.

45. (singl\$ adj blind\$).tw.

46. assign\$.tw.

47. allocat\$.tw.

Exercise-based cardiac rehabilitation for adult patients with an implantable cardioverter defibrillator (Review) 
48. volunteer\$.tw.

49. crossover procedure/

50. double blind procedure/

51. randomized controlled trial/

52. single blind procedure/

53. 38 or 39 or 40 or 41 or 42 or 43 or 44 or 45 or 46 or 47 or 48 or 49 or 50 or 51 or 52

54. (animal/ or nonhuman/) not human/

55.53 not 54

56. 37 and 55

57. limit 56 to embase

\section{Psycinfo}

1. exp exercise/

2. exercis ${ }^{\star} . t w$.

3. exp sports/

4. sport ${ }^{\star}$. tw.

5. exertion.tw.

6. physical fitness/

7. (fitness or fitter or fit).tw.

8. physical education/

9. (muscle ${ }^{\star}$ adj3 (train* or activ $\left.\left.{ }^{\star}\right)\right)$. tw.

10. (train* $\operatorname{adj5}\left(\right.$ strength $^{\star}$ or aerobic ${ }^{\star}$ or exercise $\left.\left.{ }^{\star}\right)\right)$.tw.

11. ((aerobic or resistance) adj3 (train* or activ $\left.\left.{ }^{\star}\right)\right)$. tw.

12. (physical ${ }^{\star}$ adj5 (fit ${ }^{\star}$ or train ${ }^{\star}$ or therap ${ }^{\star}$ or activ $^{\star}$ or strength or endur ${ }^{\star}$ or exert ${ }^{\star}$ or capacit $\left.{ }^{\star}\right)$ ).tw.

13. ((exercise ${ }^{\star}$ or fitness) adj3 (treat* or interven* or program* or train* or physical or activ*)).tw.

14. rehabilitation/

15. rehabilitat ${ }^{\star}$.tw.

16. kinesiotherap*.tw.

17. danc ${ }^{\star}$. tw

18. (("lifestyle" or life-style) adj5 activ*).tw.

19. (("lifestyle" or life-style) adj5 physical $\left.{ }^{\star}\right)$.tw.

20. ((lifestyle or life-style) adj5 (intervent* or program* ${ }^{\star}$ or treatment*)).tw.

21. walk*.tw.

22. run*.tw.

23. jog*.tw.

24. (patient $^{\star}$ adj5 educat $\left.{ }^{\star}\right)$.tw. 
25. or/1-24

26. (implantable adj2 defibrill*).tw.

27. (cardioverter adj2 defibrill $\left.{ }^{\star}\right)$.tw.

28. ICD.tw.

29. ICD-CRT.tw.

30. or/26-29

31. 25 and 30

32. random\$.tw.

33. factorial\$.tw.

34. crossover\$.tw.

35. cross-over\$.tw.

36. placebo\$.tw.

37. (doubl\$ adj blind\$).tw.

38. (singl\$ adj blind\$).tw.

39. assign\$.tw.

40. allocat\$.tw.

41. volunteer\$.tw.

42. control ${ }^{\star}$. tw.

43. "2000".md.

44. or/32-43

45. 31 and 44

CINAHL

S46S27 AND S45

$\mathrm{S} 45 \mathrm{~S} 28$ or $\mathrm{S} 29$ or $\mathrm{S} 30$ or $\mathrm{S} 31$ or $\mathrm{S} 32$ or $\mathrm{S} 33$ or $\mathrm{S} 34$ or $\mathrm{S} 35$ or $\mathrm{S} 36$ or $\mathrm{S} 37$ or $\mathrm{S} 38$ or $\mathrm{S} 39$ or $\mathrm{S} 40$ or $\mathrm{S} 41$ or $\mathrm{S} 42$ or $\mathrm{S} 43$ or $\mathrm{S} 44$

S44TX cross-over*

S43TX crossover*

S42TX volunteer*

S41(MH "Crossover Design")

S40TX allocat*

S39TX control *

S38TX assign*

S37TX placebo*

S36(MH "Placebos")

S35TX random*

S34TX (doubl* N1 mask*) 
S33TX (singl ${ }^{\star}$ N1 mask ${ }^{\star}$ )

S32TX (doubl* N1 blind*)

S31TX (singl* N1 blind $\left.{ }^{\star}\right)$

S30TX (clinic* N1 trial?)

S29PT clinical trial

S28(MH "Clinical Trials+")

S27S21 AND S26

S26S22 OR S23 OR S24 OR S25

S25ICD

S24"cardioverter defibrill*"

S23"implantable defibrill*"

S22(MH "Defibrillators, Implantable")

S21S1 OR S2 OR S3 OR S4 OR S5 OR S6 OR S7 OR S8 OR S9 OR S10 OR S11 OR S12 OR S13 OR S14 OR S15 OR S16 OR S17 OR S18 OR S19 OR S20

S20"patient* educat*"

S19walk* or run* or jog*

S18"life style" or life-style of lifestyle

S17danc*

S16kinesiotherap*

S15rehabilitat*

S14(MH "Rehabilitation")

S13"aerobic train*" or "resistance train"

S12"train* strength" or "train* aerobic*" or "train* exercise*"

S11"muscle* train*" or "muscle* activ*"

S10(fitness or fitter or fit)

S9(MH "Physical Fitness")

S8exertion

S7(MH "Exertion+")

S6sport*

S5(MH "Sports+")

S4(MH "Exercise Tolerance+")

S3(MH "Therapeutic Exercise+")

S2exercis*

S1(MH "Exercise+")

\section{LILACS}

(exercis\$ OR sport\$ OR physical\$ OR train\$ OR activ\$) [Words] and defibrill\$ [Words]

Exercise-based cardiac rehabilitation for adult patients with an implantable cardioverter defibrillator (Review) 


\section{Web of Science}

\section{\# 8 \#7 AND \#6}

\# 7 TS=(random ${ }^{\star}$ or blind ${ }^{\star}$ or allocat ${ }^{\star}$ or assign ${ }^{\star}$ or trial ${ }^{\star}$ or placebo ${ }^{\star}$ or crossover $^{\star}$ or cross-over $\left.^{\star}\right)$

\# 6 \#5 AND \#4

\# 5 TS=(defibrill* or cardioverter or ICD)

\# 4 \#3 OR \#2 OR \#1

\# 3 TS=("patient educat*")

\# 2 TS=(rehabilitat* or danc ${ }^{\star}$ or kinesiotherap* or walk* or run* or jog* of lifestyle or life-style or "life style")

\# 1 TS=(exercis ${ }^{\star}$ or sport* or exertion or fitness or fitter or fit or train* or activ*)

\section{Clinical trial registers}

1 implantable cardiac defibrillator

2 ICD

3 rehabilitation

4 exercise

\section{Appendix 2. Detailed criteria for all risk of bias domains}

\section{Generation of random sequence}

- Low risk of bias: sequence generated using a computer random-number generator or a table of random numbers. Drawing lots, tossing a coin, shuffling cards or envelopes, and throwing dice are all adequate if performed by an independent adjudicator, or the method is unlikely to introduce selection bias;

- Unclear risk of bias: insufficient information provided to assess whether the method used could cause bias;

- High risk of bias: the method used is improper and likely to be confounding (e.g. there is a non-random component in the generation of the sequence).

\section{Allocation concealment}

- Low risk of bias: the method used will probably not cause bias on the final observed effect (e.g. allocation is controlled by a central and independent randomisation unit and the assignment cannot be foreseen);

- Unclear risk of bias: insufficient information about concealment of allocation provided to assess whether the method used could cause bias on the estimate of the effect;

- High risk of bias: the method used will probably cause bias on the final observed effect (e.g. the allocation sequence is open and known to the trial investigators).

\section{Blinding of participants and personnel}

- Low risk of bias: any intervention is delivered blinded to the participants or personnel, or both, and neither the participants nor the personnel are aware of the group to which participants are allocated;

- Unclear risk of bias: there is insufficient information to assess whether the participants or personnel are blinded to the intervention;

- High risk of bias: the patients and personnel are not blinded to the intervention.

Due to the type of intervention being investigated in this Cochrane Review, we expect high risk of bias in this domain. This applied to all included studies, as it is impossible to blind participants when the intervention consists of physical exercise.

\section{Blinding of outcome assessment}

- Low risk of bias: if the trial investigators performing the outcome assessments are blinded to the treatment allocation, and this is described;

- Unclear risk of bias: if the procedure of blinding is insufficiently described;

- High risk of bias: if blinding is not performed, or the procedure cannot be classified as at 'low risk of bias'. 


\section{Incomplete outcome data}

- Low risk of bias: the number and reasons for dropouts and withdrawals are properly described, and valid methods, such as multiple imputation, have been used to handle missing data;

- Unclear risk of bias: the study made the impression of having no dropouts or withdrawals, but this aspect was described insufficiently;

- High risk of bias: if the pattern of dropouts can be described as being different in the two intervention groups or the methods being used to handle missing data were unsatisfactory (e.g. last observation carried forward).

\section{Selective outcome reporting}

- Low risk of bias: all primary and clinically relevant outcomes of the trial were reported. The hierarchy of the outcome measures are documented in a protocol before launch of randomisation;

- Unclear risk of bias: not all primary or clinically relevant outcomes are reported, or reported sufficiently, or whether these outcomes were recorded is unclear;

- High risk of bias: not all primary or clinically relevant outcomes reported.

\section{Performance bias}

- Low risk of bias: any co-interventions are delivered equally across intervention and control groups;

- Unclear risk of bias: there is insufficient information to assess whether co-interventions were present, or equally delivered across groups, and that could put the trial at a risk of bias;

- High risk of bias: the co-interventions are not delivered equally across intervention and control groups.

\section{Intention-to-treat (ITT) analysis}

- Low risk of bias: the trial reports the analysis were conducted according to an ITT analysis, which include all the principles of such analysis, e.g. keeping participants in the intervention groups to which they were randomised, regardless of the intervention they actually received; and measure outcome data on all or the majority of participants (i.e. $>90 \%$ of those randomised) or include imputation of all missing data in the analysis, using appropriate methodology, e.g. multiple imputation;

- Unclear risk of bias: it is unclear if and how the trial has performed an ITT analysis;

- High risk of bias: the trial does not include an ITT analysis, or there is a substantive loss of outcome data (e.g. > 20\%) and analyses are performed according to imputation methods known to create bias, such as last observation carried forward.

\section{Groups balanced at baseline}

- Low risk of bias: if the characteristics of the participants before the start of intervention in the intervention/control groups are reported to be comparable or can be judged to be comparable in terms of likely main prognostic factors;

- Unclear risk of bias: it is not reported whether the participants' characteristics between groups are balanced at baseline and there is inadequate information reported to assess this;

- High risk of bias: if there is evidence of substantive imbalance in the baseline characteristics of the intervention/control groups with regard to likely major prognostic factors.

\section{For-profit bias}

- Low risk of bias: the trial was free of industry sponsorship or other support from a for-profit organisation that may have an interest in a given result;

- Unclear risk of bias: it was unclear how the trial was funded;

- High risk of bias: the trial was sponsored by the industry or had received other support from a for-profit organisation that may have had an interest in a given result.

\section{CONTRIBUTIONSOF AUTHORS}

KMN drafted the review with supervision by SKB, JCJ, JL, JHS, LA, ADZ and RST. KMN and SKB identified the included trials, extracted data and assessed bias from the trials. Analysis was mostly done by KMN, but with assistance from RST, JL and JCJ. All authors revised and contributed to the drafting of the review, and all approved the final version of the review.

\section{DECLARATIONS OF INTEREST}

Selina K Berg1 ${ }^{1}$, Jane Lindschou ${ }^{2}$, Jesper H Svendsen ${ }^{3}$ and Ann-Dorthe Zwisler ${ }^{4}$ are involved academic investigators in RCTs, investigating the effect of cardiac rehabilitation for people:

- with atrial fibrillation treated with radiofrequency ablation1, 2, 3, 4 (Risom 2017);

- treated for infective endocarditis $1,2,4$;

- after heart valve surgery1, 2, 4 (Sibilitz 2016);

Exercise-based cardiac rehabilitation for adult patients with an implantable cardioverter defibrillator (Review) 
- treated with ICD1, 3, 4 (Berg 2014).

Trial acronym: COPE-ICD, CopenHeart and DanRehab. These trials are funded by the Danish government and by external funds. The funders have no influence on the research.

Rod Taylor is a co-author on a number of current Cochrane Reviews of cardiac rehabilitation and co-chief investigator of a research programme designing and evaluating a de novo home-based rehabilitation intervention for patients with heart failure and their carers.

Lindsey Anderson is an author on a number of other Cochrane cardiac rehabilitation Reviews.

Janus C Jakobsen and Kim M Nielsen have no known conflicts of interest.

\section{SOURCES OF SUPPORT}

\section{Internal sources}

- The Heart Centre, Rigshospitalet, Copenhagen University Hospital, Denmark.

Salary

\section{External sources}

- This project was supported by the National Institute for Health Research (NIHR) via Cochrane Infrastructure, Cochrane Programme Grant or Cochrane Incentive funding to the Cochrane Heart Group. The views and opinions expressed therein are those of the authors and do not necessarily reflect those of the Systematic Reviews Programme, NIHR, National Health Service (NHS) or the Department of Health, UK.

- The Cochrane Heart Group US Satellite is supported by intramural support from the Northwestern University Feinberg School of Medicine and the Northwestern University Clinical and Translational Science (NUCATS) Institute (UL1TR000150), USA.

\section{DIFFERENCES BETWEEN PROTOCOLANDREVIEW}

We planned to report on all-cause mortality and cardiovascular mortality, but after reviewing the included trials, we found that trials only reported on all-cause mortality. Therefore we chose to only report on all-cause mortality.

We also planned to only report on ICD shock, but after comments from the reviewers, we separated the endpoint into appropriate shock, inappropriate shock and all shock (if it is not clear whether shock was appropriate or inappropriate).

\section{INDEX TERMS}

\section{Medical Subject Headings (MeSH)}

*Exercise Therapy; *Quality of Life; Cardiac Rehabilitation [adverse effects] [ ${ }^{\star}$ methods] [ ${ }^{\star}$ psychology]; Cause of Death; Defibrillators, Implantable [adverse effects] [* psychology]; Exercise Tolerance; Oxygen Consumption; Randomized Controlled Trials as Topic

\section{MeSH check words}

Aged; Female; Humans; Male; Middle Aged 